\title{
A socioeconomic and spatial analysis of obesity in West Virginia: Policy implications
}

Anura Kumara Amarasinghe

West Virginia University

Follow this and additional works at: https://researchrepository.wvu.edu/etd

\section{Recommended Citation}

Amarasinghe, Anura Kumara, "A socioeconomic and spatial analysis of obesity in West Virginia: Policy implications" (2006). Graduate Theses, Dissertations, and Problem Reports. 2502.

https://researchrepository.wvu.edu/etd/2502

This Dissertation is protected by copyright and/or related rights. It has been brought to you by the The Research Repository @ WVU with permission from the rights-holder(s). You are free to use this Dissertation in any way that is permitted by the copyright and related rights legislation that applies to your use. For other uses you must obtain permission from the rights-holder(s) directly, unless additional rights are indicated by a Creative Commons license in the record and/ or on the work itself. This Dissertation has been accepted for inclusion in WVU Graduate Theses, Dissertations, and Problem Reports collection by an authorized administrator of The Research Repository @ WVU.

For more information, please contact researchrepository@mail.wvu.edu. 


\title{
A Socioeconomic and Spatial Analysis of Obesity in West Virginia: Policy Implications
}

\author{
Anura Kumara Amarasinghe \\ Dissertation submitted to the \\ Davis College of Agriculture, Forestry, and Consumer Sciences \\ at West Virginia University \\ in partial fulfillment of the requirements \\ for the degree of \\ Doctor of Philosophy \\ in \\ Natural Resource Economics \\ Gerard D'Souza, Ph.D., Chair \\ Cheryl Brown, Ph.D. \\ Cindy Fitch, Ph.D. \\ Hyungna Oh, Ph.D. \\ Tatiana A. Borisova, Ph.D. \\ Tim Phipps, Ph.D.
}

Agricultural and Resource Economics Program

Division of Resource Management

Morgantown, West Virginia

2006 


\title{
Abstract \\ A Socioeconomic and Spatial Analysis of Obesity in West Virginia: Policy Implications
}

\author{
Anura K. Amarasinghe
}

This dissertation integrates both theoretical and empirical insights to facilitate understanding of the current obesity epidemic in WV given heterogeneity in socioeconomic, demographic and built environment characteristics of the state. In meeting this objective, county-level and individual-level health demand analyses using secondary data sources were conducted. County-level obesity differences were studied using spatial and non-spatial random and fixed effects frameworks under a panel data structure. Individual health demand was investigated by recursive estimation of individual health responses to ordered self-assessed health (SAH) in terms of lifestyle choices, socioeconomic, demographic and built environment characteristics using Behavioral Risk Factor Surveillance System (BRFSS) data.

County level findings reveal that, while the percentage of the population with a completed college degree and the number of food stores available per thousand population are negatively and significantly correlated to county prevalence of obesity, mean commuting time, average annual wage and the total number of business establishments per thousand population positively and significantly contribute to obesity. Although there is no evidence for unobserved county fixed effects or serial correlation, empirical and spatial investigations suggest that obesity is a spatially non-random event clustered in certain geographic regions which also have the highest poverty and least education.

The individual health demand analysis shows that the risk of obesity increases at a decreasing rate with per capita income and age. Marginal impacts indicate that as the level of education increases, the probability of being obese decreases by $3 \%$. Physical inactivity increases the risk of being obese by $9 \%$, while smoking reduces the risk of being obese by $14 \%$. Fruit and vegetable consumption lowers the probability of being obese by $2 \%$, while each oneminute increase in commute time raises the probability of being obese by $0.04 \%$. In addition, individuals living in economically distressed counties are less likely to have good health. In general, the overall causes for, and consequences of, obesity are found to be complex and multifaceted.

In terms of policy interventions, educational attainment that raises both human and social capital, as well as changes in the built environment can play a vital role in controlling obesity in West Virginia.

Keywords: obesity, health, random and fixed effects, spatial and built environment characteristics, policy interventions. 


\section{Acknowledgments}

I wish to extend my sincere gratitude to my major supervisor Professor Gerard D'Souza who paved the way to undertake this research. His able guidance and genuine support throughout my PhD study period made this dissertation successful. His constant encouragement, patience, and the time spent on reading and editing my drafts are gratefully appreciated.

A special word of thanks is due to Assistant Professor Dr. Cheryl Brown for sharing her knowledge, valuable comments and for reading and editing my dissertation. I would also like to thank my other committee members, Dr. Oh for her guidance in econometrics, Dr. Phipps for his encouraging comments and his support, Dr. Tatiana Borisova for her useful discussions and comments, and Dr. Cindy Fitch for her kind support and advice.

I wish to extend my sincere thanks to the Division Director, Professor Peter Schaeffer, Academic Dean Professor Dennis Smith, ARE Program Chair, Professor Alan Collins, NRAC director Prof. Jerald Fletcher and all the other faculty in the division, and also to the administrative staff for their generous support during my stay at WVU.

I wish to express my deepest gratitude to my parents who sacrificed in many ways to bring me up to this stage. Their constant love and support has been inspirational. I am also grateful to my brothers and sisters for their love and support throughout. My greatest thanks

goes to my family, my wife Ranamalie who has been a pillar of strength and my two little daughters Dinuki and Devmi who inspired me to work hard.

I dedicate this dissertation to my mother and to the memory of my loving father. 


\section{Table of Contents}

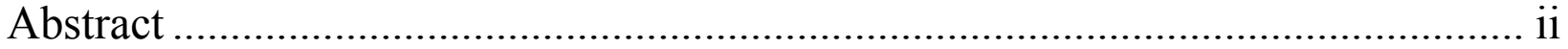

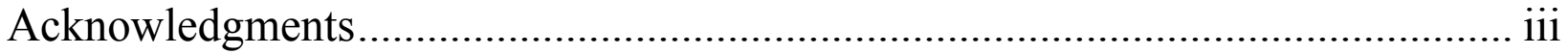

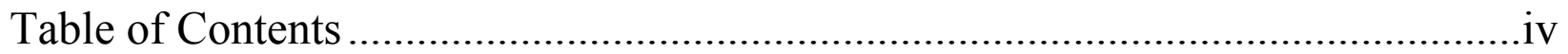

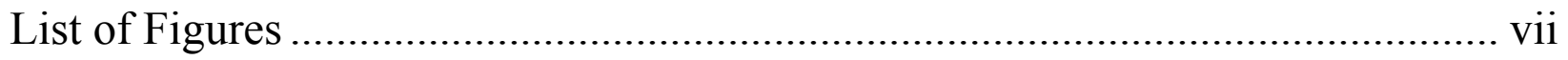

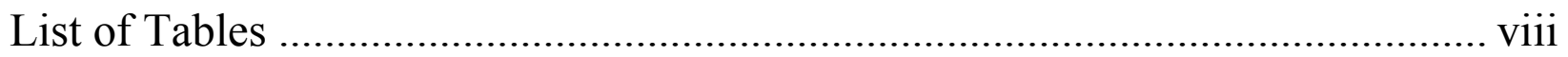

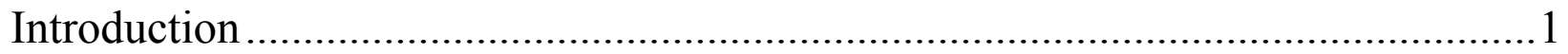

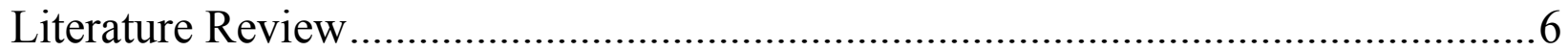

2.1. Economic Perspectives of Health and Obesity ……........................................................... 6

2.2. Social Welfare Implications and Public Health Policy.................................................... 13

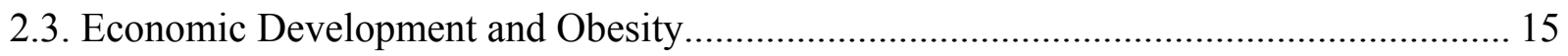

2.3.1. Food Security, Hunger, Food Away from Home and Obesity .................................... 15

2.3.2. Relationship between Poverty and Obesity ............................................................. 24

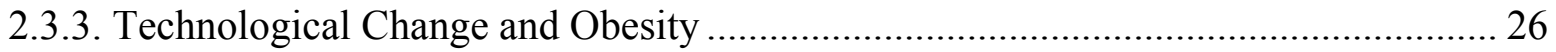

2.3.4. Time Use, Leisure, Physical Inactivity and Obesity................................................... 29

2.3.5. Built Environment and Obesity ............................................................................. 32

2.3.6. Food Policy, Health and Obesity ................................................................................... 36

Theoretical Framework and Methodology ........................................................44

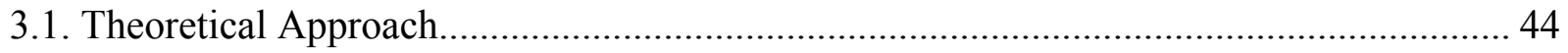

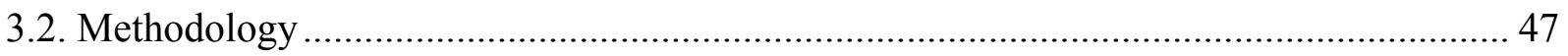

3.2.1. Random and Fixed Effects Modeling of Obesity in WV Counties ............................ 48 
3.2.1.2. Minimum Chi-Squared Logit (MCSL) and Minimum Chi-Squared Probit

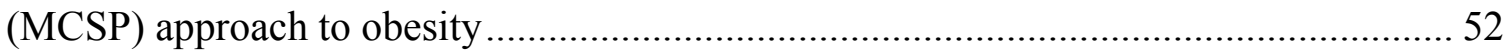

3.2.2. Spatial Autoregressive Approach to Obesity Analysis .......................................... 53

3.2.2.1. Spatial Autoregressive Approach (SAR) .................................................... 54

3.2.2.2. Spatial Error Model (SEM) ..................................................................... 55

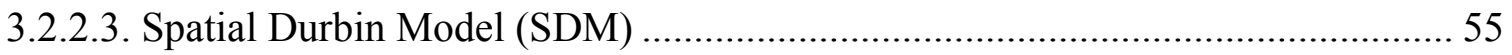

3.2.3. Micro-Level Health Demand Analysis ....................................................... 55

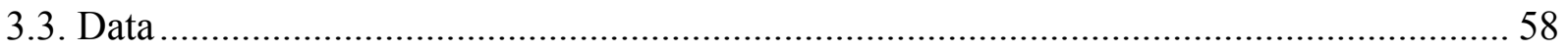

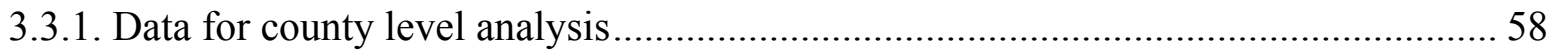

3.3.2. Data for Individual Health Demand Analysis.................................................. 65

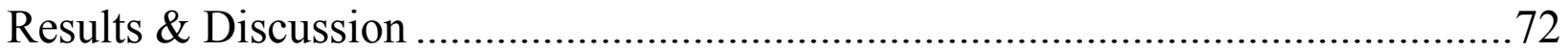

4.1. Aggregate County Level Health Demand Analysis................................................. 73

4.1.1. Random and Fixed Effects Estimation of Obesity ......................................... 73

4.1.1.1. Random Effect Estimation of County Prevalence of Obesity .......................... 73

4.1.1.2. Fixed Effects Estimation of County Prevalence of Obesity ........................... 78

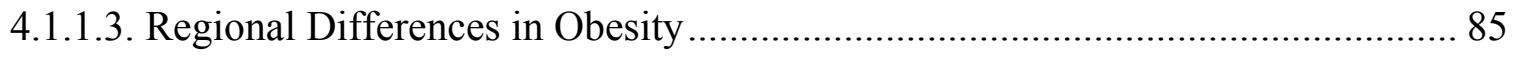

4.1.1.4. Minimum Chi Square Probit and Logit Estimation ...................................... 88

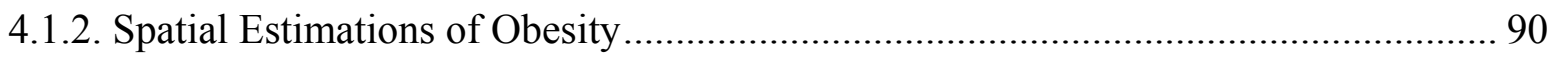

4.1.2.1. Spatial Error (SEM) and Spatial Autoregressive (SAR) Approaches to Obesity 91

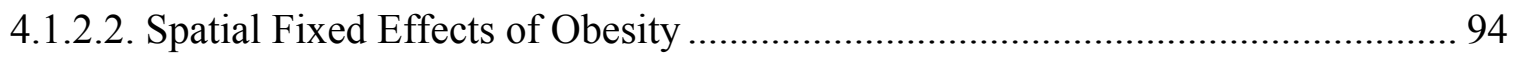

4.1.2.3. Spatial Durbin Approach to Obesity............................................................ 96

4.1.3. Discussion: Aggregate Health Demand Analysis ............................................ 98

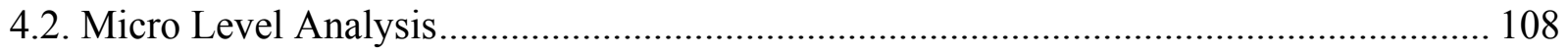


4.2.1. Discussion: Micro Level Health Analysis ....................................................... 116

Conclusions and Policy Implications........................................................ 121

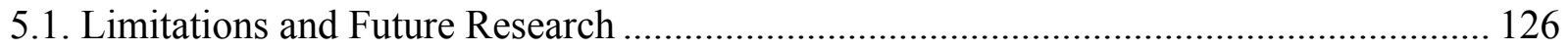

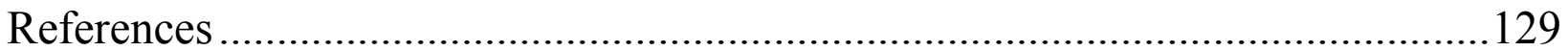

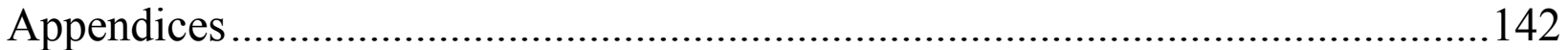




\section{List of Figures}

Figure 1.1. Obesity Prevalence in West Virginia and the United States

Figure 2.1. Social Welfare Implications of Government Supported Health

Programs

Figure 2.2. Possible Linkages between Socioeconomic and Demographic Factors

and Obesity.

Figure 4.1. Different Analytical Procedures Considered for the Study...................72

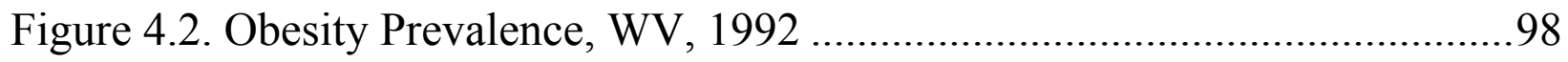

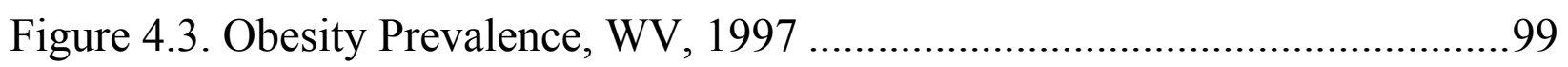

Figure 4.4. Obesity Rates versus Average College Education Completed During

1992

Figure 4.5. Obesity Rates versus Average College Education Completed During

1997

Figure 4.6. Obesity and Poverty in 1997 (numbers show poverty rate by county)104

Figure 4.7. Obesity and Poverty in 1992 (numbers show poverty rate by county)104

Figure 4.8. County Business Patterns and Prevalence of Obesity, WV, 1997 ......108 


\section{List of Tables}

Table 3.1. County Socioeconomic and Demographic Variables

61

Table 3.2. Behavioral Factors and Dummy Variables..........................................62

Table 3.3. Built-Environment Variables ................................................................63

Table 3.4. County Level Descriptive Statistics.......................................................64

Table 3.5. Behavioral and Dummy Variable Descriptive Statistics .......................65

Table 3.6. Built-Environment Factors Descriptive Statistics ...............................65

Table 3.7. Definition of Variables and their Descriptive Statistics .......................67

Table 3.8. Definition of Variables and their Descriptive Statistics of Micro Level

Analysis: Marital Status, Physical Inactivity, Age, and Other Covariates ..............69

Table 3.9. Descriptive Statistics: Micro Level Analysis: Dependent Variable,

Educational Level, Demographic, Income, Employment and Gender Categories..70

Table 3.10. Definition of Variables and their Descriptive Statistics of Micro Level

Analysis: Marital Status and Other Covariates.................................................... 71

Table 4.1. OLS \& GLS Estimates of Random Effects of Obesity in WV: .............74

Dependent Variable \% of Obesity in the County ..................................................74

Table 4.2. Hausman Test and Breusch-Pagan (BP) Test for Random Effects ........77

Table 4.3.1. Cross Sectional and Time Series Effects of County Prevalence of

Obesity : Cross Sections CS1 to CS18 
Table 4.3.2. Cross Sectional and Time Series Effects of County Prevalence of

Obesity: Cross Sections CS19 to CS36

Table 4.3.3. Cross Sectional and Time Series Effects of County Prevalence of

Obesity Cross Sections: CS37 to CS55

Table 4.3.4. Cross Sectional and Time Series Effects of County Prevalence of

Obesity: Time Effect and Other Socioeconomic Variables 82

Table 4.4. Between and Within Effects Estimations ..........................................84

Table 4.5. Regional Random and Fixed Effects .................................................. 86

Table 4.6. Minimum Chi Square Probit and Logit Estimations ..............................89

Table 4.7. Random Effects Spatial Error (RSEM) and Spatial Autoregressive

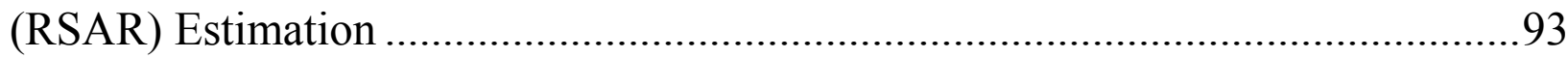

Table 4.8. Fixed Effects Spatial Error (FSEM) and Spatial Autoregressive (FSAR)

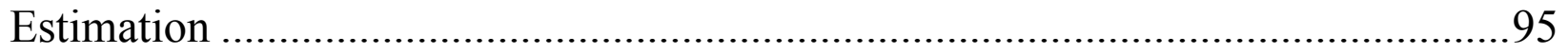

Table 4.9. Restricted F-tests for Regional Random and Fixed spatial approaches 96

Table 4.10. Spatial Durbin Estimation.................................................................97

Table 4.11. Maximum Likelihood Probit and Logit Estimates of Obesity Risk ...111

Table 4.12. Marginal Probabilities of Risk of Being Obese.

Table 4.13. Maximum Likelihood Ordered Probit and Logit Estimates of an

Individual's Self Assessed Health 


\section{Chapter 1}

\section{Introduction}

Our health, well-being and quality of life are directly related to the food we eat. Poor health contributes to lost productivity, low economic growth, and decreasing quality of life. Over the past few years there have been dramatic changes to dietary patterns worldwide. This nutrition transition is characterized not only by an increase in the overall intake of calories but also by a shift in the composition of the diet towards high caloric meals, rich in saturated fats and cholesterol. Increased consumption of such caloric foods, in association with a more sedentary life style, have together brought about a rapid increase in the prevalence of overweight, obesity and related non-communicable diseases. These increasing health concerns have also given rise to an intense debate about possible remedies to stop and reverse the obesity epidemic in developed and developing countries.

Obesity is reaching epidemic proportions across the U.S., and especially in the state of West Virginia (WV), the study area. In fact, the U.S. Centers for Disease Control and Prevention (CDC) has classified obesity as a disease. Obesity is defined in terms of Body Mass Index (BMI), which is a measure of body fat content, and is a function of both height and weight. According to National Institute of Health (NIH) guidelines, individuals having a BMI $\geq 30$ are considered obese, and those with a BMI between 25 and 29.9 are considered overweight. In the U.S., $61 \%$ of adults were overweight or obese in 1999 (Office of the Surgeon General, 2003). In addition, $13 \%$ of children aged 6 to 11 and $14 \%$ of adolescents aged 12 to 19 were reported to be overweight in 1999 (Office of the Surgeon General, 2003). There are about 300,000 deaths per year in the U.S. that are associated with obesity, making it the second leading cause of preventable deaths after smoking, which accounts for 400,000 
deaths (Anderson, Butcher, and Levine, 2003). In 2000, the economic cost of obesity in the U.S. was estimated to be $\$ 117$ billion with $\$ 61$ billion in direct costs such as medical expenditures and $\$ 56$ billion in indirect costs such as lost wages, disability, or premature deaths (Kuchler and Ballenger, 2002). According to a report in a local newspaper (The Dominion Post, 2004), the WV legislature estimated that obesity costs the state \$2 billion annually in health care costs and lost productivity.

Overweight and obesity are also known risk factors for heart disease, diabetes, hypertension, gallbladder disease, osteoarthritis, sleep apnea and other breathing problems, and some intrauterine, breast, colorectal, kidney and gallbladder cancers. For example, obesity accounts for $61 \%$ of type 2 diabetes in the U.S. (CDC, 2003). The World Health Organization (WHO) estimated that between one-fourth and one-third of cancers in the world are attributable to excess weight and physical inactivity (WV Department of Health and Human Resources, 2002) The heaviest children in a society are $77 \%$ more likely to have asthma symptoms (WV Department of Health and Human Resources, 2002). In addition, obesity is known to be associated with pregnancy complications, high blood cholesterol, menstrual irregularities, physiological disorders, and increased surgical risk. Obesity also negatively affects mental health due to social discrimination against overweight persons.

The $\mathrm{CDC}$ has reported that obesity rates have been growing across all ages, races, ethnic groups and in both genders in every state (Kuchler and Ballenger, 2002). In fiscal year 2002, Congress approved $\$ 27.5$ million for the CDC to address physical inactivity, poor nutrition, and obesity (CDC, 2003). These funds allowed the CDC to support 12 states to plan for and initiate nutrition and physical activity programs to help prevent and control obesity and other chronic diseases. In fiscal year 2003, with funding of $\$ 34$ million, the 
CDC expanded these programs and supported research to increase physical activity and to improve nutrition in states and communities (CDC, 2003). The significance of this problem is also quite evident in federal government initiatives such as Healthy People 2010 and the 2004 Obesity Bill. The latter has authorized a $\$ 60$ million pilot project to help communities develop programs to combat obesity. It highlights the fact that in the past 30 years, the number of overweight children has doubled while the number of overweight adolescents has tripled.

An important policy issue related to obesity is that it causes external costs to society through increased health-care costs borne by taxpayers. Because of the alarming trends in behavioral health disorders and the possible externalities, policy makers are beginning to pay a great deal of attention to alternative policy programs which could curtail the problem. On the other hand, farmers, foresters, and other landowners are facing opportunities as well as challenges as consumers become increasingly concerned about food safety and health. These concerns bring into question the long-term sustainability of the food system in a highly competitive environment for land and other natural resources.

The obesity prevalence in West Virginia (WV) has been consistently higher than that for the U.S. Figure 1.1 presents obesity prevalence and associated trends in WV over the past decade. In 1990, the WV rate of adult obesity was 15\%, compared with a U.S. rate of $12 \%$. By 2000 , WV's obesity rate had climbed to $23 \%$, compared with $20 \%$ nationally. The obesity rate has increased in virtually all WV counties over the past decade with the highest prevalence found in the southern and western portions of the state, as well as the Eastern Panhandle (WV Department of Health and Human Resources, 2002). Considering the high prevalence of obesity and associated health-related problems, together with proximity to 
environmentally diverse natural amenities and growing population centers, WV can be a model state for national planners to understand and develop strategies and policy options to reverse the recent obesity trend. The main objective of this dissertation is to contribute to our understanding of the obesity problem in the state of WV, and, in the process, to examine the socioeconomic and policy implications. More specifically this study contributes to existing knowledge by:

1. Investigating the possible trends, causes and consequences, and spatial characteristics of obesity in West Virginia,

2. Examining how individual decision making with respect to alternative food, recreational and physical activity choices affect obesity, and

3. Evaluating the resulting implications for policy formulation.

Figure 1.1. Obesity Prevalence in West Virginia and the United States

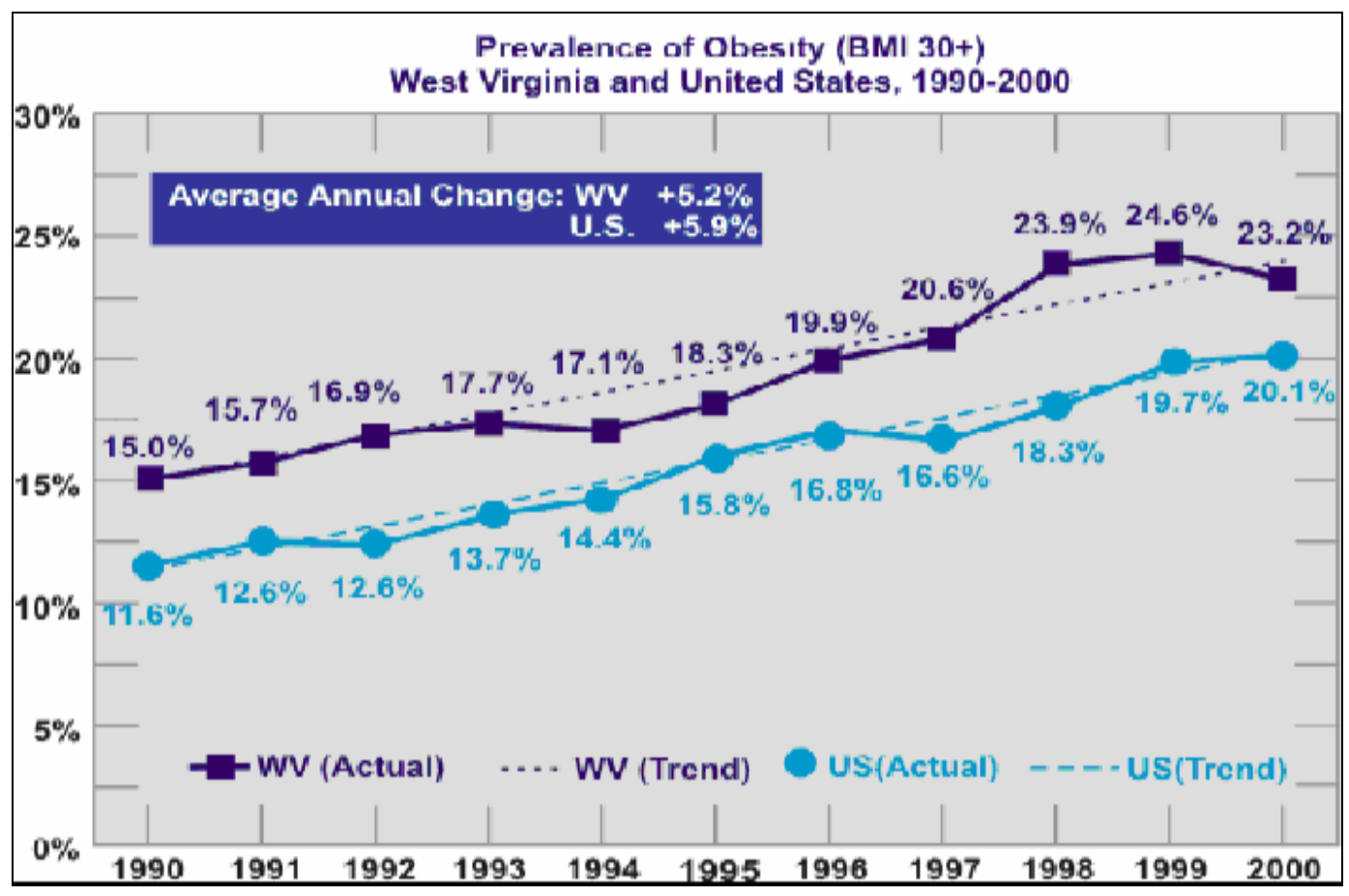

Source: West Virginia Department of Health and Human Resources. 
The next chapter reviews the literature on health, obesity, and lifestyle choices especially as they pertain to economics in particular and the social sciences in general. In the process, it also provides a background on the interrelationships among food production and consumption, food stores, recreation, policy and other factors that interact in complex ways to determine health outcomes. Chapter 3 explains the theoretical approach and methodology that are employed in this study, and data sources used in estimation. Chapter 4 presents the empirical results and discussion within the context of two econometric modeling approaches: (a) an aggregate county level health demand analysis under a panel data structure, and (b) a recursive, multivariate probit and logit analysis of micro level (individual) health demand. The final chapter summarizes the overall contributions of this study and the resulting socioeconomic and policy implications. 


\section{Chapter 2}

\section{Literature Review}

This chapter explores health and obesity from an economic perspective. It summarizes briefly the existing contributions in the areas of health economics and other related disciplines in understanding the obesity issue.

\subsection{Economic Perspectives of Health and Obesity}

Health, a form of human capital, can raise consumers' productivity in both market and nonmarket sectors of the economy (Grossman, 1972; Becker, 1965). A household production function, the new approach to consumer behavior, draws a sharp distinction between fundamental objects of choice called commodities and market goods (Becker, 1965; Lancaster, 1966; Muth, 1966). In this approach, households produce commodities with input of marketed goods and their own time. The household production function framework and the theory of time allocation proposed by Lancaster (1966) and Becker (1965), show that consumers can invest their time and resources to produce a commodity of good health that enters his/her utility function. These investment decisions can have direct impact on the outlay of marketed goods and the opportunity cost of time that must be withdrawn from other competing uses. Gross investments in health capital are produced by household production functions whose direct inputs include the time of the consumer along with market goods such as medical care, diet, exercise, recreation, and housing as well as exogenous socio-economic and demographic characteristics (Grossman, 1972).

Health is a multi-attribute concept, which encompasses both physical and mental components (Cutler and Richardson, 1998). For example, birth weight can be used as a good indicator of a healthy newborn (Rosenzweig and Schultz, 1983). As people get older, an 
individual's health can be influenced by both observed (e.g., lifestyle choices such as smoking and drinking) and unobserved factors (e.g., unobserved genetic, hormonal and biochemical factors). Belloc and Breslow (1972) and Kenkel (1995) showed that health is affected by several lifestyle choices such as diet, smoking, exercise, alcohol consumption, sleep, weight (relative to height), and stress. Kenkel (1991) showed that schooling helps people choose healthier lifestyles by improving their knowledge of the relationship between health behaviors and health outcomes, i.e., schooling improves a household's allocative efficiency in producing health. Empirical investigations show that while schooling has a significant negative association with smoking and heavy drinking, it has a significant positive effect on exercise.

Realization of health outcomes may have a stochastic component which represents family specific health endowments inherent to the family but not controlled by them (e.g., genetic traits and environmental factors unknown to the decision maker at a time when decisions are made) (Rosenzweig and Schultz, 1983). Estimates of the technical/biological effects of health inputs (e.g., medical services) on an individual's health have been obtained from "hybrid" health equations that contain prices of inputs, income, and health measures as regressors (Harris, 1982b; Edwards and Grossman, 1979) ignoring the fact that self-selected health inputs were endogenous (Rosenzweig and Schultz, 1983). The seminal work of Rosenzweig and Schultz (1983) utilized the instrumental variable technique to obtain consistent estimates of a child's health (birth weight) production function recognizing the fact that health input choices influenced by unobserved factors also, in turn, affect health outcomes. 
Contoyannis and Jones (2004) examined the interaction between health related behavior and self-assessed health (SAH) status, in the presence of unobserved heterogeneity. A multivariate probit (MVP) analysis of British panel data from the Health and Lifestyle Survey (HALS) showed that discrete indicators of lifestyle choices such as sleeping well, exercising, and not smoking in 1984 may have a positive effect on the probability of reporting excellent or good SAH in 1991. The failure of epidemiological analyses to account for unobserved heterogeneity can give biased estimates of the relevant lifestyle choices in the socio-economic status-health relationship (Contoyannis and Jones, 2004). Self-assessed health has been extensively used as a predictor in the previous health economics literature by Kemma (1987), Berger and Leigh (1989), Kenkel (1995) and more recently by Contoyannis and Jones (2004).

Sickles and Yazbeck (1998) examined the household health production for elderly males that jointly determines the demand for leisure and consumption. A stochastic dynamic programming framework assumed that the individual maximizes lifetime utility subject to budget and time constraints and a health-production function by choosing hours of leisure and levels of consumption of health-related and health-neutral goods and services. The estimated health elasticities with respect to leisure ranged between 0.59 to 0.69 with some slight upward trend over time. The elasticity of health-related consumption is between 0.031 and 0.045 . The pattern of consumption elasticities indicates some increase over time for each cohort.

As a growing behavioral health disorder, obesity has significant effects on an individual's health and longevity and the economy as a whole (Philipson, 2001). Overweight and obesity have increased the risk of having most prevailing diseases, including diabetes 
(Egede and Zheng, 2002), cardiovascular diseases (Wang et al., 2002), and cancer

(Bianchini, Kaaks, and Vainio, 2002). Subsequently, obesity has become a major burden on welfare programs such as medicare and social security.

There is a growing body of literature on obesity from various disciplines such as public health and community planning, human nutrition, food science, and other social sciences including, more recently, from economics. Recent economic contributions (Saez et al., 2006; Gruber and Frakes, 2005; Chou, Grossman, and Saffer, 2004, 2002; Mancino and Kinsey, 2004; Kan and Tasi, 2004; Plantinga and Bernell, 2004; Philipson and Posner, 2003; Cutler, Glaeser, and Shapiro, 2003; Guthrie, Lin, and Frazao, 2002; Kuchler and Ballenger 2002 ; Anderson, Butcher, and Levine, 2003; Lakdawalla and Philipson, 2002; Smith, 2002; Ruhm, 2000; Binkley, Eales, and Jekanowski, 2000) focus on consumer demand and behavior; the food supply side; and theoretical, conceptual, technological and spatial issues of obesity. Among the studies focusing primarily on demand or food consumption aspects are: Mancino and Kinsey (2004), Chou, Grossman, and Saffer (2002), Guthrie, Lin, and Frazao (2002), Kenkel (2000), Kip (1993), Jacobson and Brownell (2000), Lin and Frazao (1999), and Stinson (2000). Studies that deal primarily with consumer demand and behavioral aspects of obesity are concerned with consumer eating habits, risk factors and prevention. Chou, Grossman, and Saffer (2002) explained that social forces such as increased participation of women in the labor force which raises the opportunity cost of time, have raised the demand for fast foods. Increasing availability of fast foods, which reduces food search and travel time, relatively cheap fast food meals, and increasingly costly homeprepared meals have had significant impacts on obesity. In addition to these factors, Chou, Grossman, and Saffer (2002) also identified smoking, unemployment and job strenuousness 
as other factors that could lead to obesity. Kenkel (1991) suggested that schooling improves the choice of health inputs by improving an individual's health knowledge. Health information, hunger and food source variables that enter into the reduced form nutrient demand functions are arguably endogenous (Mancino and Kinsey, 2004).

Studies by Philipson and Posner (1999), Lakdawalla and Philipson (2002), Smith (2002) and Ruhm (2000) discuss various theoretical issues and the implications of economic growth and technological change for obesity growth. In developing countries, long lasting economic growth tends to lead to better health. However, this relationship seems to be ambiguous for industrialized countries. An investigation of health response to the fluctuations in economic conditions (Ruhm, 2000) shows that health improves when the economy temporarily deteriorates. Ruhm (2000) shows that state unemployment rates have a significant negative impact on total mortality and eight of ten specific causes of fatalities except suicide. The author's results also show that smoking and obesity increase when the economy strengthens, whereas physical activity is reduced and diets become unhealthy.

Studies by Johanson, Mancino, and Cooper (2004), Cash, Sunding, and Zilberman (2004), Miller and Coble (2005), Kuchler and Ballenger (2002), Kuchler, Tegene, and Harris (2004), Jacobson and Brownell (2000), Baum and Ford (2004), Cawley (2004), and Bhattacharya and Sood (2005) are concerned with the consequences of, and possible policy interventions to overcome, obesity. Miller and Coble (2005) focus on the impact of U.S. agricultural policies on the current obesity epidemic. Historically, U.S. agricultural policy has been oriented towards a cheap food policy that ensures lower retail food prices for consumers. Knutson, Penn, and Boehm (1995) described this cheap food policy as one that involves the government ensuring food prices below the competitive equilibrium price. 
However, whether the U.S. is pursuing a cheap food policy remains a debatable issue regarding federal farm program payments.

Pollan (2000), noted that while, on the one hand, government is attempting to combat the recent obesity epidemic, on the other hand, it promotes or subsidizes obesity by paying farmers for every bushel of corn they grow. When there is an excess supply of corn, the market is flooded and its price falls so that food processing companies, taking advantage of low prices, convert the corn into value-added products, including high-fructose corn syrup (a sugar substitute) which induces consumption of many processed foods and beverages. Pollan also stated that surplus corn, along with other abundant and cheap agricultural commodities, can easily be converted into more compact and portable value-added products such as corn sweeteners, and corn-fed meat and chicken, paving the way for ample availability of high-fat, cheap food. He argued that unless policymakers make a substantial effort to curb surplus agricultural production, they are unlikely to have much success in establishing public health programs for changing eating habits. Probing into this issue, Miller and Coble (2005) show no existing evidence to explain that direct payments to farmers would substantially influence the affordability of food. Their findings reveal that much of the direct payments are capitalized into the cost of land essentially mitigating any significant impact on retail food prices, thus making landowners the true beneficiaries of such farm programs. Putnam (1999), in a study focusing primarily on food supply, looks at the role of the U.S. food system in contributing to obesity. Johanson, Mancino, and Cooper (2004) discuss how obesity would affect the U.S. economy, environment, and agricultural production. A reduction of domestic calorie consumption by between $2 \%$ to $6 \%$ would lead to lower 
production of primary agricultural commodities, higher exports and lower discharge of agricultural pollutants (Johanson, Mancino, and Cooper, 2004).

Childhood obesity is a poignant part of the current U.S. obesity epidemic. Obesity among children has doubled from 7\% to 13\% between 1970 and 1999 (Office of the Surgeon General, 2003). During that same period, obesity among adults has increased from $5 \%$ to 14\% (Office of the Surgeon General, 2003). A comprehensive analysis of childhood obesity by Anderson, Butcher, and Levine (2003) and a study of schooling, health knowledge and obesity by Nayga (2000) make significant contributions to understanding current obesity issues. Anderson, Butcher, and Levine (2003) indicate that, to a large extent, children's lives are governed by their parents and schools. Socioeconomic trends and policies that prevailed over the last three decades have interacted within both these realms in ways that have promoted an increase in childhood obesity. Nayga (2000) shows that knowledge is inversely related to the probability of an individual being obese.

In recent years, urban sprawl characterized by a complex pattern of land use, transportation, and economic development has had an impact on quality of life and public health. Urban sprawl, as measured by low residential density, low employment density, and poor street connectivity is associated with less walking and bicycling and with more automobile travel than in denser communities (Frank and Pivo, 1995; Frumkin, 2002). Low levels of physical activity threaten health directly. The emerging school of economic thought from the urban planning and health literature is that urban sprawl might induce sedentary lifestyles and, thus, may have an impact on obesity. Ewing et al. (2003), Lopez (2004), Blanchard and Lyson (2003), Frank, Anderson, and Schmid (2004), Rosenberger, Sneh, and Phipps (2002), and Block, Scribner, and DeSalvo (2004) discuss the possible linkages among 
obesity, physical inactivity, and the built environment. Spatial analysis of coronary heart disease and related treatment facilities across Appalachia by Barnett et al. (1998) and a geographic analysis of heart diseases and obesity by Halverson et al. (2004) significantly contribute to understanding the obesity issue.

The greater value of thinness to women than men is reflected in studies that find a greater negative correlation between earnings and being overweight for women than men (Register and Williams, 1990; Pagan and Davila, 1997). An analysis of the National Longitudinal Study of Youth by Baum and Ford (2004) stated that respondents who are obese persistently earn lower wages than their non-obese peers. Empirical findings show that an "obesity wage penalty" persists for both males and females, though this penalty is larger for females. The impact of diabetes on employment and labor market productivity by Brown, Pagan, and Bastida (2004) showed that the disease has a substantial negative effect on employment for men but not for women. Thorpe et al. (2004) stated that higher spending on health care of obese patients is mainly attributable to treatment for diabetes and hypertension. Their findings indicated that costs incurred by the obese were $37 \%$ higher than costs for those with normal weight in the year 2001.

\subsection{Social Welfare Implications and Public Health Policy}

It is a commonly accepted fact that health expenditures have been steadily increasing over time. Between 1950 and 1980, health care costs have increased from $4 \%$ of the national income of the United States to $9 \%$ of national income (Maddala, 1989). The government pays a significant portion of these health care expenditures through taxpayer financing. Rising health care costs are mainly due to growth in third party payments (payment by insurance companies and government), and it is projected that such costs will continue to 
grow at an ever-increasing rate over the next two decades (Maddala, 1989). Behavioral health disorders like obesity significantly increase health care costs. It has been estimated that the total cost of obesity and overweight to the U.S. economy in 1995 was $\$ 99$ billion, which was $5.7 \%$ of the total cost of all illnesses (Wolf and Colditz, 1998). Estimates of national health interview surveys conducted in 1994, indicated that 39 million workdays were lost annually due to obesity-related problems (Wolf and Colditz, 1998). This has caused a significant burden on taxpayer financed U.S. Medicare and Social Security programs. Figure 2.1 shows some social welfare implications of government supported health care programs.

Figure 2.1. Social Welfare Implications of Government Supported Health Programs

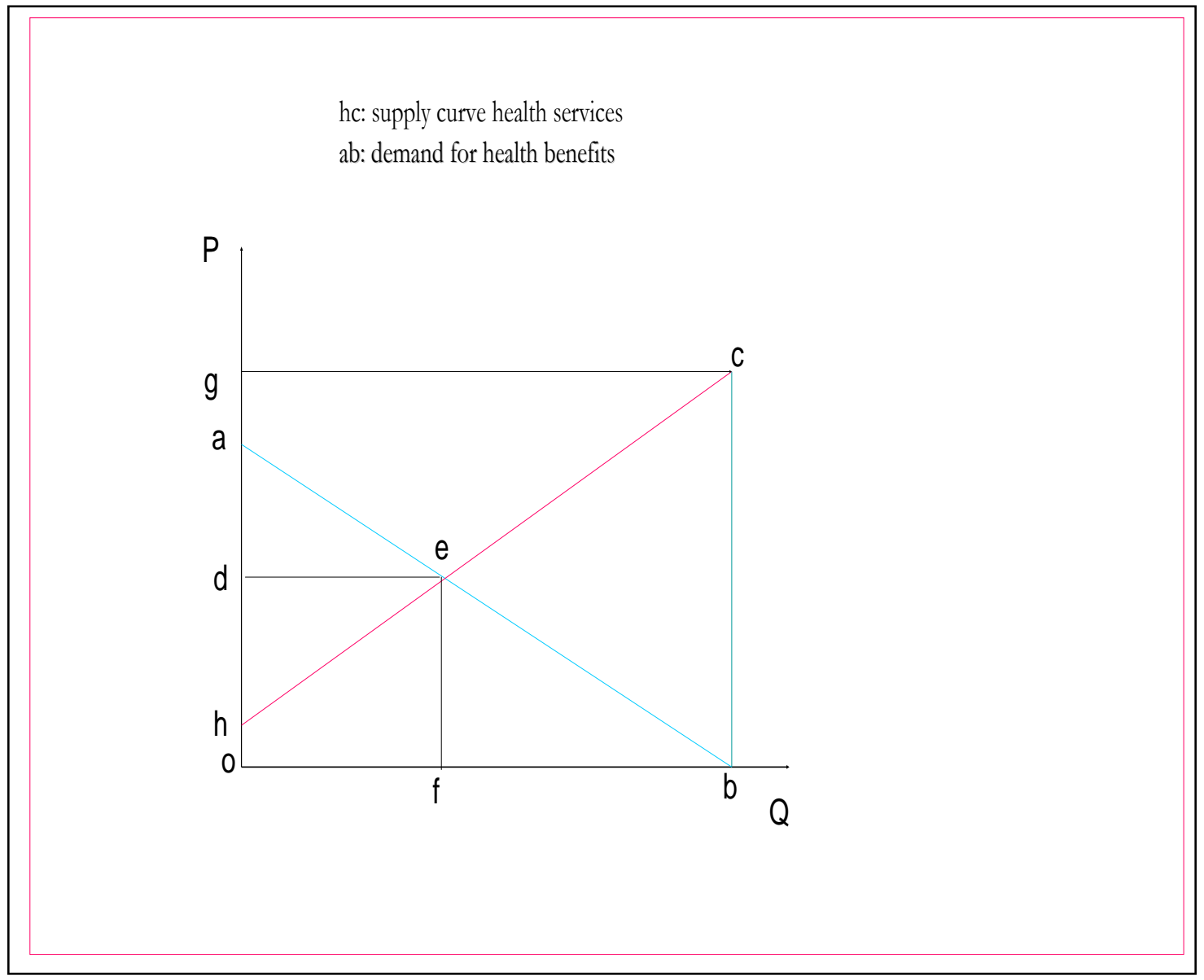

Source: Maddala (1989) 
In Figure 2.1, line ab represents the demand for medical care in the absence of government insurance. Let line hc be the supply of medical services. Initially the price is od, the quantity of medical care provided is of and total consumer expenditures equal the area odef. The consumers' and producers' surpluses are represented by areas ade and deh, respectively. Under the assumption that the government pays all the expenses for medical care for everyone, the demand curve becomes completely price inelastic, represented by the vertical line bc. As a result, the price increases from $\mathbf{o d}$ to $\mathbf{0 g}$ and the total amount of medical care consumed increases from of to $\mathbf{o b}$. Total medical expenditures increase from odef to ogcb, which is paid for by the government. Since the sum of the total increase in consumers' and producers' surplus (odeb + dgce) is less than the government expenditure, society would end up with a net welfare loss represented by the area ecb. This welfare or deadweight loss is financed by taxpayers. Therefore, government financed medical care has created a negative externality for society. This implies that higher costs of obesity will lead to higher health costs and, in turn, lead to greater welfare losses for society.

\subsection{Economic Development and Obesity}

There is a growing literature from various disciplinary perspectives such as the health sciences, food sciences, and, more recently, from economics, which offers different hypotheses to explain the growing epidemic of obesity. This section summarizes some important caveats regarding the growing obesity problem. Figure 2.2 explains some possible linkages between different socio-economic and demographic factors and obesity.

\subsubsection{Food Security, Hunger, Food Away from Home and Obesity}

Fast food consumption is believed to be one of the major contributory factors to obesity. Recent economic and health studies reveal that fast foods, which contain high levels 
of calories and saturated fats, have a positive impact on gaining body weight (Anderson, Butcher, and Levine, 2002; Ebbeling, Dorota, and David, 2002; French, Harnack, and Jeffery, 2000; Binkley, Eales, and Jekanowski, 2000; Lin and Frazao, 2001).

Figure 2.2. Possible Linkages between Socioeconomic and Demographic Factors and

\section{Obesity.}

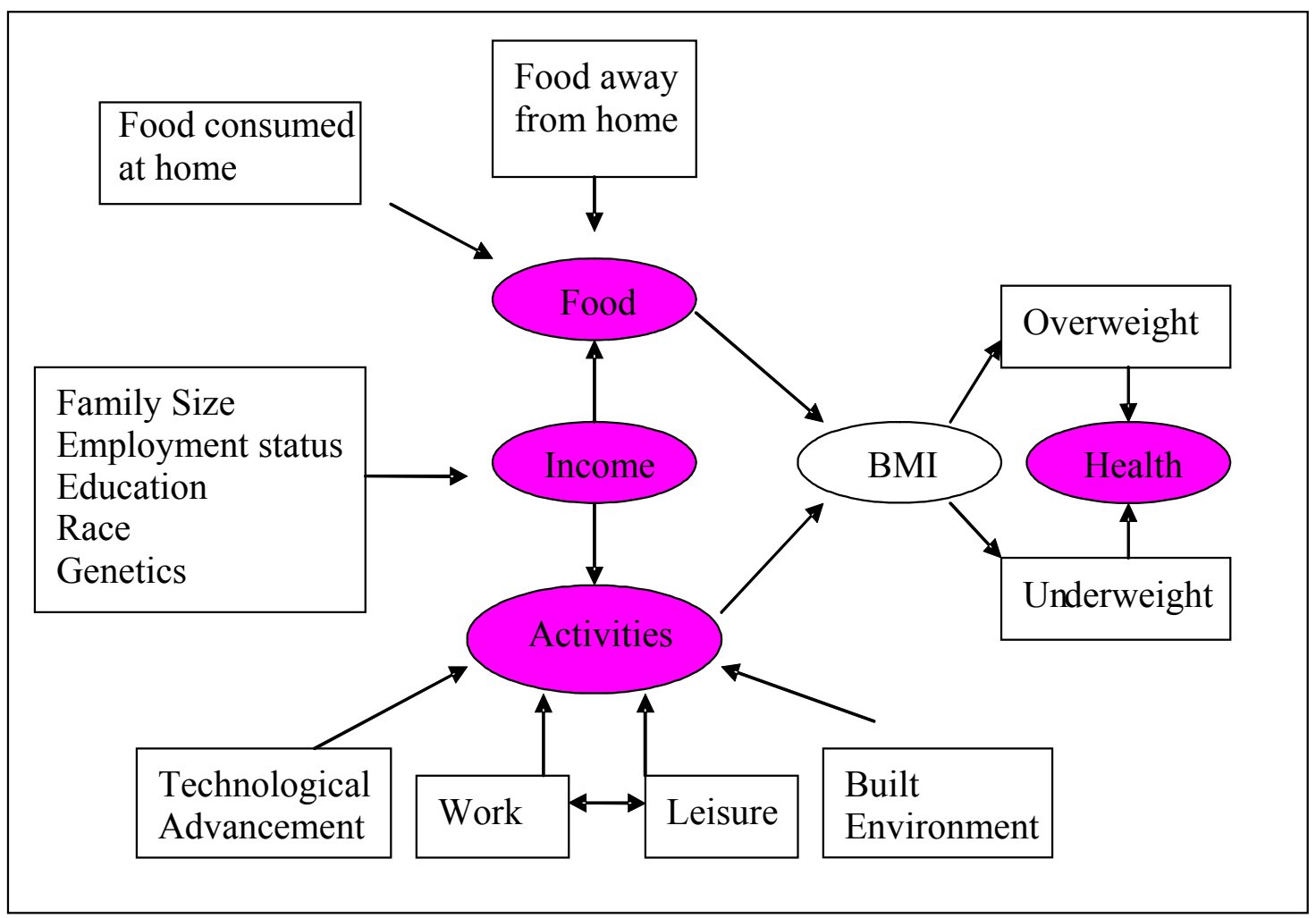

Anderson, Butcher, and Levine (2003) and Ebbeling, Dorota, and David (2002) note that fast foods contain all the ingredients, such as saturated trans-fatty acids, high glycemic index, high energy density and large portions, which give rise to unhealthy meals. Studies done by French, Harnack, and Jeffery (2000) and Binkley, Eales, and Jekanowski (2000) reveal that fast food consumption and bodyweight are positively correlated. From the late 1970 's to the late 1990 's, meals eaten away from home by children have increased from $17 \%$ to $30 \%$ (Ebbeling, Dorota, and David, 2002). During that period, the fast food contribution 
to total caloric intake of children rose from 2\% to 10\% (Ebbeling, Dorota, and David, 2002). Similarly, daily per capita soft drink consumption of children increased from 179 to 520 grams for boys and from 148 to 337 grams for girls between 1965 and 1996 (Cavadini, Siega-Riz, and Popkin, 2000). Knutson, Penn, and Boehm (1995) indicated that there is increasing consensus that the American diet is contributing to chronic illnesses such as heart disease and cancer, greatly affecting people later in life. Per capita nutrients available for consumption have increased from 3300 calories in 1978 to 3600 calories in 1988 (Knutson, Penn, and Boehm, 1995). Although recommended energy intakes vary with age, fewer than 3000 calories generally is recommended (Knutson, Penn, and Boehm, 1995).

Stewart et al. (2004) predicted that consumer spending at full-service and fast food restaurants will continue to grow over the remainder of this decade and the next. An even larger increase is expected to occur at full-service restaurants. Considering a modest growth in household income with expected demographic developments, simulations suggest that per capita spending could rise by $18 \%$ at full-service restaurants and by $6 \%$ at fast food restaurants between 2000 and 2020. Stewart et al. (2004) also pointed out that while the increasing proportion of households containing a single person or multiple adults without live-at-home children have higher away-from-home food expenditures, the aging of the population has caused spending on fast foods to decrease by about $2 \%$.

Other empirical analyses (Guthrie, Lin, and Frazao, 2002; McCracken and Brandt, 1987; Byrne, Capps, and Saha, 1998) also show how specific economic and demographic characteristics influence the demand for food away from home. Both fast food restaurants and full-service restaurants can provide leisure for households, as households are freed from cooking, cleaning and shopping. Along with additional leisure, households with more 
income tend to buy more variety and other dining amenities. Thus, households with higher incomes tend to spend more on fast food and full-service meals and snacks (McCracken and Brandt, 1987; Byrne, Capps, and Saha, 1998). Also, households that spend long hours working outside the home prefer consuming fast foods, if such meals are accessible within a reasonable location (Mancino and Kinsy, 2004). As household labor force participation increases, spending on fast foods has been shown to increase. However, traveling to and from dining at full-service restaurants can take the same amount or less time as food preparing, eating and cleaning up after meals at home (Byrne, Capps, and Saha, 1998). Thus, there is no clear theoretical relationship between a household's demand for food at fullservice restaurants and its time constraints (Byrne, Capps, and Saha, 1998). In addition, household income, size, and increasing hours of labor force participation, household manager's age, race and ethnicity, and educational level, along with region of residence, are also contributing factors for demand for food away from home (Hiemstra and Kim, 1995; McCracken and Brandt, 1987; Friddle, Mangraj, and Kinsey, 2001). Given the different opportunities to socialize, and to eat out, young and older people choose different establishments for dining out. On balance, empirical studies find that households with younger members tend to spend more money on fast food, while households with older people tend to spend more money on full-service dining (Byrne, Capps, and Saha, 1998; Friddle, Mangraj, and Kinsey, 2001).

Guthrie, Lin, and Frazao (2002) noted that between 1997-98 and 1994-96 the consumption of food away from home (FAFH) increased from $18 \%$ to $32 \%$ of total calories. Their analysis showed that meals and snacks based on food prepared away from home not only contained more calories per eating occasion, but they were also higher in fat and 
saturated fat and lower in dietary fiber, calcium and iron. In linking the source of food preparation to health outcomes, Guthrie, Lin, and Frazao (2002) summarized studies that found more frequent consumption of fast foods related to overweight in women (Jeffrey and French, 1998), body fatness associated with more frequent restaurant eating (McCrory et al., 1999) and higher serum cholesterol levels in children who ate weekly in a restaurant (Purath, Lansinger, and Ragheb, 1995). Longer work days, a growing tendency of both spouses to hold full time jobs and perhaps rising incomes are widely credited for the rise in away-fromhome expenditures. Benefiting from these growing trends in household lifestyles, a wide array of food service firms, including full service restaurants, fast food establishments, hotels, retail stores, recreation places, bars and operators of vending machines are competing for the consumers FAFH dollar. However, it seems that full service and fast food restaurants have captured the bulk of the market share with 39\% and 38\% percent of total sales in 2002 (Stewart et al., 2004). Full-service restaurants, defined as establishments with wait staff, tend to offer more varied menu and dining amenities. The key marketing strategy of fast food markets is convenience. As the number of fast food restaurants proliferates in convenient locations, consumers have to travel less on average, thus, boosting the demand for fast foods (Jekanowski, Binkley, and Eales, 2001). The proliferation of fast food restaurants can be seen in a trend known as "channel-blurring" whereby gas stations and retail stores, such as Wal-Mart and Target, are hosting outlets for fast food giants (Stewart et al., 2004). According to Jekanowski (1999), McDonald's has nearly 700 locations in Wal-Marts across the U.S. and almost 200 outlets in Chevron and Amoco service stations. Jekanowski (1999) also observed that McDonald's marketing strategy is to monitor the changing lifestyles of consumers and intercept them at every turn to gain market share. Emerging trends in the fast 
food sector show that total FAFH expenditures, defined to include all food dispensed for immediate consumption outside the consumer's home, amounted to $\$ 415$ billion in the year 2002 (Stewart et al., 2004). This amount is about $58 \%$ greater than annual away from home expenditures in 1992, which totaled \$263 billion.

Jekanowski (1999) also showed that food expenditures typically account for less than one-third of the cost of a meal, and as much of this food was processed before it entered the retail outlet, the farm value of these inputs was even less. Therefore, changes in the price of farm commodities have an exceedingly small effect on restaurant and fast food prices, and vice versa. Many other factors influence menu prices, including the general inflation rate, wage rates, and competition between firms.

Economic analyses by Capps et al. (2005), Guthrie and Morton (2000), and Yen and Biing-Hwan (2002) suggested that non-alcoholic beverages that are complementary in nature to fast food consumption may also be a contributory factor to current obesity trends. Consumers are offered a wide variation of choices among nonalcoholic beverages and there is a decreasing trend toward consumption of milk and increased consumption of other beverages, especially soft drinks. Beverage choices may have important implications for intake of calories and therefore for obesity risk, as well as for adequacy of important nutrients such as calcium. Analysis of U.S. Department of Agriculture (USDA) food consumption survey data by Yen and Biing-Hwan (2002) showed that, on average, for each 1-ounce reduction in milk consumption, a child's calcium consumption declines by $34 \mathrm{mg}$. Guthrie and Morton (2000) showed that soft drinks are the major source of added sugars in American diets, contributing approximately a third of the added-sugars intake of Americans 2 years of age and older. This is an important source of added sugars for young children, 
contributing approximately $19 \%$ to the added-sugars intake of children 2-5 years of age (Guthrie and Morton, 2000). USDA food supply data show that availability of regular soft drinks rose from 29 gallons per capita in 1977 to a high of 38 gallons in 1999 (Capps et al., 2005). Figures for 2000-01 show a slight decline to 37 gallons per capita in 2001. Despite Americans' professed concern with losing weight, diet soft drinks grew slowly from 4 gallons per capita in 1977 to 12 gallons per capita in 2001 (Capps et al., 2005).

It is clear that the U.S. economy is becoming increasingly service-oriented, and over the past several decades, foodservice industries that offer the highest levels of convenience have been rewarded with strong sales growth. In the face of rising incomes and increasingly hectic work schedules, a nearly insatiable demand for convenience will continue to drive fast food sales and associated complementary food products. Firms will strive to find ways to make their products even more accessible. However, these developments in the demand for foodservice meals and snacks could also reflect important changes in the diets and health of the American population.

Body weight is greatly influenced by the difference between energy intake and its expense. The amount of calories consumed and expended daily are influenced by a myriad of factors, including the price of goods and services, a person's income, time constraints, cooking skills, level of education, gender, age, cultural background, and genetic endowment (Frazao, 1996). Each factor may play a multifaceted role, affecting an individual's knowledge about health and nutrition, his or her choice of what to eat, and how many calories he or she expends. A multivariate analysis of data from the 1994-96 Continuing Survey of Food Intakes by individuals and the 1994-96 Diet and Health Knowledge Survey by Mancino, Lin, and Ballinger (2004) both show that certain behaviors and attitudes are 
significantly associated with alternative weight outcomes. Mancino, Lin, and Ballinger (2004) found that individuals who exercise more frequently, watch less television, drink fewer sugary beverages, and eat a higher quality diet are more likely to have a healthy body weight. Attitudes about diet and health may also have an impact on health behaviors (Kuchler and Ballenger, 2002; Lin, Huang, and French, 2004). Mancino, Lin, and Ballinger (2004) also indicated that obese women are less likely to believe that they have control over their weight. Similarly, overweight and obese men are less likely to accurately assess their weight status. Nearly $60 \%$ of overweight and obese men consider themselves to have a healthy weight. Differences in obesity rates across population subgroups indicate that socioeconomic factors significantly and systematically affect an individual's ability to achieve good health. Individuals with higher incomes tend to make greater investments in their own health. They watch less TV and eat a higher quality diet. Men with higher incomes are more accurate about their weight status, while women with higher incomes drink fewer sugary beverages, exercise more frequently, and are more confident that they can control their weight. Time constraints may limit personal investments in healthy behaviors. These time constraints seem to correlate with household composition. Compared with single parents, married parents have a higher quality diet, eat breakfast more often, and drink fewer sugary beverages (Mancino, Lin, and Ballinger, 2004). Formal education also seems to motivate individuals to make greater investments in their own health. Individuals with a college education watch less TV, eat a higher quality diet, drink fewer soft drinks, and eat breakfast more often (Mancino, Lin, and Ballinger, 2004). Women with a college education have a greater feeling of control over their own weight and exercise more frequently 
(Mancino, Lin, and Ballinger, 2004). Kenkel (1991) also suggests that schooling improves the choice of health inputs by improving an individual's health knowledge.

Mancino and Kinsy (2004) showed that per-meal nutrient demand is a function of food prices, an individual's wage rate, body weight, caloric expenditures, information about health and nutrition, per-meal situational factors that affect one's sensitivity to time delay, and the amount of time spent preparing the meal. Empirical investigation shows that situational factors influence food choices and that the use of nutritional information changes as one becomes hungrier, busier, and eats more foods away from home.

With the help of the almost ideal demand system (AIDS) framework, Huang and Lin (2000) showed that consumers' demand for food at home is influenced by a wide array of socio-demographic factors such as per capita household income, per capita at-home food expenditures, away-from-home share of the food budget, education, race, urbanization, regional differences, and composition and size of the household. Empirical estimates indicate that budget shares of beef, other meat, eggs, cereal, and bread decrease as total food expenditures increase, while the budget shares of poultry, fruits, vegetables, and juice increase with an increase in expenditures. The results also indicate that larger households allocate more of their food expenditures to beef and pork, and less to bread and juice. Households headed by those who attended college allocate more of their food budgets to poultry, fruits, and vegetables, and less for beef, pork, other meat, and eggs. In terms of differences by race, black households allocated more of their food budgets for pork, poultry, other meat, fish, eggs, and juice than white households, but less for dairy, bread, and fruits. City and suburban households allocate less of their food budgets for pork and fats, and more for fruits and juice than rural households. With regard to regional and seasonal differences in 
food budget allocation, households in the West devoted a greater proportion of their food budget to dairy products and fruits than other households and less to pork and other meat. Families with children aged 2-5 tend to spend more of their food budgets on dairy products.

\subsubsection{Relationship between Poverty and Obesity}

Knutson, Penn, and Boehm (1995) found that poor health leads to poor nutrition and poor nutrition results in poor health. Infection exacerbates malnutrition and malnutrition exacerbates infection. Therefore, poverty, hunger, and poor health foster one another (Knutson, Penn, and Boehm, 1995). Many health disparities in the United States are linked to inequalities in education and income. Drewnowski (2003) showed that wealth and poverty have profound effects on diet structure, nutrition and health. His study emphasized that income and the macronutrient composition of diets are linked at the aggregate and most likely at the individual level. Applying Engel's law to the aggregate level, Drewnowski (2003) showed that the percentage of personal consumption of at-home foods diminishes as per capita gross domestic product rises. U.S. residents spent the lowest amount (less than 8\%) of disposable income on at-home food followed by Canada and the United Kingdom (Drewnowski, 2003). However, in higher income nations, cost per unit of food energy is low such that those nations are associated with high-energy intakes. Accordingly, people in higher income nations consume more added sugars and fats than those in low-income nations. In addition, low-income consumers within rich nations consume lower quality diets than do higher income consumers.

Drewnowski and Specter (2004) found evidence to support occurrence of the highest rates of obesity among population groups with the highest poverty rates and the least education. The authors believe that there is an inverse relationship between energy density, 
mega joule per kilogram $(\mathrm{MJ} / \mathrm{kg})$ and energy cost $(\$ / \mathrm{MJ})$, such that energy-dense foods composed of refined grains, added sugars, or fats are a low-cost option for the consumer. Therefore, the selection of energy dense foods by food insecure, low-income consumers may represent a deliberate strategy to save money. Also, poverty and food insecurity are associated with lower food expenditures, low fruit and vegetable consumption, and lowerquality diets (Drewnowski and Specter, 2004). Food insecurity, which is defined as limited or uncertain availability of nutritionally acceptable safe foods, appears to be linked with obesity (Mokdad, Ford, and Bowman 2003; Basiotis and Lino, 2002). The 1995 Current Population Survey (CPS) shows that 12\% of U.S. households are food insecure (Carlson, Andrews, and Bickel, 1999). However, not all food-insecure households showed evidence of hunger, and therefore the relationship between food security and hunger is complex (Levedahl and Oliveira, 1999). Since food insecure people are more likely to receive food assistance, there is a positive correlation between food insecurity and food stamp participation (FSP) (Alaimo et al., 1998). An analysis of the third National Health and Nutrition Examination Survey (NHANES III) by Basiotis and Lino (2002) showed that women, but not men, in food-insufficient households were more likely to be overweight than food-sufficient women. The corollary of Engel's law is that low-income households spend a higher proportion of disposable income on food relative to what they earn. While U.S. households with incomes greater than $\$ 70,000$ per year spent $7 \%$ of disposable income on food, low-income families $(\$ 10,000-15,000$ per year) spent approximately $25 \%$ (Drewnowski and Specter, 2004). The authors hypothesized that consumption of energy dense diets is an important strategy for low-income people to extend their food budget which, in turn, results in higher rates of obesity and type 2 diabetes. 
An investigation of the economic determinants and dietary consequences of food insecurity and hunger in the United States by Rose (1999) shows that hunger rates decline sharply with rising incomes. Despite this strong relationship studies using other national data showed that there is no one-to-one correspondence between poverty-level incomes and hunger. Evidence from the 1995 Current Population Survey (CPS) shows that $17 \%$ of households with incomes less than $50 \%$ of the poverty level $(\$ 12,158$ for a family of three) were affected by some form of hunger, whereas the rate falls to $1.4 \%$ for those with incomes greater than $185 \%$ of the poverty level (Hamilton et al., 1997). Similar declines in food insufficiency rates with rising incomes can be seen in data from the 1988-1994 Third National Health and Nutrition Examination Survey (NHANES III) (Alaimo et al., 1998), the 1992 Survey of Income and Program Participation (SIPP), and the 1989-1991 Continuing Survey of Food Intake by Individuals (CSFII) (Rose, Gundersen, and Oliveira, 1998). Rose (1999) noted that other factors such as food stamp participation, homeowner occupancy, level of education, and age and ethnicity of household members also have an impact on food insecurity. However, important policy concerns are the nutrition and health consequences of food insecurity and hunger. Even though there is evidence to link food insecurity, hunger, and poverty, their causation of health consequences, such as obesity, seems to still be a paradox.

\subsubsection{Technological Change and Obesity}

Even though the market price reflects the major component of the cost of the product, its full cost is comprised of other components such as time cost and information cost. For example, the full cost of a home-prepared meal includes not only the cost of ingredients bought at the store, but also the travel cost to the store and back, the cost of time spent preparing the food 
and information costs related to nutrition knowledge and cooking techniques. A change in any component of these costs will change the incentive for consuming that product, as well as its closely related alternatives (Variyam, 2005). Prices change over time due to a variety of reasons, including availability of resources, but the prime mover of prices is technology. Better production and distribution technologies generate more and better goods, driving prices down. Food prices, whether at the store or at a restaurant, have been declining relative to prices of all other items between 1952 and 2003. The ratio of food prices to the price of all other goods has fallen by $12 \%$ (Variyam, 2005).

Cutler, Glaeser, and Shapiro (2003) suggest that the increase in food consumption prompted by the falling time cost of food is the major cause behind the surge in obesity since 1980. They note that technological innovations—including vacuum packing, improved preservatives, deep freezing, artificial flavors, and microwaves - have enabled food manufacturers to cook food centrally and ship it to consumers for rapid consumption. In 1965, a married woman who didn't work spent over two hours per day cooking and cleaning up from meals. In 1995, the same tasks took less than half the time. Although greater convenience, growing portion sizes, and increased accessibility of restaurant meals have been blamed for contributing to the rise in obesity, in economic terms, these are quality attributes that are valued by consumers.

Putnam (1999) considered the role of food supply systems as a contributing factor to obesity. As suggested by Philipson and Posner (2003), obesity has been accompanied by innovations that economize on time previously allocated to the non-market or household sector. New innovations have reduced the time spent on food preparation at home through the introduction of convenience foods at low cost for home consumption and also through the 
increased number of fast food and full-service food outlets. It is reported that the number of fast food outlets has doubled from 1972 to 1997 (Chou, Grossman, and Saffer, 2002). In the same period the number of full-service restaurants has risen by $35 \%$, according to the Census of Retail Trade (Chou, Grossman, and Saffer, 2002). An increasing trend of fast food consumption in favor of labor intensive preparation of food at home can be partly attributed to labor market developments since 1970 . The real income of single earner households has declined from 1970 to 1993, and it was only 1\% higher in 1998 than 1970. Increases in hours of work and labor force participation, reduction in wage rates, and decline or modest increase in real incomes has stimulated the demand for inexpensive, convenient, fast foods which are also high in caloric content. At the same time, the reduction in the time available for active leisure has reduced the calories expended (Chou, Grossman, and Saffer, 2002).

Philipson (2001) argued that in an agricultural or industrial society, work tends to be strenuous, and, in turn, the worker is paid to exercise. In most post-industrial and redistributive societies, such as the U.S., most work entails little exercise, and not working does not lead to starvation or cause reduction in weight, because of food stamps and other welfare programs. As a result, people must pay for undertaking, rather than being paid to undertake, physical activity. Payment is mostly in terms of forgone leisure, because leisure weight control must be substituted for weight control by physical exertion at work (Philipson, 2001). The jogging and gym 'revolution' and the limiting of calorie consumption as a result of deliberate dieting can thus be interpreted as substitutions brought about by technological changes in market and household work. Despite these off-the-job substitutions, overall obesity can still rise as the result of technological changes that cause fewer calories to be expended in market and non-market work. 


\subsubsection{Time Use, Leisure, Physical Inactivity and Obesity.}

The seminal work of Becker (1965), the theory of time allocation, has paved the way for economists to analyze the tradeoffs of time use decisions that affect an individual's daily life. Gross investments in health capital can be produced by household production functions whose direct inputs include the time of the consumer and market goods such as medical care, diet, exercise, recreation, and housing. An individual's health, in turn, also determines the total amount of time available for market and non-market activities (Grossman, 1972).

Gronau (1977) stated that wages and unearned income are the most important economic determinants of labor supply of married women, in the short run. His empirical findings show that an increase in the market wage is expected to reduce work at home, while its effect on leisure and work in the market is indeterminate. An increase in income may increase leisure, reduce work in the market and leave work at home unchanged. His study also shows that the marginal effect of a wage change on leisure of the employed is more than four times its effect on work at home, although the wage elasticities are almost identical.

The wage penalty or the opportunity cost of time, time use decisions, and health of a family have become important issues today as more and more women participate in the labor force. The labor force participation rate of women with young children (under 6 years of age) increased from 39\% in 1975 to $62 \%$ in 1996 (Guthrie, Lin, and Frazao, 2002). Increased participation of women in the labor force has reduced time available for nonmarket household activities and motivated people to consume relatively cheap high-caloric foods (Chou, Grossman, and Saffer, 2002).

Sturm (2004) focuses on how people divide their time between five categories of activities - sleep, leisure, occupation (paid work), transportation, and home production 
(unpaid work) - collectively referred to by the acronym SLOTH. A substantial change, in terms of expenditures and time allocation, has been observed in the area of leisure time and travel/transportation. Since 1965, overall leisure time has increased by greater than 4 hours per week, time spent at paid work and on productive activities at home (cooking, cleaning, repairing things, childcare) has diminished, transportation time has increased and time for personal care (taking showers, getting dressed or eating) remained the same. Along with these developments, many individuals tend to spend more of their leisure time engaged in sedentary activities at the expense of physical activities, such that increasing weight is accompanied by increased leisure time (Strum, 2004). There is evidence to suggest that children who engage in less vigorous physical activity, mostly television viewing, tend to be more overweight (Anderson, Butcher, and Levine, 2003). Curtin and Hofferth (2004) found that overweight children spent fewer hours per week in sports and more time in marginally active or sedentary activities. In 2001, fewer than half of U.S. adults achieved recommended levels of physical activity, and most of those who walked for exercise did not walk long enough, often enough, or briskly enough to obtain health benefits (Pratt et al., 2004).

The determinants of time allocation for leisure, home cooking, and other activities could also be influenced by socioeconomic and demographic factors such as education, household income, and ethnicity. Mancino, Lin, and Ballinger (2004) showed that individuals with higher incomes or education were more likely to engage in healthy behaviors including eating a healthier diet. Sturm (2004) found that television watching declined with education, and active sports increased. A WV study found a modest positive relationship between an active lifestyle and a healthy diet (Krummel et al., 2002), which may 
be linked to the similarity of the determinants of these two characteristics (e.g., higher income and/or education).

Curtin and Hofferth (2004) examined the extent to which weekly time spent in various leisure activities was associated with a child being overweight. Results showed that overweight children spent 6-12 fewer hours per week in sports, particularly in team sports. Overweight children spent more time than their normal weight counterparts in marginally active and sedentary activities such as shopping, studying, visiting, and time on the computer. There were no significant differences between overweight and normal-weight children in time spent playing or viewing television. It appears that normal weight children are not just more likely to participate in active leisure pursuits, but are more likely to be involved in team sports in their leisure time than overweight children.

Knadula (2005) investigated the effects of ethnicity and duration of residence in the U.S. on leisure time physical activity (LTPA), non-leisure time physical activity (NLTPA), and occupational physical activity among the six largest Asian subgroups using populationbased data from California. LTPA is defined as physical activity performed during exercise, recreation, or any time other than that associated with one's regular occupation, housework, or transportation. NLTPA includes walking or cycling for transportation, occupational activity, and housework. The author's results show that Asian Americans, especially immigrants, are at risk for low levels of LTPA and high levels of physical inactivity. NLTPA does not offset these lower levels of LTPA. Increasing physical activity is the key to protecting the health of this rapidly growing population. 


\subsubsection{Built Environment and Obesity}

There is a growing concern that urban sprawl and the structure of the built environment have an impact on the recent escalation of non-contagious health disorders. While sprawl is a somewhat imprecise and difficult to measure phenomenon, it is often characterized by low-density urban development that consumes land faster than the growth of the population. Simply put, it is poor accessibility, as such, nothing is within easy walking distance of anything else.

Most Americans now live in suburban areas (Foster-Bey, 2002). This redistribution of the nation's population to suburbs and away from central cities and rural areas has given rise to undesirable impacts on metropolitan residents and communities. These impacts include the destruction of open space and farmland, increased automobile congestion and pollution, the geographic isolation of low-income and minority residents, and a mismatch between the location of jobs and the residences of workers, especially, low-skilled, lowincome workers.

Transportation, which is a key factor of our everyday life, could also be a decisive factor of changes in physical activity as small shifts in travel modes noticeably alter energy expenditure. While time spent on transportation has increased (Sturm, 2004), suburbanization, street design, and land use patterns reduce the amount of physical activity that can be achieved through transportation (Sturm, 2004; Salens et al., 2003; Frank and Pivo, 1995; Frank, Anderson, and Schmid, 2004; Handy et al., 2002). The influence of transportation on energy expenditure is mainly affected through the built environment in which the cities and transportation corridors are planned and developed (Pratt et al., 2004). 
Ewing et al. (2003) considered sprawl to be any environment characterized by: (1) a population widely dispersed in low-density residential development; (2) rigid separation of homes, shops, and workplaces; (3) a lack of distinct, thriving activity centers, such as strong downtowns or suburban town centers; and (4) a network of roads marked by large block size and poor access from one place to another. Compact development is the opposite of sprawl, keeping complementary uses close to one another. The authors probe into the hypothesis that residents of sprawling places: (1) walk less, (2) weigh more, and (3) have a higher prevalence of health problems linked to physical inactivity than those living in more compact places. The evidence supports their hypothesis; after controlling for demographic and behavioral factors, the county sprawl index had a small but significant association with minutes walked, obesity, and hypertension. Residents of sprawling counties were also more likely to walk less during leisure time, weigh more, and have a greater prevalence of hypertension than residents of compact counties.

Ewing, Schieber, and Zegeer (2003) also indicated that county sprawl is highly correlated with the overall traffic fatality rate, as well as with an array of transportation outcomes (e.g., percentage of residents walking or taking public transit to work, average vehicle ownership, and vehicle miles traveled per capita) and environmental outcomes. (e.g., ground-level ozone levels). The most compact counties (i.e., those with the highest population density and street accessibility and, therefore, the higher index value) had lower traffic fatality rates and for every $1 \%$ increase in the index, the traffic fatality rate decreased by $1.49 \%$.

The consequences of urban sprawl could include increased reliance on automobile transportation and decreased ability to walk to destinations, decreased neighborhood 
cohesion, and environmental degradation (e.g., greenhouse gas emissions and destruction of open space) (Freeman, 2001). Lopez (2004) found that a higher level of urban sprawl was associated with an increased risk of being obese. The empirical results showed that, after controlling for socioeconomic and demographic factors, for each one point rise in the urban sprawl index ( $0-100$ scale), the risk of being overweight increased by $0.2 \%$ and the risk of being obese increased by $0.5 \%$ Lopez (2004). Urban sprawl may reduce the time available for physical activity because parks or fitness facilities are more distant. It may also affect diets by increasing the distance to supermarkets or by the increased cost of nutritious foods caused by the conversion of farmland to urban areas (Frumkin, 2002).

Derry (2004) emphasized that the built environment may play a major role in controlling weight by shaping food access and availability. Recent research suggests that supermarkets are more likely to be located in wealthier and predominantly white areas, and that fruit and vegetable intake is positively associated with the presence of a supermarket, even after controlling for personal economic factors (Morland et al., 2002). Though the relationship between different types of eating-places and dietary consumption has not been well examined, availability, type and distribution of restaurants and the diffusion of food advertising represent other means by which the environment affects weight imbalances.

Blanchard and Lyson (2003) indicated that the establishment of "supercenter" retail grocery stores tends to create food deserts for the rural population. When a supercenter is opened in a non-metropolitan county, it draws customers from a wide radius such that existing small retailers in these areas go out of business due to loss of customers. This places low-income earners at a disadvantage when it comes to finding low cost grocery stores. 
Frank, Anderson, and Schmid (2004) pointed out that the likelihood of obesity apparently declines with an increase in mixed land use, but rises with time spent per day in a car. While each $25 \%$ increase in mixed land use has declined the risk of being obese by $12 \%$, each additional hour spent in a car raises the likelihood of obesity by $6 \%$. Also, each additional kilometer walked per day is associated with a $5 \%$ reduction in the likelihood of obesity. Salens et al. (2003) indicated that a more walkable environment has been found to be associated with higher physical activity and lower obesity levels. Handy et al. (2002) stated that a combination of urban design, land use patterns, and transportation systems that promote walking and bicycling will help create more active, healthier and livable communities.

Rosenberger, Sneh, and Phipps (2002), showed that the rates of physical inactivity of WV counties are positively related to expenditures on health care treatments for diseases and disorders of the circulatory system. Results also showed that quantities of variously measured recreational opportunities are negatively related to physical inactivity, but not to obesity. Increasing recreation opportunities have the potential to decrease health care expenditures and rates of obesity through increasing rates of physical activity.

A study by Block, Scribner, and DeSalvo (2004) showed that there is a geographic correlation between exposure of black and low-income neighborhoods to fast food restaurants. It reveals that predominantly black neighborhoods have 2.4 fast food restaurants per square mile compared to 1.5 restaurants in predominantly white neighborhoods. A study which addressed fast food restaurant density and median individual income in Melbourne, Australia showed that residents of low income neighborhoods have 2.5 times more exposure to fast food restaurants than those living in affluent neighborhoods (Reidpath et al., 2002). 
On the other hand, there are studies that claim that lower-population densities encourage physical activity, hence, lowering the risk of being obese. More recently, Plantinga and Bernell (2005) utilized a theoretical model to examine the possible link between urban land use and obesity. They emphasize that a shortcoming of urban planning and public health literature on sprawl and obesity is that it treats land use (or more broadly the built environment) as exogenous. From this perspective, weight gain is caused by land use patterns that discourage physical activity. The authors believe that in these empirical approaches, there is no room for consumers to express preferences for land use patterns, for individuals to undertake averting behaviors to avoid health risks and for prices to ration housing in desirable (e.g., healthy) locations. Plantinga and Bernell (2005) developed a spatial land market model which integrates utility maximizing preferences. They considered a monocentric city where households maximize utility defined over housing, weight and calories. The authors believe that income, weight, location and land development densities are endogenous choices such that there is a tradeoff between time allocated to work and leisure and between the consumption of food and other goods. If weight outcomes and development densities (i.e. sprawl) are endogenous, single equation empirical estimation seems to be invalid. In particular, low-density developments should not be viewed as a cause of high obesity rates any more than they should be considered as a cause of higher commuting costs.

\subsubsection{Food Policy, Health and Obesity}

Kuchler and Ballenger (2002) considered obesity a result of market failure. Like environmental pollution, it imposes an external cost to society so that public intervention to control obesity is justified. In order to reduce the consumption of unhealthy foods, it has 
been suggested that foods high in calories, fat or sugar be taxed, and that healthy foods such as fruits and vegetables be subsidized. A steep tax would probably reduce consumption of taxed foods and could be used to generate funding to subsidize healthful foods (Jacobson and Brownell, 2000). Jacobson and Brownell (2000) stated that it is highly likely that a fruit and vegetable subsidy would increase sales, but there are mixed opinions on the feasibility and desirability of a steep 'junk food' tax. A small tax may be more politically feasible and still could generate significant revenues to support health measures.

A study of pricing effects on food choices by French, Harnack, and Jeffery (2000) shows that price reduction strategies promote the choice of targeted foods by lowering their cost relative to alternate food choices. Two community-based intervention studies showed that price reductions resulted in a four-fold increase in fresh fruit sales and a two-fold increase in baby carrot sales (French, Harnack, and Jeffery, 2000). Their study also concluded that price reductions are an effective strategy to increase the purchase of more healthful foods in community-based settings such as work sites and schools.

Previous studies suggest that economic incentives such as taxes are a means of changing the behavior of consumers. Some of the studies (Grossman, 1989; Ohsfeldt, Boyele, and Capilouto, 1998; Lewit and Coate, 1981; Harris, 1982; Coate and Grossman, 1988) directly or indirectly deal with tax or price effects on alcohol and tobacco consumption. Grossman (1989) showed that increased taxation, which results in higher prices, would decrease alcohol abuse and cigarette smoking. Recent studies (Jacobson and Brownell, 2000; Leicester and Windmeijer, 2004; Kuchler, Tegene, and Harris, 2004; Bahl, 1998) have dealt with the implications of taxes on snack foods and soft drinks. 
Jacobson and Brownell (2000) identified 19 states and cities that levy taxes on soft drinks, candy, chewing gum or snack foods (potato chips, pretzels, and others). These taxes were levied at the wholesale or retail level in terms of a fixed tax per volume of product (i.e., excise tax), or as a percentage of sales price (sales tax). They estimated that in the state of Arkansas, a tax on soft drinks, about 2 cents per 12 ounces $(360 \mathrm{ml})$, would generate $\$ 40$ million per year. A $7.25 \%$ sales tax on soft drinks in the state of California would generate about \$281 million in revenues annually. Nationally, special taxes on soft drinks, candy and snacks generate about $\$ 1$ billion per year. As far back as 1951, West Virginia enacted a tax on carbonated and non-carbonated soft drinks, fruit drinks and chocolate milk, at $\$ 0.01$ per half liter and $\$ 0.80$ per gallon of syrup, paid by manufacturers or wholesalers. Annual tax revenues of $\$ 13$ million were used to support the West Virginia University medical, dental and nursing schools (Jacobson and Brownell, 2000).

Kuchler, Tegene, and Harris (2004) examined the impact of varying excise tax rates on salty snack purchases and possible consumer price responses. The authors showed that a relatively small ad valorem tax would not immediately change a consumer's diet, but would raise tax revenues substantially. A relatively low tax rate of $1 \%$ per pound and $1 \%$ of value would not significantly alter consumption, thus having little effect on diet quality or health outcomes. However, such low taxes would generate $\$ 40-\$ 100$ million in tax revenues (Kuchler, Tegene, and Harris, 2004). Nevertheless, Kuchler, Tegene, and Harris (2004) concluded that without a clear statement of the efficiency problems caused by overweight and obesity, it could not be confirmed whether such taxes might increase or decrease economic efficiency by having benefits exceed costs. They also stated that many public 
health communities have proposed interventions, and taxing snack food has been advocated frequently.

Cash, Sunding, and Zilberman (2004) investigated the possible health effects of a "thin subsidy" on broad categories of fruits and vegetables. They estimated the change in consumption that could be induced by modest subsidies in retail prices. By using these estimates of changes in consumption, they further calculated the number of diseases avoided and the cost per statistical life saved. These estimates compared favorably with the cost per life saved for many existing U.S. regulatory programs. Their simulations showed that, on average, the present value of the cost per statistical life saved for a $1 \%$ fruit and vegetable subsidy is $\$ 1.29$ million. Cash, Sunding, and Zilberman (2004) also mentioned that fat taxes are regressive, since tax incidence would be felt hardest by low income families. In contrast to fat taxes, subsidy programs would likely be progressive as the largest benefits would go to low income earners. But, these subsidy programs have to be funded by taxpayers so it is necessary to investigate whether or not such policies would be cost-effective in achieving health improvement.

Bahl (1998) showed that developing economies resort to discriminatory excise taxes as stopgap measures to solve short term problems. Since more advanced economies do not have such short term problems, justification for a discriminatory excise tax on soft drinks is weak. It was concluded that the use of discriminatory excise taxes other than on "sin" products have little justification in modern tax systems.

Taxing alcoholic beverages to reduce the social cost of alcohol consumption has been a debated public policy issue. It has been argued that public health costs and other external costs associated with alcoholic beverages are so significant that imposing a substantial excise 
tax on those beverages is justified (Pogue and Sgontz, 1989). It has also been argued that an imposed tax on alcoholic beverages would cause dissatisfaction for sensible drinkers without necessarily reducing the harm caused by a few excessive drinkers. Pogue and Sgontz (1989) applied a framework to evaluate the above two views of efficiency (welfare) effects of alcohol taxes. In addition to the value of resources used to produce and distribute alcohol, alcohol abuse generates an extra cost which is borne by the abuser him/herself (internal) and other external parties. Increased medical expenses, lost income, increased health and automobile premiums and pain, discomfort, emotional and physical stress are some of the internal costs associated with alcohol consumption. External costs take the form of injury to others and property damage. No matter whether cost is internal or external, some of these costs will be realized in future time periods (Pogue and Sgontz, 1989). Pogue and Sgontz (1989) concluded that significantly higher rates are needed for alcoholics to loose their utility gain from alcohol consumption, if alcoholism is accepted as a disease.

Leicester and Windemeijer (2004) studied the potential impact of the introduction of a "fat tax" in the U.K. in an effort to reduce the growing prevalence of obesity in Britain. A fat tax can be imposed on the nutrient content of foods such that those containing more fat or salt are subjected to steeper taxes. Alternatively, particular types of foods, such as snacks and soft drinks could be subjected to a tax, or a value-added tax (VAT) could be extended to foods that are currently zero-rated but have high fat content. They concluded that obesity rates have risen substantially in the U.K. even over the past decade and the trend is likely to continue. A fat tax could be one way in which the government can intervene to reverse the trend. Leicester and Windemeijer (2004) also stated that a fat tax would be regressive, 
costing the poor more than the rich since consumption of fat and other "bad" nutrients does not differ much across income levels.

Harris (1999) employed the concept of a "continuum of addiction" model to test the hypothesis that: (a) the price elasticity of demand for cigarettes declines with average age, (b) the youngest smokers, those who have not yet smoked everyday, are the most price sensitive; and (c) when faced with higher cigarette prices, adolescent smokers are less likely to progress to regular daily cigarette use, while young adult smokers are more likely to reduce the number of cigarettes smoked. Their results showed that the probability of current smoking was inversely related to both price and family income. Smoking is associated with several market failures such as negative externalities and imperfect information of market participants (Hana and Chaloupka, 2003). Smoking creates a substantial health cost which is partly paid for by public funds. Rising health insurance premiums and lower labor productivity are some of the market failures that warrant government intervention in tobacco products. Hana and Chaloupka (2003) also showed that higher cigarette prices, irrespective of the way they are measured, reduce the probability of youth cigarette smoking.

Saffer and Dave (2003) studied the impact of alcohol advertising on adolescent alcohol consumption. The results, based on National Longitudinal Survey of Youth (NLSY97) data, suggest that a complete ban on all alcohol could reduce adolescent monthly alcohol participation by about $24 \%$ and binge participation by $42 \%$. The past month priceparticipation elasticity was estimated at -0.28 and the price-binge-participation elasticity was estimated at -0.51 . They showed that both price and advertising policies have a substantial impact on reducing alcohol consumption. 
"Sin" taxes, such as taxes on cigarettes and alcohol consumption, produce economic benefits by reducing various external costs. However, these taxes also create an economic cost, for example, by tempting people to consume less of the desired commodity and more of other commodities than they otherwise would. Other taxes, like a labor tax, create an economic cost since they reduce the returns to work effort and reduce labor supply below levels that would maximize economic efficiency. The marginal excess burden (MEB) of a tax refers to the welfare loss (or gain), net of any external benefits caused by the increase in the tax necessary to raise an extra dollar of revenue for the government. Information on the MEB of different taxes would help to determine the economic case for tax reforms such as the effect of cutting one tax at the expense of raising another tax, holding total tax revenue constant. As noted by Parry (2001), the MEB of the tax system also plays a role in determining the economically efficient size of government (Feldstein, 1997). The economic costs of any public spending (defense, aid for the needy, health, education) include not only the monetary outlays but also the additional excess burden from the higher taxes necessary to finance the required amount of revenue. In principle, maximizing economic efficiency involves expanding programs to the point where the social benefit from an extra dollar of spending equals one plus the MEB (Parry, 2001).

In summery, this section explores the possible usage of economic incentives in controlling behavioral health problems such as obesity, smoking and alcoholism. Even though the usage of economic incentives to correct externalities of such health disorders are economically justifiable, in reality, their applicability depends on the tradeoff between the marginal excess burden of economic incentives (e.g., taxes) in controlling such health issues and the marginal external cost of such health issues to society. If marginal external costs of 
obesity are greater than the marginal excess burden of taxes to control it, the use of taxes would create a Pareto improvement in society. Therefore, the use of economic incentives such as taxes to control obesity is a researchable question. 


\section{Chapter 3}

\section{Theoretical Framework and Methodology}

\subsection{Theoretical Approach}

The household production function framework (Lancaster, 1966), the theory of time allocation (Becker, 1965), as well as the concepts of health capital and health demand (Grossman, 1972) together underlie the theoretical background for this analysis. Becker (1965) and Lancaster (1966) used household production models in which consumers maximize utility derived from desirable attributes created at home from consumption of marketed goods combined with household labor, subject to budget and time constraints (cooking food for example). Grossman (1972) extended this framework to derive the demand for the commodity "good health." Health can be considered a desirable attribute that is produced by a household, entering into the household's utility function. Gross investment in health capital can be produced by a household's production function whose direct inputs include the time of the consumer and market goods such as medical care, diet, exercise, recreation, housing as well as exogenous or given socio-economic and demographic characteristics (Grossman, 1972). In this analysis, it is also assumed that a rational consumer allocates time and other resources to produce the commodity "good health" together with other desirable attributes that yield utility or satisfaction. Thus, the $i^{\text {th }}$ individual's utility maximization problem can be represented as

$$
\operatorname{Max}_{i}=U_{i}\left[X, Y, Z, L, L_{a}, H_{i}\left(X, Y, Z, L_{a}, S\right)\right]
$$

where $X$ is a numeraire good, $Y$ is fast food, and $Z$ is healthy food (such as fruits and vegetables), $L$ is passive leisure, which includes time spent socializing with family and 
friends, watching TV, etc., whereas $L_{a}$ is active leisure, such as time spent at the gym or on other strenuous physical activities that help maintain good health, $H_{i}$; $S$ is a vector of socioeconomic and demographic factors that also affect health. Here it is assumed that the $i^{\text {th }}$ individual's utility function is separable with its arguments, quasi-concave and continuously differentiable (Varian, 2002). Therefore, these marginal utilities, $\delta U_{i} / \delta X, \delta U_{i} / \delta Y$, $\delta U_{i} / \delta Z, \delta U_{i} / \delta L$, and $\delta U_{i} / \delta H_{i}$, are all greater than or equal to zero. This implies that some positive marginal utility is derived from consuming the numeraire good, fast food and healthy goods. It is also assumed that better health and passive leisure yield positive marginal utility to the consumer. The impact of active leisure on health, $\delta U_{i} / \delta L_{a}$, can be either greater than or equal to zero or less than or equal to zero, as its impact depends on the individual's subjective preference towards physical activities. For example, the pain that might arise from physical activities can give discomfort or negative utility to an individual. The individual's health production function can be represented as

$$
H_{i}\left(X, Y, Z, L_{a}, S\right) .
$$

The individual's health production function is assumed to be a continuously differentiable function with respect to its inputs. Therefore, the impact of fast food on health $\delta H_{i} / \delta Y$ is considered to be less than or equal to zero. Similarly, the marginal impact of a numeraire good, $\delta H_{i} / \delta X$, is considered as either greater than, less than, or equal to zero. The marginal contributions of fruit and vegetable consumption and active leisure, $\delta H_{i} / \delta Z$ and $\delta H_{i} / \delta L_{a}$ are considered to be greater than or equal to zero. Utility is maximized subject to the budget constraint: 


$$
P_{Z} Z+P_{Y} Y+P_{X} X+D(H(\cdot)) \leq I+w\left(T-L-L_{a}\right),
$$

where $P_{Y}, P_{Z}$, and $P_{X}$ are respective prices of goods $Y, Z$ and $X ; D(H(\cdot))$ depicts expenditures on medical services that are assumed to be a function of individual health status, $I$ represents non-wage income, $w$ is the wage and $T$ is total time available for market and non market activities, thus, $w\left(T-L-L_{a}\right)$ represents the labor income derived after spending time on both inactive and active leisure activities. Medical expenditures include money spent on services such as doctor bills and prescription drugs.

The Lagrangian for the above utility maximization can be represented as:

$$
\begin{aligned}
\operatorname{Max} \Omega= & U_{i}\left[X, Y, Z, L, L_{a}, H\left(X, Y, Z, L_{a}, S\right)\right] \\
& +\lambda\left[I+w\left(T-L-L_{a}\right)-P_{X} X-P_{Y} Y-P_{Z} Z-D(H(\cdot))\right]
\end{aligned}
$$

The first order conditions for utility maximization for the choice can be derived as:

$$
\begin{aligned}
& \Omega_{X}=U_{X}(\cdot)+U_{H} H_{X}-\lambda P_{X}-\lambda D_{H} H_{X}=0, \\
& \Omega_{Y}=U_{Y}(\cdot)+U_{H} H_{Y}-\lambda P_{Y}-\lambda D_{H} H_{Y}=0, \\
& \Omega_{Z}=U_{Z}(\cdot)+U_{H} H_{Z}-\lambda P_{Z}-\lambda D_{H} H_{Z}=0, \\
& \Omega_{L}=U_{L}(\cdot)-\lambda w=0, \\
& \Omega_{L_{a}}=U_{L_{a}}(\cdot)+U_{H} H_{L_{a}}-\lambda w-\lambda D_{H} H_{L_{a}}=0, \\
& \Omega_{H}=U_{H}(\cdot)-\lambda D_{H}=0, \\
& \Omega_{\lambda}=I+w\left(T-L-L_{a}\right)-P_{X} X-P_{Y} Y-P_{Z} Z-D(H(\cdot))=0 .
\end{aligned}
$$

Solving the first order conditions for utility maximization, and invoking the implicit function theorem yields the individual demand function for health as well as other goods:

$$
H_{i}=f\left(I, w, P_{X}, P_{Y}, P_{Z}, D_{H}, S\right) .
$$


Individual health, indirectly measured by BMI (Body Mass Index), is a function of income other than wages, the wage rate, prices of marketed goods and the marginal implicit price of health, $D_{H}$, i.e., the marginal expenditure that an individual would spend to remain healthy, and socioeconomic and demographic characteristics, $S$. The first order conditions also imply that:

$$
\frac{U_{X}(\cdot)+U_{H} H_{X}}{P_{X}+D_{H} H_{X}}=\frac{U_{Y}(\cdot)+U_{H} H_{Y}}{P_{Y}+D_{H} H_{Y}}=\frac{U_{Z}(\cdot)+U_{H} H_{Z}}{P_{Z}+D_{H} H_{Z}}=\frac{U_{L}(\cdot)}{w}=\frac{U_{H}(\cdot)+H_{L_{a}}}{w}=\frac{U_{H}(\cdot)}{D_{H}}=\lambda .
$$

This equi-marginal principle of optimality says that a rational consumer will allocate his/her resources up to the point where marginal benefits derived from the last dollar spent should be equal across all commodities consumed. Equation (13) implies that marginal benefits derived from the last dollar spent should not only be equal across commodities consumed but also for the other factors such as health and leisure that provide utility or satisfaction.

\subsection{Methodology}

This section presents the specific analytical approaches employed to investigate obesity in West Virginia. Two main analytical procedures, which emphasize (a) aggregate county level obesity differences, and (b) micro-level health differences were undertaken to address the objectives of this study. Aggregate county level analysis uses both non-spatial and spatial random and fixed effect modeling approaches under a panel data structure. In addition, an extension to the county level analysis is the non-linear minimum chi squared estimation of obesity. The micro level health study utilizes a recursive system estimation of individual self-assessed health (SAH) within a limited dependent variable setting. 


\subsubsection{Random and Fixed Effects Modeling of Obesity in WV Counties}

Panel data analysis is a popular method of studying a socioeconomic phenomenon that varies across space and time. A panel is a cross-section of a group of people, firms, or a geographic entity (such as a county) which has been observed over a defined time frame. It provides a rich environment for the development of estimation techniques and theoretical results for issues that cannot be studied using either cross sectional or time series data alone (Greene, 2003; Baltagi, 2001). Panel data analysis allows explicit consideration of both random and unobserved time invariant (fixed) effects between geographic entities (Mundlak, 1978; Gujarati, 2003). Aggregate county levels analysis uses random and fixed effects modeling approaches to investigate the county prevalence of obesity.

In general, the panel specification for the $i^{\text {th }}$ cross sectional unit can be represented as

$$
y_{i t}=\mu+\beta^{\prime} x_{i t}+a_{i}+e_{i t} \quad i=1,2, \ldots, N ; t=1,2, \ldots, T .
$$

The subscript $t$ denotes the time dimension of the panel. In this study, $\mathrm{N}$ is the number of counties in $\mathrm{WV}, 55$, and $\mathrm{T}$ is the number of time periods, 2 . The dependent variable, $y_{i t}$, denotes the $i^{\text {th }}$ county for time period $t$. The scalar, $a_{i}$, represents an unobserved latent component or heterogeneity among the counties; $\beta$, is a $K \mathrm{x} 1$ vector of parameters to be estimated and $x_{i t}$ is the observation for county $i$ for each of $K$ explanatory variables which may change across $t$ but not $i$, or vise versa. The errors are $e_{i t}$ which change across $i$ and over $t$.

The scalar $a_{i}$ could be either fixed or random among the counties. If scalar $a_{i}$ is orthogonal or uncorrelated with each $x_{i t}$, i.e., covariance $\left(x_{i t}, a_{i}\right)=0$, then $a_{i}$ is another 
unobserved factor affecting $y_{i t}$ that is not systematically related to the observable explanatory variables whose effects are of interest (Wooldridge, 2002).

The assumption covariance $\left(x_{i t}, a_{i}\right)=0$ leads to a random specification of the panel data structure which can be represented as:

$$
y_{i t}=\mu+\beta^{\prime} x_{i t}+v_{i t}, \quad t=1,2, \ldots, T,
$$

where $v_{i t}=a_{i}+e_{i t}$ is the composite error term of the unobserved effects, $a_{i}$, and the error term, $e_{i t}$. It is also assumed that expected values of the error term and the unobserved effects are: $\mathrm{E}\left(e_{i t} \mid x_{i}, a_{i}\right)=0, t=1,2, \ldots, T$, and $\mathrm{E}\left(a_{i} \mid x_{i}\right)=\mathrm{E}\left(a_{i}\right)=0$, where $x_{i}=\left(x_{i 1}, x_{i 2}, \ldots, x_{i T}\right)$. Orthogonality between $a_{i}$ and $x_{i}$ implies that knowing information about $x_{i}$ does not reveal anything about $a_{i}$. As long as the vector $a_{i}$ is stochastic, i.e., $\mathrm{E}\left(a_{i} \mid x_{i}\right)=0$, ordinary least squares (OLS) gives unbiased and consistent estimates. However, OLS estimates will be less efficient due to the composite error term, which is serially correlated and/or heteroskedastic due to the presence of $a_{i}$ in each time period. Since the variance of $e_{i t}$ is $\mathrm{E}\left(e_{i} e_{i}{ }^{\prime} \mid x_{i}, a_{i}\right)=\sigma_{e}^{2} I_{T}$, the variance of $a_{i}$ is $\mathrm{E}\left(a_{i} a_{i}{ }^{\prime} \mid x_{i}\right)=\sigma_{a}^{2}$, and the mean of $v_{i t}$ is $\mathrm{E}\left(v_{i t}\right)=\mathrm{E}\left(a_{i}+e_{i t}\right)=0$, it can be shown that the variance of the diagonal elements equals $\mathrm{E}\left(v_{i t}^{2}\right)=\sigma_{a}^{2}+\sigma_{e}^{2}$ and the covariance of the off diagonal elements equals $\mathrm{E}\left(v_{i t} v_{i s}\right)=\sigma_{a}^{2}$ (the derivation of which is shown in appendix A). The $t$ and $s$ subscripts represent error terms of adjacent time periods. Therefore, the covariance matrix of the composite error term, $\mathrm{E}\left(v_{i} v_{i}{ }^{\prime}\right)$, equals $\Omega=\sigma_{a}^{2} j_{T} j_{T}{ }^{\prime}+\sigma_{e}^{2} I_{T}$, where, $j_{T} j_{T}{ }^{\prime}$ is a $T \mathrm{x} T$ matrix with a one in every element and $I_{T}$ is a $T \times \mathrm{x}$ identity matrix. Since the variances and co-variances of $\Omega$ violate the assumptions of constant conditional variance and zero co-variance of the error term, 
instead of ordinary least squares(OLS), generalized least squares (GLS) is the best linear unbiased and efficient (BLUE) estimator. The GLS estimator can be represented as $\hat{\beta}_{G L S}=\left(X^{\prime} \Omega^{-1} X\right)^{-1} X^{\prime} \Omega^{-1} y$. However, as $\Omega$ is unknown to the researcher, the feasible GLS estimator becomes $\hat{\beta}_{F G L S}=\left(X^{\prime} \hat{\Omega}^{-1} X\right)^{-1} X^{\prime} \hat{\Omega}^{-1} y$, in which $\hat{\Omega}$ is estimated using information on the variance of $y$ (see appendix A) and this estimator would be the BLUE random effect estimator.

On the other hand, if covariance $\left(x_{i t}, a_{i}\right) \neq 0$, putting $a_{i}$ into the error term can cause serious problems (Wooldridge, 2002). Instead $a_{i}$ can be considered as an unobservable individual factor that is arbitrarily correlated with the explanatory variables. This leads to a fixed effects specification of the panel, which can be represented as:

$$
y_{i t}=\mu+a_{i}+\beta^{\prime} x_{i t}+e_{i t} \text {. }
$$

In this scenario, both $\mu$ and $a_{i}$ are unobserved scalar parameters to be estimated and stochastic disturbances $e_{i t}$ are assumed to be independently and identically distributed (IID), i.e., $e_{i t} \sqcup \operatorname{IID}\left(0, \sigma_{e}^{2}\right)$. However, for this model, the intercept $\left(\mu+a_{i}\right)$ is estimable, but $\mu$ and $a_{i}$ cannot be estimated separately unless arbitrary restrictions such as $\sum_{i=1}^{N} a_{i}=0$ or $\mu=0$ are imposed to avoid the dummy variable trap. Assuming that $\mu=0$, the model can be represented in matrix form as: $y=D \alpha+\beta X+e$, where $y$ is an $N T$ x 1 vector of the dependent variables, $D$ is an $N T$ x $N$ matrix of dummy variables, $\alpha$ denotes an $N$ x 1 vector of dummy variable parameters to be estimated, $\beta$ is a $K \times 1$ vector of parameters to be estimated, and $X$ is an $N T$ x $K$ matrix of $K$ regressors. The term $e$ is an $N T$ x 1 vector of residuals. The above model is usually referred to as the least squares dummy variable 
(LSDV) model. The LSDV estimator is the best, as long as $e_{i t}$ is IID with zero mean and a variance-covariance matrix of $\sigma_{e}^{2} I_{N T}$ (Baltagi, 2001). The least squares estimator is thus: $\hat{\beta}_{L S D V}=\left(X^{\prime} M_{D} X\right)^{-1} X^{\prime} M_{D} y$, where $M_{D}=I-D\left(D^{\prime} D\right)^{-1} D^{\prime}$, is a symmetric, idempotent and orthogonal matrix to $D$ which is as defined above and $I$ is a conformable identity matrix (Greene, 2003).

\subsubsection{Empirical Model}

In this study, county level health status is used to represent an aggregation of each

individual's demand for health. County level health status can be represented as $\sum_{j=1}^{n} H_{i j}$ $j=1,2, \ldots, n$ and $i=1,2, \ldots, N$, where $n$ is number of individuals classified as obese for a particular county, and $N$ is the 55 counties in $\mathrm{WV}$ used for the study. The proportion of the population considered obese in a county is the dependent variable used to estimate the model. Thus the empirical model considered for this study is:

$$
H_{i t}=\alpha^{\prime} d+\beta^{\prime} x_{i t}+\gamma_{t}+e_{i t},
$$

where $H_{i t}$ is the percentage of population that is obese in county $i$ in time period $t$. The vector $\alpha$ is unobserved county impacts on obesity that may be correlated with the vector of observable explanatory variables, $x_{i t}$, with $\beta$ the associated parameters. The term $d$ represents the vector of county specific dummy variables relevant to the unobserved fixed effect parameters. The scalar $\gamma_{t}$ represents the fixed time effects on the model. In order to reduce the large loss of degrees of freedom due to the incidental parameter problem (i.e., larger number of cross sectional units relative to time series), counties can be grouped into distinct regions. Therefore, in a regional comparison, the vector $d$ actually represents 
regional effects instead of county-level effects. Stochastic disturbances, $\varepsilon_{i t}$, are assumed to be independently and identically distributed $\left(\varepsilon_{i t} \sim \operatorname{IID}\left(0, \sigma_{\varepsilon}^{2}\right)\right)$.

\subsubsection{Minimum Chi-Squared Logit (MCSL) and Minimum Chi-Squared Probit (MCSP) approach to obesity}

Two minimum Chi squared estimation approaches, logit and probit, are extensions of the county level analysis used to address the econometric issue that may arise due to the limited range of the dependent variable, county obesity rate. In these approaches, it is assumed that $H_{i t}$, the proportion of obesity in county $i$ at time $t$, equals $n_{i t} / M_{i t}$, where $M_{i t}$ is the number of individuals corresponding to a particular county, and $n_{i t}$ is the number of times that the event (i.e., a person being obese) occurred. Then the approximate probability that the event will occur, $\hat{P}_{i t}$, can be represented as $\hat{P}_{i t}=n_{i t} / M_{i t}$.

Following Maddala (1983) and Gujarati (2003), if theoretical probabilities are written as $P_{i t}=\beta^{\prime} x_{i t}$, and it is assumed that $\hat{P}_{i t} \approx P_{i t}$, minimum chi-squared logit, $\hat{L}$, for the county prevalence of obesity can be specified as $\hat{L}=\ln \left(\frac{\hat{P}_{i t}}{1-\hat{P}_{i t}}\right)=\beta^{\prime} x_{i t}+u_{i t}$, where $u_{i t}$, the error term, follows the normal distribution with zero mean, and variance $=\frac{1}{M_{i}\left(\hat{P}_{i t}\left(1-\hat{P}_{i t}\right)\right)}$, i.e, $u_{i t} \sim\left[0, \frac{1}{M_{i}\left(\hat{P}_{i t}\left(1-\hat{P}_{i t}\right)\right)}\right]$, and $\beta$ is a parameter vector associated with the vector of explanatory variables, $x_{i t}$. Since the disturbance term is heteroskedastic, a weighted least squares (WLS) estimator is used, where the weights, $w_{i t}$, are equal to $M_{i}\left(\hat{P}_{i t}\left(1-\hat{P}_{i t}\right)\right.$. The transformation of variables with weights will eliminate the heteroskedasticity bias. 
In the case of minimum chi-squared probit, the probability is $\hat{P}_{i t}=\Phi\left(\beta^{\prime} x_{i t}\right)$, where $\Phi($.$) is the standard normal cumulative distribution function (CDF). The inverse of the CDF$ is $\Phi^{-1}()=.G\left(\hat{P}_{i t}\right)=\beta^{\prime} x_{i t}$. The $G\left(\hat{P}_{i t}\right)$ term, which is called the normit of $\hat{P}_{i t}$, can be written as $G\left(P_{i}\right)=\beta^{\prime} x_{i t}+u_{i t}$, where $u_{i t} \sim\left[0, \frac{\hat{P}_{i t}\left(1-\hat{P}_{i t}\right)}{M_{i}\left(f^{2}{ }_{i}\right)}\right]$, where $f_{i}^{2}$ is the standard normal density function evaluated at $G\left(P_{i}\right)$ (Gujarati, 2003). Since the normit takes negative values, whenever $\hat{P}_{i t}<0.5$, the addition of the number 5 to $G\left(P_{i}\right)$ will the give the minimum chisquared probit (Gujarati, 2003). Similar to the minimum chi-squared logit, the disturbance term is heteroskedastic such that the weighted least squares estimator (where the weight, $w_{i t}$,

equals $\left.\frac{M_{i}\left(f_{i}^{2}\right)}{\hat{P}_{i}\left(1-\hat{P}_{i}\right)}\right)$ yields unbiased consistent estimates. In the absence of the actual counts of the number of people who are obese with respect to the number of people in a given county, the given percentage of obesity in a county is considered as the approximate probability of a person being obese for both MCSP and MCSL modeling approaches.

\subsubsection{Spatial Autoregressive Approach to Obesity Analysis}

Natural amenities impact regional economies through aggregate measures of economic performances such as population, income and/or employment growth, and housing development (Kim, Marcouiller, and Deller, 2005). Also, there are increasing concerns that the built environment, a component of the natural environment, has substantial influence on people's quality of life and health (Freudenberg, Galea, and Vlahov, 2005; Frumkin, 2002). Previous studies using spatial analyses have demonstrated the relationships between human mortality and regional characteristics related to the environment, health-related behavior, 
and economic and demographic factors (Fukuda et al., 2005; Lin, 2003; Fukuda, Nakamura, and Takano, 2004). Rapid suburbanization is hypothesized to be associated with rising obesity, decreased physical activity, increased social isolation and the breakdown of social capital (Freudenberg, Galea, and Vlahov, 2005).

Since the attributes associated with the built environment and natural amenities are spatially located, it is reasonable to hypothesize that health disorders like obesity are spatially clustered based on neighboring socioeconomic, demographic and environmental attributes. Thus, this analysis is extended to test the hypothesis that prevalence of obesity is spatially correlated across counties. In evaluating this hypothesis, alternative spatial approaches, including a spatial autoregressive (SAR), spatial error (SEM) and a spatial Durbin model (SDM) are considered. Their econometric specifications are discussed below.

\subsubsection{Spatial Autoregressive Approach (SAR)}

Spatial dependence can be caused by trans-boundary spillovers among counties in which the activities in one county have a direct influence on activities in other counties. Following Elhorst (2003), the fixed effects model is extended to include spatial lag effects, thus specification of the SAR approach can be represented as:

$$
H_{i t}=\rho W H_{j t}+\beta X_{i t}+\alpha d+\gamma_{t}+\varepsilon_{i t}, \quad i=1,2, \ldots, N, \quad i \neq j, \quad \varepsilon_{i t} \sim\left(0, \sigma^{2} I_{N T}\right),
$$

where $\rho$ is an $N T$ x 1 vector of spatial autoregressive coefficients to be estimated that indicates contiguity between counties, thus the spatial autoregressive relationship; $W$ is the spatial weights matrix $(N \times N)$ where elements $W_{i j}>0$ and $W_{i i}=0$. The explanatory variable, $H_{j t}$, is the weighted average of the prevalence of obesity in neighboring counties as specified by the spatial contiguity matrix $W$. The rest of the right hand side explanatory and the corresponding parameter vectors are the same as previously defined. 


\subsubsection{Spatial Error Model (SEM)}

The degree of spatial autocorrelation could also depend on the potential correlation of the error term across counties. The spatial autocorrelation of the error structure can be incorporated by specifying the error term as $\varepsilon_{i t} \sim \lambda W \varepsilon_{i t}+\eta_{i t}$, where $\lambda$ is the spatial autocorrelation coefficient, and $\eta_{i t} \sim\left(0, \sigma_{\eta}^{2} I_{N T}\right)$ such that the empirical model becomes:

$$
H_{i t}=\beta X_{i t}+\alpha d+\gamma_{t}+\varepsilon_{i t}, \quad \varepsilon_{i t} \sim \lambda W \varepsilon_{i t}+\eta_{i t}, \quad \eta_{i t} \sim\left(0, \sigma_{\eta}^{2} I_{N T}\right) \text {, }
$$

where the other variables and parameters are as previously defined.

\subsubsection{Spatial Durbin Model (SDM)}

In this specification, the above modeling approaches have been extended to incorporate neighboring socioeconomic impacts, such that the SDM specification can be represented as:

$$
H_{i t}=\lambda W H_{j t}+\beta X_{i t}+W X_{j t} \gamma+\alpha d+\gamma_{t}+\varepsilon_{i t}, \quad \varepsilon_{i t} \sim\left(0, \sigma^{2} I_{N T}\right) \text {. }
$$

The $K \times 1$ parameter vector $\gamma$ measures the marginal impact of the explanatory variables from a neighboring county $(j)$ on the dependent variable in the $i^{\text {th }}$ county. The product of $W$ and $X$ gives the spatial lags of the explanatory variables that reflect the average of neighboring observations (socioeconomic, demographic and built environment characteristics).

\subsubsection{Micro-Level Health Demand Analysis}

In this analysis, the theoretical specification of the health demand model was extended to investigate micro-level (individual) information on obesity. This study uses a recursive multivariate logit/probit approach to estimate the unobserved latent variable of self-assessed health in terms of an individual's lifestyle choices, socioeconomic, demographic and built 
environment characteristics. Previous studies suggest that an individual's health can be affected by myriad observed and unobserved heterogeneous factors. Thus, the lifestyle choices which enter into health demand functions are arguably endogenous in nature (Rosenzweig and Schultz, 1983; Contoyannis and Jones, 2004). If the lifestyle choices are correlated with the stochastic error term, the single equation estimations would yield biased and inconsistent estimates.

In order to overcome this endogeneity issue, a two stage recursive approach was used for this analysis. This analysis follows the two stage estimation techniques proposed by Heckman (1978), Lee (1982) and Rosenzweig, and Schultz (1983). In this two stage estimation process, an ordered latent-class variable of self-assessed health is considered to be explained by the individual's socioeconomic, demographic and environmental covariates. Denoting individual $i$ 's unobserved latent health status as $H^{*}{ }_{i}$, the model can be written as: $H^{*}{ }_{i}=\varphi^{\prime} L^{*}{ }_{i}+\omega^{\prime} X+u_{i}$, where $u_{i} \sim(0,1)$. The vectors $L^{*}$ and $X$ represent lifestyle choices and other socioeconomic and demographic characteristics, respectively. The individual's health status, $H_{i}$, is equal to $k$, if $\mu_{i k}<H^{*}{ }_{i} \leq \mu_{i k+1}$ where the parameter $k=1,2,3$, represent three self-assessed health categories, "poor", "fair" and "good" health. The parameter $\mu_{i k}$, which varies from $-\infty$ to $+\infty$, denotes the unknown threshold levels of health categories that are to be estimated together with parameters $\varphi$ and $\omega$. Thus, the probability, $P$, of having a certain health status can be defined as:

$$
\begin{aligned}
& P\left[H_{i}=1 \mid X, L\right]=\Phi\left(\mu_{k}-\varphi^{\prime} L_{i}^{*}+\omega^{\prime} X\right), \\
& P\left[H_{i}=2 \mid X, L\right]=\Phi\left(\mu_{k}-\varphi^{\prime} L_{i}^{*}+\omega^{\prime} X\right)-\Phi\left(\mu_{k+1}-\varphi^{\prime} L_{i}^{*}+\omega^{\prime} X\right),
\end{aligned}
$$




$$
P\left[H_{i}=3 \mid X, L\right]=1-\Phi\left(\mu_{k+1}-\varphi^{\prime} L_{i}^{*}+\omega^{\prime} X\right)
$$

where $\Phi$ denotes the cumulative distribution function (CDF) of the standard normal distribution. Since the vector of lifestyle choices, $L_{i}^{*}$, is assumed to be endogenous to the system, it could be correlated with the unobserved factors affecting one's self-assessed health (SAH). In order to overcome such endogeneity bias, a recursive estimation process is used in which the first stage predictions of lifestyle choices are incorporated into the self-assessed health demand. The fully recursive system can then be specified as:

$$
\begin{aligned}
& H^{*}{ }_{1 i}=\varphi^{\prime} \hat{L}_{2}^{*}+\omega^{\prime} X_{1}+u_{1 i}, \quad u_{1 i} \sim\left(0, \sigma_{u_{1 i}}{ }^{2}\right), \\
& L^{*}{ }_{2 i}=\omega^{\prime} X_{2}+u_{2 i}, \quad u_{2 i} \sim\left(0, \sigma_{u_{2 i}}{ }^{2}\right),
\end{aligned}
$$

where $\mathrm{E}\left(u_{1 i} u_{2 i}\right)=\sigma_{12}, i \ldots \ldots \ldots I ; j=1,2, \quad \mathrm{E}\left(u_{j i} u_{j^{\prime \prime}}\right)=0$ for $j, j^{\prime}=1,2, i \neq i^{\prime}$, and $L_{2 i}^{*}$ is another latent-class variable of lifestyle choices. For example, obesity, which is used as a proxy for an individual's weight status, is considered a latent-class dependent variable in equation (26) above.

In summary this section described the different empirical methodologies at two levels of aggregation (i.e., county level and individual level), in order used to better identify the possible socioeconomic, demographic and built environment factors affecting obesity. The county level analysis utilizes both spatial and non-spatial random and fixed effects estimations as well as non-linear minimum chi square probit/logit empirical approaches. The individual level analysis employed a recursive estimation approach to investigate individual responses to ordered self-assessed health (SAH) in terms of individuals' specific lifestyle choices, socioeconomic, demographic and county specific socioeconomic variables. 


\subsection{Data}

Data complied for the empirical investigations are gathered from various secondary data sources. This section describes the data and their descriptive statistics, data sources and variable definitions considered for the multivariate regression analyses.

\subsubsection{Data for county level analysis}

County level differences regarding the percentage of the population considered obese were studied using a panel data structure which emphasizes both random and fixed effects. The county prevalence of obesity in the years 1992 and 1997 and the associated data for the explanatory variables relevant for these different time periods were pooled across the 55 counties of WV. A description of the variables used in this analysis and their sources are in Tables 3.1, 3.2 and 3.3. Descriptive statistics for the variables are in Tables 3.4, 3.5 and 3.6. Obesity prevalence in WV counties for 1992 and 1997 were obtained from the County Health Profiles published by the WV Department of Health and Human Resources (2000). Socioeconomic data relevant to these two time periods were obtained from state and federal agencies including the Appalachian Regional Commission (ARC), WV Bureau of Employment, Natural Resource Analysis Center of West Virginia University, and the U.S. Census Bureau.

The percentage of county prevalence of obesity (OBESITY) is the dependent variable for both spatial and non-spatial random and fixed effect models. The PROBOBEWT and LOOBWT are transformed dependent variables of OBESITY for minimum chi square logit and probit estimations. Normit (PROOBE) is the normal inverse transformation of OBESITY, using the NORMINV function of Excel. The Probit transformation of obesity (PROBOBE) was computed by adding an arbitrary number (5) 
to Normit (PROOBE) (see section 3.2.1.2 above). Finally, the dependent variable for the Minimum Chi-Squared Probit (PROBOBEWT) was calculated by multiplying PROOBE by the appropriate weight variable of WTPROBT, which is based on the formula given in section 3.2.1.2. The LOOBE is the logit transformation of OBESITY. The dependent variable for the Minimum Chi-Squared Logit (LOOBEWT) is the weighted variable of LOOBE, where weights, WTLOGT, were calculated according to the formula outlined in section 3.2.1.2.

Respective built environment variables, except travel time to work, considered in Table 3.3 are gathered from the County Business Patterns (CBP) of the Economics Census, U.S. Census Bureau. The Standard Industrial Classification codes (SIC) for the relevant built environment variables are Total number of Business Establishments (TESTB) (SIC52); Food Stores (FSTOR, (SIC5400); Eating and Drinking Places (EDPLA) (SIC5800); Physical Fitness Activity Places (PPFAC) (SIC7991); and Health Care Services (HESER) (SIC8000).

County Business Patterns reflect economic activities of counties. An establishment is a single physical location at which business is conducted or services or industrial operations are performed. It is not necessarily identical with a company or enterprise, which may consist of one or more establishments. When two or more activities are carried on at a single location under a single ownership, all activities generally are grouped together as a single establishment. Total Establishment counts (TESTB) represent the number of locations with paid employees any time during the year. However, this series excludes government establishments except for wholesale liquor 
establishments, retail liquor stores, federally-chartered savings institutions, federallychartered credit organizations and hospitals.

The food stores SIC encompasses a broad range of retail stores that sell food products, mainly grocery stores and other stores that sell food for home preparation and consumption. The eating and drinking places SIC includes retail establishments engaged in selling prepared food and drinks for consumption on the premises. Also included are caterers which serve prepared food other than at the place of business and lunch counters and refreshment stands selling prepared foods and drinks for immediate consumption. The Health Care Services (HESER) group includes establishments primarily engaged in furnishing medical, surgical, and other health services to persons. The average travel time to work (TVTRT) is attributable to U.S. Census Bureau data for 1990 and 2000. 
Table 3.1. County Socioeconomic and Demographic Variables

\begin{tabular}{|c|c|c|}
\hline Variable & Definition & Source \\
\hline \multicolumn{3}{|c|}{ Dependent variable } \\
\hline OBESITY & $\%$ of obesity & A \\
\hline PROOBE & Normit & - \\
\hline PROBOBE & Probit transformation of obesity & - \\
\hline WTPROBT & Associated weights for Probit & - \\
\hline PROBOBEWT & Dependent variable for Minimum Chi-squared Probit & - \\
\hline LOOBE & Logit transformation of obesity & - \\
\hline WTLOGT & Associated weights Logit & - \\
\hline LOOBEWT & Dependent variable for Minimum Chi-squared Logit & - \\
\hline \multicolumn{3}{|c|}{ Socioeconomic and Demographic factors } \\
\hline POPUL & Population 1990 and 2000 & B \\
\hline PPSM & Population density (persons/square mile) 1990 and 2000 & B \\
\hline PR & $\%$ of population below poverty line & B \\
\hline PINC & Average per capita income $1990-94$ and $1995-99$ in $\$$ & $\mathrm{C}$ \\
\hline $\mathrm{AE}$ & $\%$ of population who completed college & B \\
\hline UR & $\%$ of unemployment & B \\
\hline SSPB & Social Security program beneficiaries per 1000 population & $\mathrm{C}$ \\
\hline WAGE & Average annual wage 1992 and 1998 & $\mathrm{C}$ \\
\hline \multirow[t]{2}{*}{ PAFSTS } & Food stamp benefits per thousand population & \\
\hline & (\$1000) 1992 and 1997 & $\mathrm{C}$ \\
\hline \multirow[t]{2}{*}{ PMCAREB } & Medicare benefits per thousand population & \\
\hline & (\$1000) 1992 and 1997 & $\mathrm{C}$ \\
\hline
\end{tabular}

A: Department of Health and Human Resources, West Virginia Health statistics, Bureau

of Public Health; http://www.wvdhhr.org/bph/oehp

B: Online Resource Center, Appalachian Regional Commission; http://www.arc.gov

C: Bureau of Economic Analysis, U.S. Department of Commerce: CA35 personal income transfer receipts

http://www.bea.gov/regional/reis/ 


\section{Table 3.2. Behavioral Factors and Dummy Variables}

\begin{tabular}{llc}
\hline Variable & Definition & Source \\
\hline PSMOKE & \% of population who smoke 1992 and 1997 & A \\
PNHINU & \% of population with no health insurance 1992 and 1997 & A \\
DT & Dummy Time $(1=1997$ and $0=1992)$ & $*$ \\
DN & Dummy North & $*$ \\
DNE & Dummy Northeast & $*$ \\
DSE & Dummy Southeast & $*$ \\
DSW & Dummy Southwest & $*$ \\
DWT & Dummy West & $*$ \\
DC & Dummy Central & $*$ \\
DNW & Dummy Northwest & $*$ \\
DLIN & Dummy Lower Income group $(P I N C<\$ 12000)$ & $*$ \\
DHIN & Dummy Median Income group $(\$ 12000<P I N C<\$ 20000)$ & $*$
\end{tabular}

A: Department of Health and Human Resources, West Virginia Bureau Health Statistics

* Created by the author from information from WV Department of Health and Human Resources and per capita income data from the Bureau of Economic Analysis, U.S. Department of Commerce http://www.bea.gov. 


\section{Table 3.3. Built-Environment Variables}

\begin{tabular}{llc}
\hline Variable & Definition & Source \\
\hline TESTB & Total number of establishments per 1000 population 1993 and 1997 & D \\
FSTOR & Total number of food stores per 1000 population 1993 and 1997 & D \\
EDPLA & Eating and drinking places per 1000 population 1993 and 1997 & D \\
HESER & Health care services per 1000 population 1993 and 1997 & D \\
PPFAC & Physical fitness activity places per 1000 population 1992 and 1997 & D \\
TVTRT & Average travel time to work 1990 and 2000 & E \\
\hline D: U.S. Census Bureau, Economic Census 1992, 1993 and 1997 & \\
E: U.S. Census Bureau, Decennial Census 1990 and 2000: Summary Files/Detailed tables \\
http://factfinder.census.gov/servlet/
\end{tabular}


Table 3.4. County Level Descriptive Statistics

\begin{tabular}{|c|c|c|c|c|}
\hline Variable & Mean & Std Dev & Minimum & Maximum \\
\hline OBESITY & 18.92 & 4.2 & 10.2 & 30.3 \\
\hline PROBE & -0.90 & 0.16 & -1.27 & -0.51 \\
\hline PROBOBE & 4.10 & 0.16 & 3.72 & 4.48 \\
\hline WTP & 4.76 & 0.67 & 3.37 & 6.59 \\
\hline PROBOBEWT & 19.91 & 3.52 & 12.57 & 29.56 \\
\hline LOOBE & -1.50 & 0.28 & -2.17 & -0.83 \\
\hline WTL & 3.88 & 0.34 & 3.02 & 4.59 \\
\hline LOOBEWT & -5.64 & 0.59 & -6.58 & -3.82 \\
\hline POPUL & 32743.83 & 32430.43 & 5192.00 & 207619.00 \\
\hline PPSM & 94.66 & 101.16 & 9.58 & 479.01 \\
\hline PR & 20.32 & 6.36 & 9.30 & 39.20 \\
\hline $\mathrm{AE}$ & 11.10 & 4.57 & 4.60 & 32.40 \\
\hline UR & 7.57 & 3.03 & 2.4 & 17.1 \\
\hline SSPB & 211.83 & 30.37 & 135.00 & 308.00 \\
\hline FPCEXP & 3860.91 & 776.72 & 2135.00 & 6324.00 \\
\hline WAGE & 20915.87 & 4076.85 & 14434.63 & 32826.85 \\
\hline PINC & 15438.23 & 3006.40 & 9848.98 & 24363.89 \\
\hline PAFSTS & 142.07 & 51.89 & 57.70 & 278.90 \\
\hline PMCAREB & 3862.56 & 19021.40 & 355.50 & 195588.57 \\
\hline
\end{tabular}


Table 3.5. Behavioral and Dummy Variable Descriptive Statistics

\begin{tabular}{lcrrr}
\hline Variable & Mean & Std dev & Minimum & Maximum \\
\hline PSMOKE & 26.01 & 4.82 & 18.40 & 40.20 \\
PNHINU & 23.23 & 5.60 & 10.70 & 36.10 \\
DT & 0.50 & 0.50 & 0.00 & 1.00 \\
DN & 0.11 & 0.31 & 0.00 & 1.00 \\
DNE & 0.16 & 0.37 & 0.00 & 1.00 \\
DSE & 0.15 & 0.35 & 0.00 & 1.00 \\
DSW & 0.13 & 0.33 & 0.00 & 1.00 \\
DWT & 0.15 & 0.35 & 0.00 & 1.00 \\
DC & 0.20 & 0.40 & 0.00 & 1.00 \\
DNW & 0.11 & 0.31 & 0.00 & 1.00 \\
DLIN & 0.12 & 0.32 & 0.00 & 1.00 \\
DMIN & 0.81 & 0.38 & 0.00 & 1.00 \\
DHIN & 0.06 & 0.24 & 0.00 & 1.00 \\
\hline
\end{tabular}

Table 3.6. Built-Environment Factors Descriptive Statistics

\begin{tabular}{lrrrr}
\hline Variable & Mean & Std dev & Minimum & Maximum \\
\hline TESTB & 20.48 & 5.84 & 7.75 & 37.36 \\
FSTOR & 0.88 & 0.27 & 0.27 & 1.78 \\
EDPLA & 1.38 & 0.64 & 0.30 & 4.37 \\
HESER & 1.36 & 0.72 & 0.135 & 3.96 \\
PPFAC & 0.04 & 0.07 & 0 & 0.58 \\
TVTRT & 26.12 & 5.77 & 17.10 & 36.10 \\
\hline
\end{tabular}

\subsubsection{Data for Individual Health Demand Analysis}

Individual data are compiled from the Behavioral Risk Factor Surveillance

System (BRFSS) year 2003 micro data files that investigated adult health behavior across 
the state. County specific land use and other socioeconomic variables were obtained from other secondary data sources. The Behavioral Risk Factor Surveillance System (BRFSS) is a monthly telephone survey conducted by the CDC that allows states to monitor health behaviors among their adult population $\left(18^{+}\right)$. The BRFSS was begun in 1984 with 15 participating states and has monitored obesity since that time, expanding to 52 states and territories in 1997.

The respective variables considered for this study and their definitions are given in Tables 3.7 and 3.8. Their summary statistics are presented in Tables 3.9 and 3.10. OBESE and OGENHLTH are categorical dependent variables in the recursive system discussed in section 3.2.3. OBESE is a binary dependent variable which indicates whether a person is obese (equal to 1 ) or not (equal to 0 ). Individuals whose body mass index (BMI) is greater than or equal to 30 , are considered to be OBESE. OGENHLTH is an ordered latent-class dependent variable which indicates the individual's ordered selfassessed health (SAH) responses of "good", "fair" or "poor".

Level of education (LEDUCA) is an ordered categorical explanatory variable which varies from 0 to 5 . Thus, six educational categories are: (0) never attended school or kindergarten, (1) attended elementary school, (2) attended some high school, (3) high school graduate, (4) attended college, and (5) college graduate. Per capita income (PINC) is created by considering the mid-points of the income categories to which an individual belongs. Individuals who have incomes equal to or greater than $\$ 50,000$ are assumed to have per capita income of $\$ 50,000$. 
Table 3.7. Definition of Variables and their Descriptive Statistics

\begin{tabular}{|c|c|c|}
\hline Variable & Definition & Source \\
\hline \multicolumn{3}{|c|}{ Dependent Variables } \\
\hline OBESE & Obesity: indicator & $*$ \\
\hline OGENHLTH & Ordered health: indicator "good", "fair" and "poor. & $*$ \\
\hline \multicolumn{3}{|l|}{ Covariates } \\
\hline \multicolumn{3}{|c|}{ Demographic categories } \\
\hline LEDUCA & Level of education: Ordered categorical variable & $*$ \\
\hline DMALE & Male (Dummy Variable) & $*$ \\
\hline OMNONH & Other multicultural non-Hispanic (Dummy) & $*$ \\
\hline WNONH & White Non-Hispanic (Dummy) & $*$ \\
\hline BNONH & Black Non-Hispanic (Dummy) & $*$ \\
\hline HISP & Hispanic (Dummy Variable) & $*$ \\
\hline AGE & Age (Continuous) & * \\
\hline AGESQ & Age Squared (Dummy) & $*$ \\
\hline \multicolumn{3}{|c|}{ Income Categories } \\
\hline PINC & Per capita income (Continuous) & $*$ \\
\hline INCSQ & Per capita income squared (Continuous) & \\
\hline DINLT15 & Income group less than $\$ 15,000$ (Dummy) & $*$ \\
\hline DIN1535 & Income group between $\$ 15,000<\$ 35,000$ (Dummy) & $*$ \\
\hline DIN3550 & Income group between $\$ 35,000<\$ 50,000$ (Dummy) & * \\
\hline DINOV50 & Income group over $\$ 50,000$ (Dummy) & $*$ \\
\hline \multicolumn{3}{|c|}{ Employment Status } \\
\hline OTHERE & Other employment (Dummy) & $*$ \\
\hline EMPLOYD & Employed (Dummy) & * \\
\hline STUDENT & Student (Dummy) & * \\
\hline RETD & Retired (Dummy) & $*$ \\
\hline
\end{tabular}

* Created by the author using the BRFSS (Behavioral Risk Factor Surveillance System) 2003 Micro Data file 
The per capita income (PINC) variable of this study ranges from $\$ 7,500$ to $\$ 50,000$. The idea of including one income variable rather than categories is to reduce the number of categorical explanatory variables included in the explanatory vector. Employed (EMPLOYD), student (STUDENT), retired (RETD) and other (OTHERE) are dummy explanatory variables which represent employment status of individuals. Other employment (OTHERE), which served as the reference category, includes individuals who are unable to work or are out of work for about one year.

Widowed (WIDOW), married or cohabited (MALT), divorced and separated (DIV_SEP) and never married (NMARRI) represent the marital status of individuals. Sedentary (SEDENT) is a dummy variable which indicates the physical inactivity of an individual. Respondents who report no moderate or vigorous physical activity or exercise are considered to be sedentary or physically inactive. SMOKING is another indicative dummy variable which takes the value 1 if an individual ever smoked 100 cigarettes in his/her lifetime and now smokes every day or some days. SMOKING takes the value 0 , if an individual does not smoke now. HCARE, RHEART, RASTHMA, RFDRHV, are also dummy indicator variables which represent whether an individual possesses a health care plan, is at risk of having heart ailments, is at risk of having asthma problems and is at risk of heavy alcohol consumption, respectively. Risk of heavy alcohol consumption (RFDRHV) is determined by whether a male respondent has more than 2 drinks per day, or a female respondent has more than 1 drink per day.

FRTINDX is an ordered categorical variable which describes fruit and vegetable consumption of respondents. The fruit and vegetable consumption frequencies, ordered from 1 to 4 , represent whether a respondent consumes fruit and vegetables at a level of 
less than 1 serving per day, 1 to less than 3 servings per day, 3 to less than 5 servings per day, or 5 or more servings per day.

Table 3.8. Definition of Variables and their Descriptive Statistics of Micro Level Analysis: Marital Status, Physical Inactivity, Age, and Other Covariates

\begin{tabular}{llr}
\hline Variable & Definition & source \\
\hline Marital Status & & $*$ \\
WIDOW & Widowed (Dummy) & $*$ \\
MALT & Married or Cohabited (Dummy) & $*$ \\
DIV_SEP & Divorced or Separated (Dummy) & $*$ \\
NMARRI & Never Married $\quad$ (Dummy) & $*$ \\
Other Covariates & & $*$ \\
SEDENT & Sedentary $\quad$ (Dummy) & $*$ \\
SMOKING & Smoking $\quad$ (Dummy) & $*$ \\
HCARE & Has health care (Dummy) & $*$ \\
RHEART & Risk of having heart problems (Dummy) & $*$ \\
RASTHMA & Risk of having Asthma (Dummy) & $*$ \\
RFDRHV & Risk of Alcohol consumption (Dummy) & $*$ \\
FRTINDX & Fruit and Vegetable consumption index (Ordered) & B \\
DDISTD & County economic status : Depressed (Dummy) & E \\
TRVT & Average travel time (minutes) to work for County & \\
\hline
\end{tabular}

* Created by the author from using BRFSS (Behavioral Risk Factor Surveillance System)

2003 Micro Data file

B: Online Resource Center, Appalachian Regional Commission; http:/www.arc.gov

E: U.S. Census Bureau, Decennial Census 2000: Summary Files/Detailed tables

http://factfinder.census.gov/servlet/

DDISTD is a county specific dummy variable which indicates the economic status of a respondent's county, i.e., whether the county is economically depressed or not. The Appalachian Regional Commission classified the county economic status as depressed if the county's three-year average unemployment rate is at least 1.5 times the national average, per capita market income is no greater than two-thirds of the national average, 
and the poverty rate is at least 1.5 times the national average; or the county has at least twice the national poverty rate and meets the criteria for either the unemployment or the income indicator. TRVT is a continuous variable which indicates average county specific travel time to work in minutes.

Table 3.9. Descriptive Statistics: Micro Level Analysis: Dependent Variable, Educational Level, Demographic, Income, Employment and Gender Categories

\begin{tabular}{|c|c|c|c|c|}
\hline Variable & Mean & Std Dev & Min & $\operatorname{Max}$ \\
\hline \multicolumn{5}{|c|}{ Dependent Variables } \\
\hline OBESE & 27.69 & 0.45 & 0.00 & 1.00 \\
\hline OGENHLTH & 1.622 & 0.67 & 0.00 & 3.00 \\
\hline \multicolumn{5}{|l|}{ Covariates } \\
\hline \multicolumn{5}{|c|}{ Demographic categories } \\
\hline LEDUCA & 3.345 & 1.14 & 0.00 & 5.00 \\
\hline DMALE & 39.50 & 0.49 & 1.00 & 0.00 \\
\hline OMNONH & 4.50 & 0.21 & 0.00 & 1.00 \\
\hline WNONH & 91.70 & 0.28 & 0.00 & 1.00 \\
\hline BNONH & 1.80 & 0.13 & 0.00 & 1.00 \\
\hline HISP & 2.01 & 0.14 & 0.00 & 1.00 \\
\hline AGE & 51.00 & 17.00 & 18.00 & 97.00 \\
\hline AGESQ & 2039.40 & 1831.90 & 324.00 & 9049.00 \\
\hline \multicolumn{5}{|c|}{ Income Categories } \\
\hline PINC & 30460.01 & 15521.59 & 7500.00 & 50000.00 \\
\hline INCSQ & 116864.00 & 94238.00 & 5625.00 & 250000.00 \\
\hline DINLT15 & 18.06 & 0.38 & 1.00 & 0.00 \\
\hline DIN1535 & 40.75 & 0.49 & 1.00 & 0.00 \\
\hline DIN3550 & 16.41 & 0.37 & 1.00 & 0.00 \\
\hline DINOV50 & 24.79 & 0.43 & 1.00 & 0.00 \\
\hline \multicolumn{5}{|c|}{ Employment Status } \\
\hline OTHERE & 14.70 & 0.35 & 1.00 & 0.00 \\
\hline EMPLOYD & 61.26 & 0.49 & 1.00 & 0.00 \\
\hline STUDENT & 2.81 & 0.17 & 1.00 & 0.00 \\
\hline RETD & 21.24 & 0.41 & 1.00 & 0.00 \\
\hline
\end{tabular}


Table 3.10. Definition of Variables and their Descriptive Statistics of Micro Level Analysis: Marital Status and Other Covariates

\begin{tabular}{lcccc}
\hline Variable & Mean & Std Dev & Minimum & Maximum \\
\hline Marital Status & 14.29 & 0.35 & 0.00 & 1.00 \\
WIDOW & 57.22 & 0.49 & 0.00 & 1.00 \\
MALT & 20.40 & 0.40 & 0.00 & 1.00 \\
DIV_SEP & 11.00 & 0.31 & 0.00 & 1.00 \\
NMARRI & & & & \\
Other Covariates & 12.81 & 0.33 & 0.00 & 1.00 \\
SEDENT & 26.14 & 0.44 & 0.00 & 1.00 \\
SMOKING & 83.63 & 0.37 & 0.00 & 1.00 \\
HCARE & 37.43 & 0.48 & 0.00 & 1.00 \\
RHEART & 8.98 & 0.29 & 0.00 & 1.00 \\
RASTHMA & 2.68 & 0.16 & 0.00 & 1.00 \\
RFDRHV & 2.70 & 0.85 & 1.00 & 4.00 \\
FRTINDX & 23.07 & 0.42 & 0.00 & 1.00 \\
DDISTD & 25.42 & 4.42 & 19.50 & 36.8 \\
TRVT & & & & \\
\hline
\end{tabular}




\section{Chapter 4}

\section{Results \& Discussion}

The focus of this chapter is on the empirical estimations obtained for the two levels of obesity analyses outlined in the previous chapter. The results of the econometric specifications extending from these two branches, namely, the aggregate county-level health differences and the micro-level health investigation, together with their implications for policy analysis are first presented, followed by a more detailed discussion later in the chapter. Before proceeding into the details of these estimations, a summary of the different empirical procedures and the relevant estimation techniques are outlined in Figure 4.1.

\section{Figure 4.1. Different Analytical Procedures Considered for the Study}

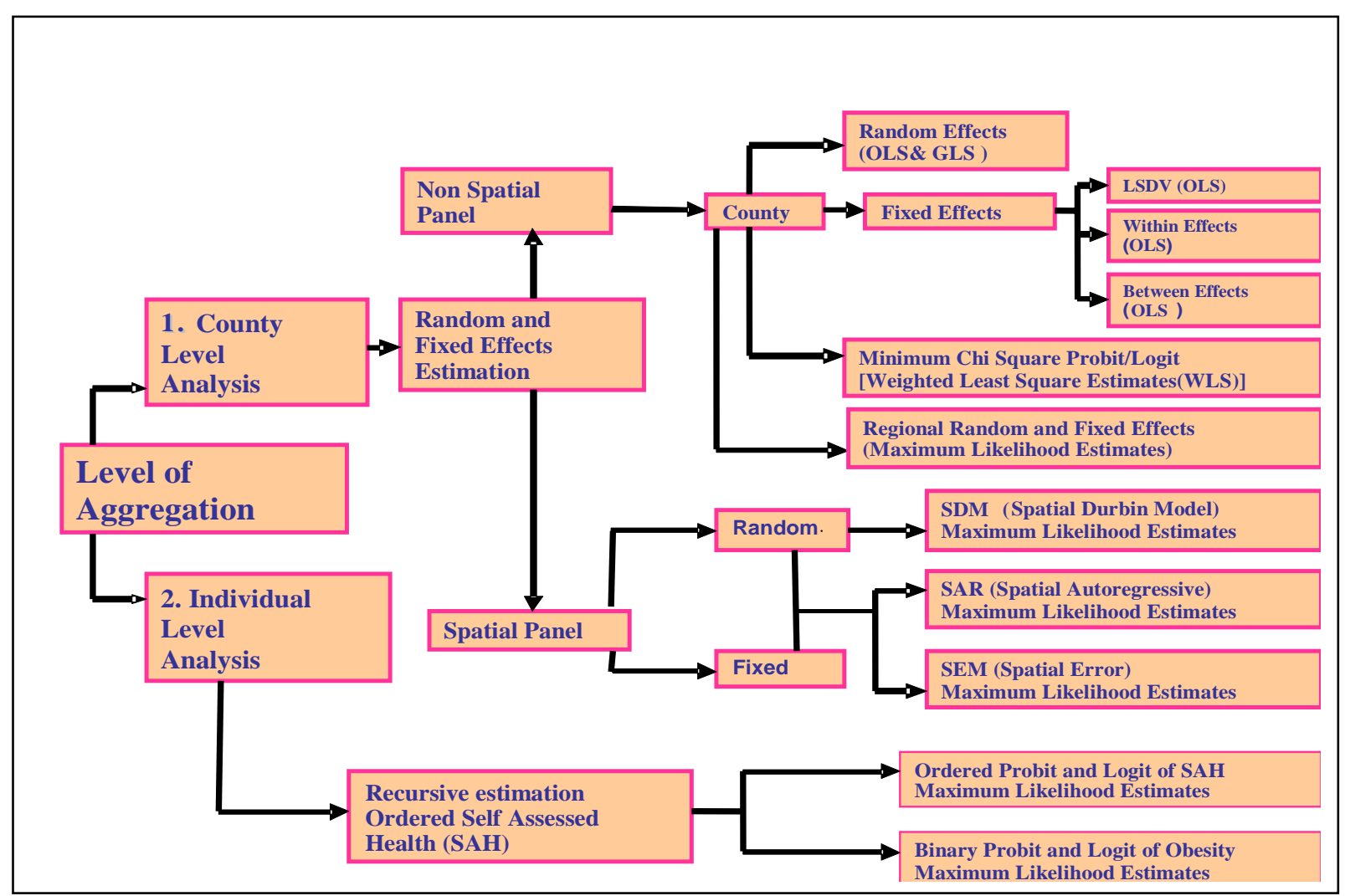




\subsection{Aggregate County Level Health Demand Analysis}

County level differences regarding the percentage of the population considered obese were studied using a panel data structure which emphasizes both random and fixed effects. The county prevalence of obesity in the years 1992 and 1997 and the associated data for the explanatory variables relevant for these different time periods were pooled across the 55 counties of WV.

\subsubsection{Random and Fixed Effects Estimation of Obesity}

In this analysis, the random and fixed effect estimation of county level prevalence of obesity was regressed against the specific county level socioeconomic, demographic, behavioral risk, built environment and other amenity factors included in the tables above. The specific variables included in the multivariate regression are explained in the relevant sections.

\subsubsection{Random Effect Estimation of County Prevalence of Obesity}

The results of the random specification, which considers the unobserved latent effects among geographic entities to be a random phenomenon, are presented in Table 4.1. Table 4.1 contains both ordinary least squares (OLS) and generalized least squares (GLS) estimates, where the county prevalence of obesity is the dependent variable in the models. Even though GLS is statistically a better estimator than OLS, both OLS and GLS results are presented for comparison purposes. The GLS estimates are based on the PROC TRCSREG (time series cross section regression) procedure of SAS which specifies the Fuller and Battese (1974) method of variance component error structure. 
Table 4.1. OLS \& GLS Estimates of Random Effects of Obesity in WV: Dependent Variable \% of Obesity in the County

\begin{tabular}{|c|c|c|c|c|c|c|}
\hline \multirow[b]{2}{*}{ Variable } & \multicolumn{2}{|l|}{ OLS } & \multicolumn{4}{|c|}{ GLS } \\
\hline & Coefficient & $\operatorname{Pr}>|t|$ & & Coefficient & $\operatorname{Pr}>|t|$ & \\
\hline CONSTANT & -7.4813600 & 0.082 & $*$ & 1.6880730 & 0.796 & \\
\hline PPSM & -0.0064700 & 0.248 & & -0.0035200 & 0.536 & \\
\hline PR & 0.1404500 & 0.111 & & 0.1379060 & 0.110 & \\
\hline PINC & 0.0006043 & 0.045 & $* *$ & 0.0003530 & 0.272 & \\
\hline $\mathrm{AE}$ & -0.2155500 & 0.062 & $*$ & -0.2551100 & 0.027 & $* *$ \\
\hline UR & 0.0128000 & 0.939 & & 0.0429100 & 0.796 & \\
\hline SSPB & -0.0007431 & 0.951 & & -0.0075000 & 0.544 & \\
\hline WAGE & 0.0003049 & 0.010 & $* * *$ & 0.0002520 & 0.033 & $* *$ \\
\hline PAFSTS & -0.0024400 & 0.835 & & -0.0056500 & 0.625 & \\
\hline PMCAREB & -0.0000150 & 0.403 & & -0.0000200 & 0.292 & \\
\hline PSMOKE & 0.1012400 & 0.202 & & 0.1473910 & 0.072 & $*$ \\
\hline PNHINU & -0.0243300 & 0.733 & & -0.0677400 & 0.357 & \\
\hline TESTB & 0.1944600 & 0.166 & & 0.2409910 & 0.086 & $*$ \\
\hline FSTOR & -2.7632300 & 0.055 & $*$ & -2.6419800 & 0.061 & $*$ \\
\hline EDPLA & -0.1785900 & 0.829 & & -0.5216400 & 0.530 & \\
\hline HESER & -0.2132600 & 0.819 & & -0.3432700 & 0.708 & \\
\hline PPFAC & -2.0643900 & 0.624 & & -1.4130400 & 0.733 & \\
\hline TVTRT & 0.3191200 & 0.001 & $* * *$ & 0.2072600 & 0.050 & $* *$ \\
\hline
\end{tabular}

Number of cross sections 55, Length of the time series 2, No of Observations 110. $* / * * / * * *$ : Significant at $10 \%, 5 \%, 1 \%$ or higher level. 
Population density (PPSM), poverty rate (PR), per capita income (PINC), percentage of the population who have completed a college education (AE), unemployment rate (UR), and average annual wage (WAGE) are considered as socioeconomic and demographic explanatory variables in the models. The percentage of the population who smokes (PSMOKE), and the percentage of the population which does not have health insurance (PNHINU) are variables which reflect county behavioral patterns. Representing fiscal policy measures are social security program beneficiaries per thousand (SSPB), and federal food stamp (PAFSTS) and Medicare benefits (PMCAREB) allocated per thousand people in a county. The total number of business establishments (TESTB), food stores (FSTOR), eating and drinking places (EDPLA), health care service businesses (HESER), and physical fitness activity places available (PPFAC), per thousand people in a particular county, are explanatory variables representing the built environment, along with TVTRT, which is a measure of mean travel time to work for county residents.

OLS estimation shows that per capita income (PINC), average college education completed (AE), number of food stores per thousand population (FSTOR), average travel time to work (TVTRT) and average annual wage (WAGE) significantly contribute to county prevalence of obesity. Contrary to expectations, per capita income is positively correlated with obesity prevalence in counties. Every $\$ 1,000$ increase in per capita income would raise county prevalence of obesity by $0.6 \%$. As expected, the prevalence of obesity is negatively and significantly correlated with education level. Results indicate that a $1 \%$ increase in the population with a completed college education will decrease the obesity rate by $0.2 \%$. 
A unit increase in the number of food stores available per thousand population would lower obesity prevalence by $3 \%$. However, a one minute increase in mean commuting time would raise the obesity rate by $0.3 \%$. Similar to per capita income, a $\$ 1,000$ increase in the average annual wage in a county would raise the obesity prevalence by $0.3 \%$. Collinearity diagnostics indicate that wage and income are not highly correlated, precluding any multicollinearity issues.

In comparison to the OLS estimates, the GLS estimation does not indicate that there is a significant contribution of income to obesity. However, GLS estimates show that county level education has a significant negative impact on obesity, with a $1 \%$ increase in college education decreasing the obesity rate by about $0.3 \%$. The built environment measures, FSTOR, TVTRT, and TESTB, are significant contributing factors to obesity. The GLS estimates show that, while the number of food stores (FSTOR) contributes significantly but negatively to county-level obesity, the total number of business establishments (TESTB) contributes significantly and positively. This indicates that a one unit increase in the number of business establishments per 1,000 population in a county will raise obesity prevalence by $0.2 \%$, whereas a one unit increase in the number of food stores in a county will lower obesity by $2.6 \%$. Again, commuting time is shown to be positively correlated to the county prevalence of obesity. A one minute increase in mean commuting time would raise the obesity rate by $0.2 \%$.

The adjusted $\mathrm{R}^{2}$ value of the OLS estimation suggests that about $48 \%$ of the variation in the prevalence of obesity across counties is explained by the explanatory variables included in this regression. Kementa (1986) noted that 0.20 is a typical $\mathrm{R}^{2}$ value for various behavioral functions estimated from cross-sectional data. Medical 
demand models generally have lower values raging from 0.07 to 0.16 (Kenkel, 1990).

The computed $\mathrm{R}^{2}$ measure for GLS shows that $37 \%$ of the variation in obesity prevalence in counties is captured by the explanatory variables included in the regression.

A Hausman specification test of the GLS estimation indicates that there is no statistical evidence to conclude that there are unobserved fixed effects that are correlated with explanatory variables contributing to county obesity rates. The orthogonality of unobserved effects is further confirmed by the Hausman and Breusch-Pagan Lagrange Multiplier (LM) test available in the "proc panel" procedure of SAS. The test results for the proc panel and proc time series and cross section (TSCSREG) estimations are shown in Table 4.2 below.

Table 4.2. Hausman Test and Breusch-Pagan (BP) Test for Random Effects PROC PANEL PROC TSCSREG

\begin{tabular}{lrrrrrrr}
\cline { 2 - 7 } $\begin{array}{l}\text { Test for Random } \\
\text { effects }\end{array}$ & DF & $\mathrm{M}$ & $\operatorname{Pr}>\mathrm{m}$ & $\mathrm{DF}$ & $\mathrm{m}$ & $\operatorname{Pr}>\mathrm{m}$ \\
\hline & 17 & 15.69 & 0.55 & & 17 & 16.96 & 0.4569 \\
Hausman & 1 & 1.51 & 0.22 & $*$ & - & - & - \\
Breusch-Pagan (BP) & & & & & & & \\
\hline
\end{tabular}

* not significant at $10 \%$ level. 


\subsubsection{Fixed Effects Estimation of County Prevalence of Obesity}

Despite the fact that there is no statistical evidence for significant unobserved fixed effects, for the completion of data analysis and further reinforcement of the statistical evidence, the fixed effect estimation of obesity among WV counties is conducted through the Proc TSCSREG procedure of SAS. Obtained results for both fixed county, and two-way fixed time and county specific effects are presented in Tables

\subsection{1, 4.3.2, 4.3.3, and 4.3.4.}

Statistical evidence of restricted F-tests of both models fail to reject the null hypothesis in favor of the alternative hypothesis of unobserved fixed effects on obesity. It should also be noted that this analysis is based on the 55 cross-sectional observations of two time periods. One of the major drawbacks of the Least Square Dummy Variable (LSDV) approach is the incidental parameter problem which arises due to the larger number of cross sectional units relative to the time series. Baltagi (2001) and Elhorst (2003) stated that the fixed effects cannot be estimated consistently, if the time series is small relative to the number of cross sectional observations.

The variables indicated by the CS series (i.e. CS1, CS2,.......,CS55) denote the respective cross sectional units or counties arranged in alphabetical order. Thus, while CS1 represents Barbour county of WV, CS55 represents Wyoming county of WV. However, for illustrative purposes, the cross sectional unit CS2 implies that the prevalence of obesity in Berkeley county (CS2) is significantly lower than the base Wyoming county (CS55). 
Table 4.3.1. Cross Sectional and Time Series Effects of County Prevalence of Obesity : Cross Sections CS1 to CS18

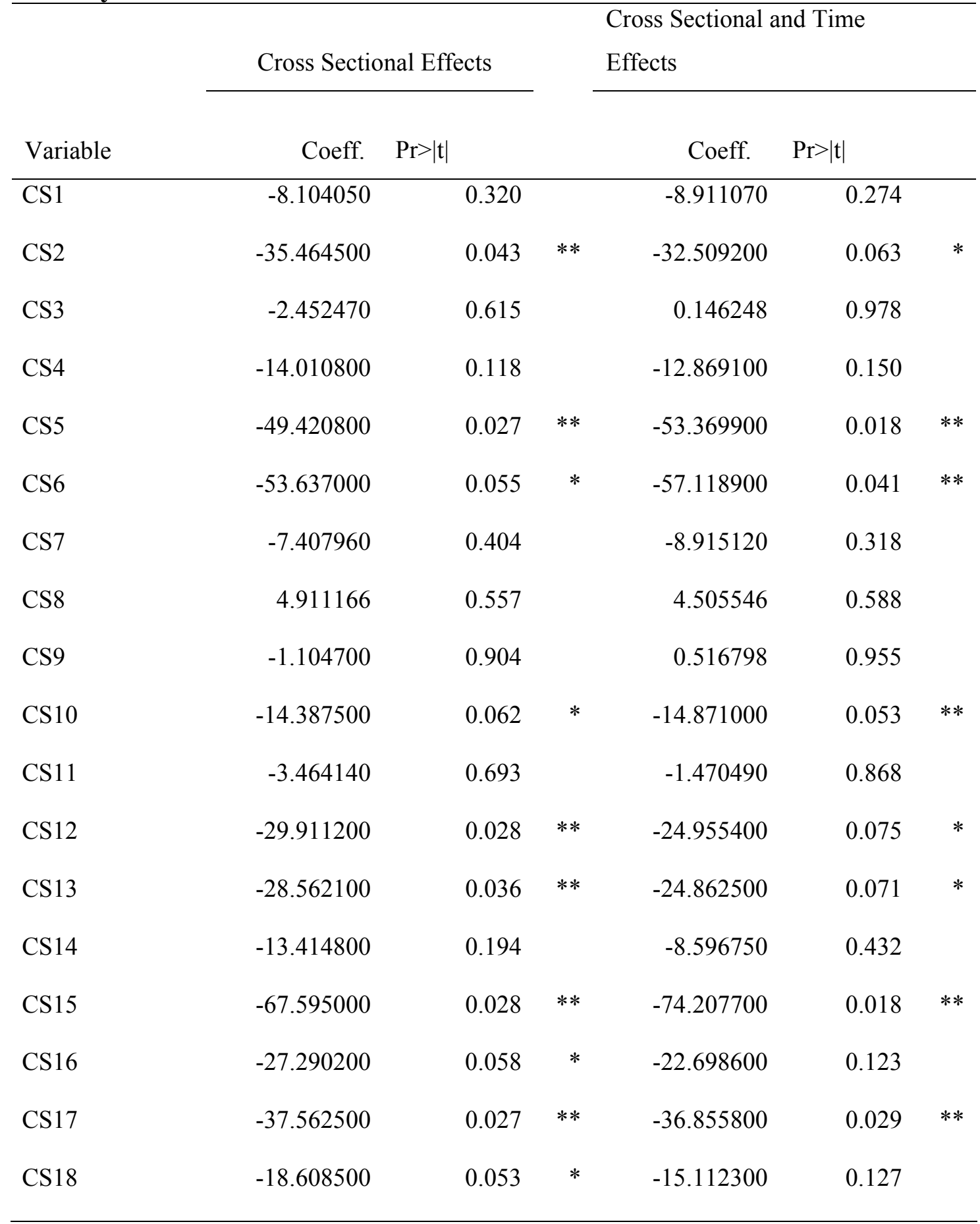

Number of cross sections: 55; Length of the time series:2; Number of Observations: 110.

$* / * * / * * *$ : Significant at $10 \%, 5 \%$, or $1 \%$ or higher level. Restricted F test of both models suggests no fixed effects on county prevalence of obesity. CS1...CS18 are cross section units representing counties arranged in alphabetical order 
Table 4.3.2. Cross Sectional and Time Series Effects of County Prevalence of Obesity: Cross Sections CS19 to CS36

\begin{tabular}{|c|c|c|c|c|c|c|}
\hline \multirow[b]{3}{*}{ Variable } & & & \multicolumn{4}{|c|}{ Cross Sectional and Time } \\
\hline & \multicolumn{2}{|c|}{ Cross Sectional Effects } & & \multicolumn{3}{|c|}{ Effects } \\
\hline & Coeff. & $\operatorname{Pr}>|t|$ & & Coeff. & $\operatorname{Pr}>|t|$ & \\
\hline CS19 & -35.508800 & 0.044 & $* *$ & -27.723100 & 0.134 & \\
\hline $\mathrm{CS} 20$ & -45.053800 & 0.036 & $* *$ & -42.073200 & 0.049 & $* *$ \\
\hline CS21 & -18.185000 & 0.054 & $*$ & -17.108000 & 0.069 & $*$ \\
\hline $\mathrm{CS} 22$ & 5.112003 & 0.474 & & 4.725277 & 0.506 & \\
\hline $\mathrm{CS} 23$ & -9.623750 & 0.207 & & -9.052620 & 0.233 & \\
\hline $\mathrm{CS} 24$ & -22.854300 & 0.068 & $*$ & -28.457400 & 0.034 & $* *$ \\
\hline $\mathrm{CS} 25$ & -34.544300 & 0.030 & $* *$ & -33.408300 & 0.035 & $* *$ \\
\hline $\mathrm{CS} 26$ & -9.864900 & 0.267 & & -8.997050 & 0.309 & \\
\hline $\mathrm{CS} 27$ & -6.711560 & 0.440 & & -6.822750 & 0.430 & \\
\hline $\mathrm{CS} 28$ & -32.565600 & 0.025 & ** & -32.171700 & 0.026 & ** \\
\hline CS29 & -19.187400 & 0.104 & & -17.161400 & 0.147 & \\
\hline $\mathrm{CS} 30$ & -5.570230 & 0.471 & & -5.228050 & 0.496 & \\
\hline CS31 & -33.230000 & 0.124 & & -31.357000 & 0.145 & \\
\hline CS32 & -19.901300 & 0.062 & $*$ & -16.333500 & 0.134 & \\
\hline CS33 & -22.518200 & 0.076 & $*$ & -15.349000 & 0.265 & \\
\hline CS34 & -20.530300 & 0.034 & $* *$ & -18.864900 & 0.052 & $* *$ \\
\hline CS35 & -80.310000 & 0.043 & $* *$ & -86.243600 & 0.031 & $* *$ \\
\hline CS36 & -25.727400 & 0.052 & $* *$ & -19.813700 & 0.154 & \\
\hline
\end{tabular}

Number of cross sections: 55; Length of the time series:2; Number of Observations: 110.

$* / * * / * * *$ : Significant at $10 \%, 5 \%$, or $1 \%$ or higher level. Restricted $\mathrm{F}$ test of both models suggests no fixed effects on county prevalence of obesity. CS19...CS36 are cross section units representing counties arranged in alphabetical order 
Table 4.3.3. Cross Sectional and Time Series Effects of County Prevalence of Obesity Cross Sections: CS37 to CS55

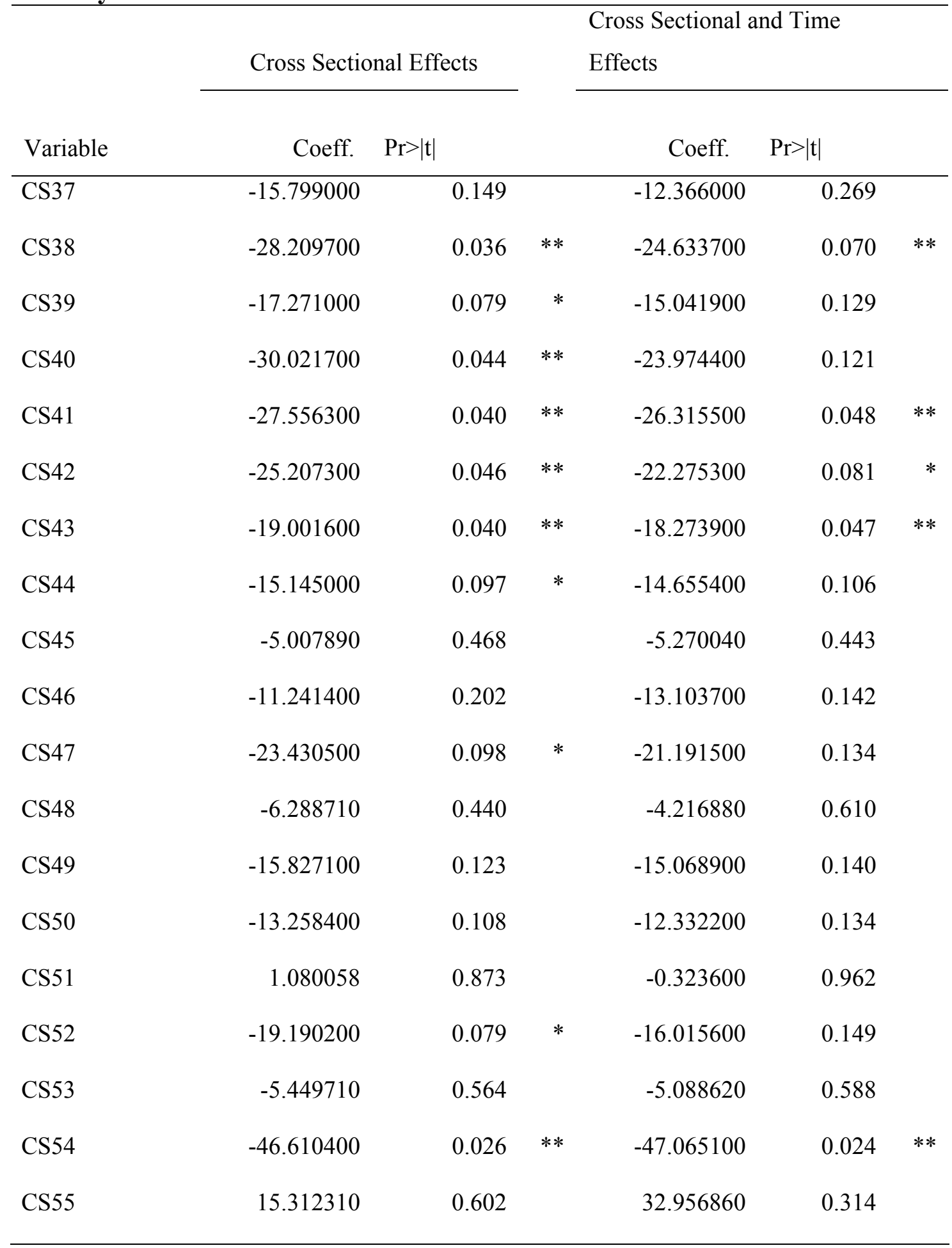

Number of cross sections: 55; Length of the time series: 2; Number of Observations: 110.

$* / * * / * * *$ : Significant at $10 \%, 5 \%$, or $1 \%$ or higher level. Restricted $\mathrm{F}$ test of both models suggests no fixed effects on county prevalence of obesity. CS37...CS55 are cross section units representing counties arranged in alphabetical order 
Table 4.3.4. Cross Sectional and Time Series Effects of County Prevalence of Obesity: Time Effect and Other Socioeconomic Variables

\section{Cross Sectional and Time}

Cross Sectional Effects

Effects

\begin{tabular}{|c|c|c|c|c|c|c|}
\hline Variable & Coeff. & $\operatorname{Pr}>|t|$ & & Coeff. & $\operatorname{Pr}>|t|$ & \\
\hline TIME & - & - & & -6.058070 & 0.228 & \\
\hline PPSM & 0.115222 & 0.114 & & 0.146915 & 0.058 & $*$ \\
\hline PR & -0.087450 & 0.815 & & -0.032310 & 0.931 & \\
\hline PINC & 0.000638 & 0.606 & & 0.000085 & 0.948 & \\
\hline $\mathrm{AE}$ & -0.760780 & 0.213 & & -0.837500 & 0.171 & \\
\hline UR & -0.147690 & 0.783 & & 0.015649 & 0.977 & \\
\hline SSPB & 0.062447 & 0.168 & & 0.054366 & 0.231 & \\
\hline WAGE & -0.000170 & 0.757 & & -0.000220 & 0.695 & \\
\hline PAFSTS & -0.101630 & 0.085 & * & -0.099580 & 0.090 & * \\
\hline PMCAREB & 0.000003 & 0.932 & & 0.000001 & 0.972 & \\
\hline PSMOKE & -0.139220 & 0.430 & & -0.155110 & 0.378 & \\
\hline PNHINU & -0.050410 & 0.744 & & -0.028160 & 0.856 & \\
\hline TESTB & 1.284967 & 0.058 & $*$ & 1.237996 & 0.066 & * \\
\hline FSTOR & -1.259940 & 0.791 & & -1.040410 & 0.826 & \\
\hline EDPLA & -2.705010 & 0.260 & & -2.495760 & 0.296 & \\
\hline HESER & -0.996390 & 0.740 & & -0.748210 & 0.802 & \\
\hline PPFAC & 3.265138 & 0.623 & & 3.224399 & 0.626 & \\
\hline TVTRT & 0.074868 & 0.820 & & -0.075060 & 0.830 & \\
\hline
\end{tabular}

Number of cross sections: 55; Length of the time series:2; Number of Observations: 110.

$* / * * / * * *$ : Significant at $10 \%, 5 \%$, or $1 \%$ or higher level. Restricted F test of both models suggests no fixed effects on county prevalence of obesity 
Given an incidental parameter problem, the best estimation method would be a within-effects model which does not use dummy variables, but uses deviation from group means (i.e., means of the cross sectional units) instead. However, since this model does not use dummy variables, the within-effects model has more degrees of freedom for the error, resulting in a small MSE (mean squared error) and a larger standard error for the parameter estimates. Between-effects models, which use means of the group or county observations for different time periods, are appropriate to test the effects between groups, assuming no group or time effects.

The estimated regressions for the deviation from group means and the betweeneffect group means are given in Table 4.4 where the dependent variable is the prevalence of obesity in a county. Both between-effect and within-effect models show that the percentage of the population that has completed a college education (AE) and the number of food stores available per thousand population (FSTOR) are negatively and significantly correlated to county prevalence of obesity. The within-effects estimation also indicates that mean commuting time to work (TVTRT), annual average wage (WAGE), and per capita income (PINC) positively and significantly contribute to obesity. In addition, the between effects model shows that smoking has a significant positive impact on county prevalence of obesity 
Table 4.4. Between and Within Effects Estimations

\begin{tabular}{|c|c|c|c|c|c|c|}
\hline \multirow[b]{2}{*}{ Variable } & \multicolumn{2}{|c|}{ Between Effects } & & \multicolumn{3}{|c|}{ Within Effects } \\
\hline & Coeff. & $\operatorname{Pr}>|t|$ & & Coeff. & $\operatorname{Pr}>|t|$ & \\
\hline CONSTANT & 3.39848000 & 0.655 & & -7.73997000 & 0.066 & $*$ \\
\hline PPSM & -0.00684000 & 0.264 & & -0.00574000 & 0.337 & \\
\hline PR & 0.14460000 & 0.146 & & 0.14276000 & 0.127 & \\
\hline PINC & 0.00033135 & 0.407 & & 0.00057869 & 0.063 & $*$ \\
\hline $\mathrm{AE}$ & -0.23654000 & 0.064 & $*$ & -0.21534000 & 0.082 & $*$ \\
\hline UR & -0.01149000 & 0.956 & & -0.00369000 & 0.983 & \\
\hline SSPB & -0.00873000 & 0.514 & & 0.00068874 & 0.956 & \\
\hline WAGE & 0.00022831 & 0.108 & & 0.00032398 & 0.008 & $* * *$ \\
\hline PAFSTS & -0.00324000 & 0.803 & & -0.00416000 & 0.732 & \\
\hline PMCAREB & -0.00000658 & 0.820 & & -0.00001466 & 0.409 & \\
\hline PSMOKE & 0.20395000 & 0.056 & $*$ & 0.10017000 & 0.222 & \\
\hline PNHINU & 2.11071000 & 0.758 & & -0.05610000 & 0.590 & \\
\hline TESTB & 0.16286000 & 0.299 & & 0.21542000 & 0.142 & \\
\hline FSTOR & -2.71727000 & 0.088 & $*$ & -2.70740000 & 0.073 & $*$ \\
\hline EDPLA & 0.06635000 & 0.947 & & -0.30317000 & 0.724 & \\
\hline HESER & -0.03622000 & 0.973 & & -0.21634000 & 0.824 & \\
\hline PPFAC & -0.08845000 & 0.354 & & -0.46355000 & 0.716 & \\
\hline TVTRT & 0.15591000 & 0.252 & & 0.33461000 & 0.000 & $* * *$ \\
\hline
\end{tabular}

Number of cross sections: 55; Length of the time series:2; No of Observations: 110.

$* / * * / * * *$ : Significant at $10 \%, 5 \%$, or $1 \%$ or higher level. 


\subsubsection{Regional Differences in Obesity}

The incidental parameter problem which arises due to the large number of cross sectional units relative to the number of time dimensions can be overcome by grouping counties into different regions of the state. Currently, WV epidemiological disease surveillance is operating under 7 distinct regions of the state (their statewide distribution is shown in appendix B). The regional fixed effects are captured by including regional dummy variables in the estimations. Accordingly, regions considered for the analysis were coded as North (N), Northeast (NE), Northwest (NW), Central (C), West (W), Southwest (SW) and Southeast (SE). In order to avoid the dummy variable trap, six regional dummies were included in the estimations leaving the Central $(\mathrm{C})$ region as the base category. In addition, a time dummy is included to capture time effects with 1997 the base category. The estimated regional random and fixed effects are presented in Table 4.5. Obtained coefficients are Restricted Maximum Likelihood (REML) estimates of the "proc mixed" procedure of SAS.

Similar to GLS estimates, regional random effects show that average college education completed (AE), total number of establishments per thousand population (TESTB), number of food stores per thousand population (FSTOR), percentage of smokers (PSMOKE) in a county, mean travel time to work (TVTRT), and average annual wage (WAGE) have a significant impact on county obesity rates. For example, a 1\% increase in the percentage of the population with a college education completed would decrease county obesity rates by about $0.2 \%$. 
Table 4.5. Regional Random and Fixed Effects

\begin{tabular}{|c|c|c|c|c|c|c|}
\hline \multirow[b]{2}{*}{ Variable } & \multicolumn{2}{|c|}{ Random Effects } & & \multicolumn{3}{|c|}{ Fixed Effects } \\
\hline & Estimate & $\operatorname{Pr}>|t|$ & & Estimate & $\operatorname{Pr}>|t|$ & \\
\hline CONSTANT & 0.812700 & 0.918 & & 4.803000 & 0.517 & \\
\hline PPSM & -0.003820 & 0.502 & & -0.003020 & 0.633 & \\
\hline PR & 0.138000 & 0.112 & & 0.125400 & 0.210 & \\
\hline PINC & 0.000379 & 0.237 & & 0.000305 & 0.388 & \\
\hline $\mathrm{AE}$ & -0.250600 & 0.031 & $* *$ & -0.231900 & 0.079 & $*$ \\
\hline UR & 0.041440 & 0.804 & & 0.088610 & 0.646 & \\
\hline SSPB & -0.006810 & 0.582 & & -0.008100 & 0.551 & \\
\hline WAGE & 0.000255 & 0.031 & $* *$ & 0.000206 & 0.102 & \\
\hline PAFSTS & -0.005170 & 0.657 & & -0.001410 & 0.917 & \\
\hline PMCAREB & -0.000020 & 0.303 & & -0.000020 & 0.329 & \\
\hline PSMOKE & 0.141100 & 0.085 & $*$ & 0.107600 & 0.251 & \\
\hline PNHINU & -0.062420 & 0.396 & & -0.046250 & 0.573 & \\
\hline TESTB & 0.237900 & 0.090 & $*$ & 0.292700 & 0.051 & $* *$ \\
\hline FSTOR & -2.657000 & 0.062 & $*$ & -2.852600 & 0.099 & * \\
\hline EDPLA & -0.482300 & 0.562 & & -0.513000 & 0.575 & \\
\hline HESER & -0.350100 & 0.704 & & -0.913000 & 0.384 & \\
\hline PPFAC & -1.496600 & 0.718 & & -1.828800 & 0.670 & \\
\hline TVTRT & 0.217000 & 0.038 & $* *$ & 0.148600 & 0.214 & \\
\hline $\mathrm{C}$ & -0.057190 & 0.746 & & - & - & \\
\hline $\mathrm{N}$ & 0.018330 & 0.918 & & 1.416400 & 0.271 & \\
\hline $\mathrm{NE}$ & 0.013520 & 0.939 & & 1.735400 & 0.252 & \\
\hline NW & -0.001060 & 0.995 & & 1.386600 & 0.362 & \\
\hline SE & 0.011950 & 0.946 & & 1.753000 & 0.177 & \\
\hline SW & 0.038120 & 0.830 & & 2.338000 & 0.084 & * \\
\hline W & -0.023660 & 0.894 & & 0.704900 & 0.605 & \\
\hline 1992 & -1.045600 & 0.430 & & -3.120100 & 0.026 & $* *$ \\
\hline 1997 & 1.045600 & 0.430 & & - & - & \\
\hline
\end{tabular}

Number of cross sections 55, Number of Regions 7, Length of the time series 2, No of Observations 110. $* / * * / * * *$ : Significant at 10\%, 5\% level. Coefficient are REML (Restricted maximum Likelihood) estimates of the PROC Mixed procedure of SAS. 
While a unit increase in the total number of establishments per thousand population (TESTB) in a county has a positive impact on county obesity rates, a unit increase in the number of food stores (FSTOR) has a negative impact. Results show that a unit increases in TESTB will raise county obesity rates by about $0.2 \%$; however, a unit increase in FSTOR will reduce the county obesity rate by $3 \%$. As the proportion of smokers in a county increases by $1 \%$, county obesity rates increase by $0.1 \%$. Similarly, a one minute increase in mean travel time to work raises county obesity prevalence by $0.2 \%$. If average annual county wage (WAGE) increases by $\$ 1,000$, the county obesity rate increases by $0.2 \%$.

In comparison to the regional random effects, the regional fixed-effects model shows that AE, TESTB and FSTOR have a significant impact on county prevalence of obesity. The magnitude and the directional impacts of these variables are quite similar to the regional random-effects model. In addition, the significant regional dummy variable, Southwest (SW), implies that the obesity prevalence in that region was significantly higher than for the base Central region during the base year 1997. However, during 1992, the prevalence of obesity was $0.8 \%$ lower than the base Central region. The significant time dummy for 1992 implies that the obesity prevalence in the base central region during this period is significantly lower than that for the period 1997. 


\subsubsection{Minimum Chi Square Probit and Logit Estimation}

Assuming that the dependent variable ( $\%$ of OBESITY in a county) is in a specific range, the linear modeling approaches have been extended to consider non-linear modeling techniques of Minimum Chi Square Probit and Logit. It should also be noted that the dependent variables for these techniques are logit and probit transformation of the probability of an individual being obese (Refer section 3.2.1.2. for further details). The weighted least squares estimates for these modeling approaches are presented in Table 4.6.

In comparison to linear modeling techniques, the considered non-linear approaches produce somewhat similar directional impacts for most of the significant variables in the linear specifications. However, there are a few contrasting results as well. In the case of the Minimum Chi Square Probit (MCSP), PINC, TESTB, FSTOR, PSMOKE, TVTRT, WAGE, PAFSTS are shown to have a significant impact on the county prevalence of obesity. In contrast to the GLS estimates, MCSP shows that as per capita income (PINC) increases, the probability of an individual being obese tends to decrease. Also, the coefficient for the MCSP reveals that the percentage of college education completed in a county (AE) does not have a significant impact on obesity as found in the GLS estimation. Similar to GLS, other variables, including TESTB, FSTOR, PSMOKE, TVTRT, AWAGE, seem to have the same directional impact on county obesity rates. While TESTB positively and significantly contributes to county prevalence of obesity, FSTOR negatively and significantly contributes to obesity. Percentage of smoking (PSMOKE) in a county has a significant positive impact on obesity. Travel time (TVTRT) also indicates a positive impact on county prevalence of 
obesity. In addition, food stamp benefits allocated per thousand population (PAFSTS)

are shown to have a significant negative impact on obesity.

Table 4.6. Minimum Chi Square Probit and Logit Estimations

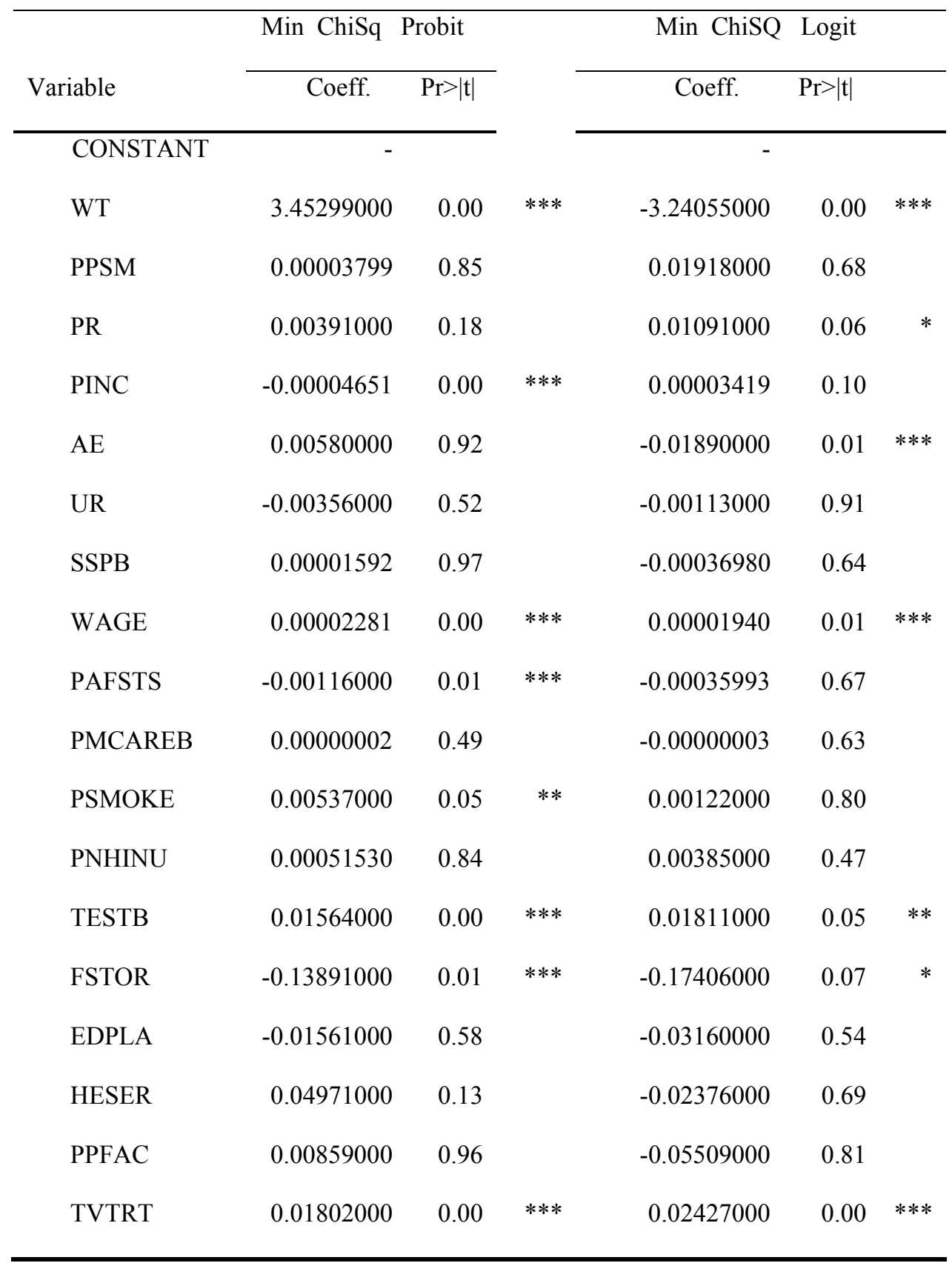

Number of cross sections 55, Length of the time series 2, No of Observations 110.

$* / * * / * * *$ : Significant at $10 \%, 5 \%$, or $1 \%$ or higher level.

Coefficients are WLS estimates of probit and logit transformation of obesity. Models do not have an intercept.

WT: variable associated with weights in transforming data. 
In the case of Minimum Chi Square Logit (MCSL), PR, AE, PESTB, PFSTOR, TVTRT and AWAGE are significant covariates influencing the county obesity rate. In contrast to both GLS and MCSP, MCSL indicates that the poverty rate (PR) has a significant positive impact on the prevalence of obesity. In general, MCSL indicates that for a $1 \%$ increase in poverty, the log odds of being obese increase by about $0.02 \%$. Similar to the GLS findings, percentage of the population with a college education completed (AE) has a significant negative impact on obesity. A $1 \%$ increase in the percentage of the population with a college education would decrease the log odds of being obese by about $0.02 \%$. While the impact of TESTB is positive and significant, the impact of FSTOR is negative and significant in both the GLS and MCSL specifications. Similar to GLS, wage (WAGE), and travel time to work (TVTRT) show a positive impact on obesity prevalence in a county. However, in the MCSL the percentage of the population which smokes (PSMOKE) does not show a significant impact on county obesity rate.

\subsubsection{Spatial Estimations of Obesity}

Having identified that there are no significant unobserved fixed effects on obesity, county level obesity analysis was extended to investigate spatial impacts on the incidence of obesity. Recent economic health and urban studies suggest that spatially located amenity factors have a profound effect on public health. However, the distribution of the local built environment, in effect, is certainly controlled by the economic activities of surrounding environments. Moreover, epidemiological and geographic health research has shown that non-contagious diseases such as heart disease and cancer are spatially 
clustered. Considering those growing concerns of spatial phenomena on public health, we extended this analysis to a spatial autoregressive approach to test the hypothesis that county prevalence of obesity is spatially correlated with neighboring counties. Spatial correlation could be a result of spatial dependence or the spatial heterogeneity of geographic entities. In the event of spatial dependence, the BLUE properties of OLS estimation are violated and, in turn, it produces biased and inconsistent estimates (LeSage and Pace, 2004). Past studies which use spatial and spatiotemporal samples often relied on dichotomous explanatory variables to control either spatial or temporal effects. However, the spatiotemporal modeling using dichotomous variables must account for both spatial and temporal dichotomous variables leading to a large number of estimated parameters. Like temporal autoregressive approaches, spatial and spatiotemporal autoregressive processes often result more parsimonious and better fitting models than those that rely on dichotomous variables (LeSage and Pace, 2004)

\subsubsection{Spatial Error (SEM) and Spatial Autoregressive (SAR) Approaches to Obesity}

Following the theoretical presentation of spatial panel data approaches of Elhorst (2003) and Baltagi (2001), we empirically investigate different spatial panel impacts on county rates of obesity. Accordingly, the empirical results obtained for the random effect spatial error model (RSEM) and spatial autoregressive (RSAR) or spatial lag model are presented in Table 4.7. The significant spatial autocorrelation coefficient $(\lambda)$ of the RSEM implies that county incidence of obesity is spatially autocorrelated. In addition the RSEM shows that county prevalence of poverty (PR), percentage of residents with at least a college education (AE) and average annual wage (WAGE) are significant 
socioeconomic factors affecting obesity. A $1 \%$ increase in poverty in a county would raise the county prevalence of obesity by $0.13 \%$. The percentage of the population with a college education completed (AE) has a significant negative impact on obesity as found in previous specifications (except MCSP) above. A 1\% increase in the percentage of the population with a completed college education reduces the county obesity rate by $0.2 \%$. A $\$ 1,000$ increase in the annual county per capita wage would raise the county obesity rate by $0.3 \%$. A unit increase in the number of business establishments per thousand population (TESTB) would raise the county obesity rate by $0.23 \%$. In contrast, a unit increase in the number of food stores per thousand population would reduce obesity by $3 \%$. A one minute increase in mean travel time to work will raise county incidence of obesity by $0.3 \%$.

In comparison to RSEM, the significant spatial autoregressive coefficient $(\rho)$ of the RSAR estimation implies that county prevalence of obesity is not only spatially autocorrelated but it also has a significant impact on the incidence of obesity in neighboring counties. The RSAR estimation also yields quite similar results to the RSEM, with regard to other significant covariates affecting obesity, except for the variable percentage of smoking (PSMOKE) in a county. RSAR indicates that PSMOKE has a significant positive impact on county prevalence of obesity. 
Table 4.7. Random Effects Spatial Error (RSEM) and Spatial Autoregressive (RSAR) Estimation

\begin{tabular}{|c|c|c|c|c|c|c|}
\hline \multirow[b]{2}{*}{ Variable } & \multicolumn{3}{|c|}{ RSEM } & \multicolumn{3}{|c|}{ RSAR } \\
\hline & Coeff. & $\operatorname{Pr}>|z|$ & & Coeff. & $\operatorname{Pr}>|z|$ & \\
\hline CONSTANT & -2.12763 & 0.633 & & 4.46105 & 0.416 & \\
\hline PPSM & -0.00405 & 0.410 & & -0.00215 & 0.674 & \\
\hline PR & 0.13452 & 0.073 & $*$ & 0.14016 & 0.068 & $*$ \\
\hline PINC & 0.00040 & 0.142 & & 0.00024 & 0.415 & \\
\hline $\mathrm{AE}$ & -0.24738 & 0.012 & $* * *$ & -0.27919 & 0.007 & $* * *$ \\
\hline UR & 0.11080 & 0.449 & & 0.06090 & 0.681 & \\
\hline SSPB & -0.00366 & 0.739 & & -0.01122 & 0.317 & \\
\hline WAGE & 0.00026 & 0.010 & $* * *$ & 0.00022 & 0.036 & $* *$ \\
\hline PAFSTS & -0.01040 & 0.308 & & -0.00822 & 0.429 & \\
\hline PMCAREB & -0.00001 & 0.695 & & -0.00002 & 0.244 & \\
\hline PSMOKE & 0.07546 & 0.309 & & 0.15212 & 0.035 & $* *$ \\
\hline PNHINU & -0.02761 & 0.680 & & -0.07957 & 0.224 & \\
\hline TESTB & 0.23983 & 0.050 & $* *$ & 0.26033 & 0.037 & $* *$ \\
\hline FSTOR & -2.90923 & 0.016 & $* * *$ & -2.56161 & 0.041 & $* *$ \\
\hline EDPLA & -0.09428 & 0.895 & & -0.57729 & 0.436 & \\
\hline HESER & -0.39789 & 0.632 & & -0.36532 & 0.656 & \\
\hline PPFAC & -3.70153 & 0.314 & & -1.28640 & 0.729 & \\
\hline TVTRT & 0.30803 & 0.000 & $* * *$ & 0.16616 & 0.079 & * \\
\hline$\lambda$ & 0.61000 & 0.000 & $* * *$ & & & \\
\hline$\rho$ & & & & 0.15400 & 0.003 & $* * *$ \\
\hline
\end{tabular}

Number of cross sections 55, Length of the time series 2, No of Observations 110.

$* / * * / * * *$ : Significant at $10 \%, 5 \%$, or $1 \%$ or higher level 


\subsubsection{Spatial Fixed Effects of Obesity}

Having considered spatial random effects, both RSEM and RSAR are extended to investigate spatial fixed effects. County specific spatial fixed effects are ignored due to the incidental parameter problem of a larger number of cross sectional units relative to the time series; instead, regional spatial fixed effects, which include regional and time dummies, are investigated. The results obtained for the regional fixed effects spatial error model (FSEM) and regional fixed effects autoregressive model (FSAR) are given in Table 4.8.

The FSEM shows that PR, AE, TESTB, FSTOR, WAGE are significant socioeconomic and built environment covariates affecting obesity. As poverty increases by $1 \%$, the county prevalence of obesity decreases by $0.14 \%$. Similar to previous modeling approaches, the impact of education (AE) is negative and significant; a $1 \%$ increase in AE would lower the incidence of obesity by $0.2 \%$. The FSEM also indicates that neither TVTRT nor PSMOKE has a significant effect on the obesity rate. Total number of business establishments per thousand population (TESTB) has a significant positive impact on obesity. A one unit increase in TESTB would raise the county obesity rate by $0.3 \%$. Negatively significant FSTOR implies that a unit increase in FSTOR would reduce obesity by about $3 \%$. Significant dummy covariates for time (DT) and the northeast (DNE), southeast (DSE) and southwest (DSW) regions imply that there are significant differences in obesity rates in the aforementioned regions for the two time periods. Obesity prevalence in the base central region in 1992 is significantly lower by $3 \%$ than that for 1997 . Also, during 1997, the prevalence of obesity in all three regions 
mentioned is significantly higher, by about $2 \%$, than the base central region. In addition, the significant $\lambda$ is evidence for spatial autocorrelation at the county level.

Table 4.8. Fixed Effects Spatial Error (FSEM) and Spatial Autoregressive (FSAR) Estimation

\begin{tabular}{|c|c|c|c|c|c|c|}
\hline \multirow[b]{2}{*}{ Variable } & \multicolumn{2}{|l|}{ Fixed SEM } & \multicolumn{4}{|c|}{ Fixed SAR } \\
\hline & Coeff. & $\operatorname{Pr}>|z|$ & & Coeff. & $\operatorname{Pr}>|z|$ & \\
\hline CONSTAT & 7.002524 & 0.267 & & -1.173769 & 0.866 & \\
\hline PPSM & -0.002231 & 0.679 & & -0.002466 & 0.648 & \\
\hline PR & 0.140892 & 0.089 & $*$ & 0.138022 & 0.105 & \\
\hline PINC & 0.000167 & 0.571 & & 0.000260 & 0.389 & \\
\hline $\mathrm{AE}$ & -0.228564 & 0.034 & $* *$ & -0.253478 & 0.024 & $* *$ \\
\hline UR & 0.134895 & 0.392 & & 0.112935 & 0.494 & \\
\hline SSPB & -0.007866 & 0.497 & & -0.010933 & 0.350 & \\
\hline WAGE & 0.000198 & 0.057 & $*$ & 0.000197 & 0.065 & $*$ \\
\hline PAFSTS & -0.005400 & 0.634 & & -0.004016 & 0.729 & \\
\hline PMCAREB & -0.000012 & 0.416 & & -0.000015 & 0.341 & \\
\hline PSMOKE & 0.073505 & 0.373 & & 0.091165 & 0.254 & \\
\hline PNHINU & -0.035378 & 0.612 & & -0.037041 & 0.598 & \\
\hline TESTB & 0.311200 & 0.012 & $* * *$ & 0.297258 & 0.019 & $* *$ \\
\hline FSTOR & -3.378136 & 0.018 & $* *$ & -2.908835 & 0.048 & $* *$ \\
\hline EDPLA & -0.256930 & 0.729 & & -0.323029 & 0.680 & \\
\hline HESER & -1.001809 & 0.254 & & -0.830886 & 0.355 & \\
\hline PPFAC & -3.567365 & 0.329 & & -2.282894 & 0.534 & \\
\hline TVTRT & 0.158643 & 0.119 & & 0.155526 & 0.127 & \\
\hline DT & -3.362627 & 0.011 & $* *$ & 4.085395 & 0.240 & \\
\hline DN & 1.111596 & 0.332 & & 1.379088 & 0.209 & \\
\hline DNE & 2.288043 & 0.087 & $*$ & 1.756787 & 0.175 & \\
\hline DSE & 1.963887 & 0.086 & $*$ & 1.616045 & 0.146 & \\
\hline DSW & 2.201709 & 0.078 & $*$ & 1.772235 & 0.131 & \\
\hline DWT & 1.193585 & 0.318 & & 0.649354 & 0.579 & \\
\hline DNW & 1.858562 & 0.162 & & 1.370587 & 0.293 & \\
\hline$\lambda$ & 0.508968 & 0.001 & $* * *$ & & & \\
\hline$\rho$ & & & & 0.34499 & 0.027 & $* *$ \\
\hline
\end{tabular}

Number of cross sections 55, Length of the time series 2, No of Observations 110.

$* / * * / * * *$ : Significant at $10 \%, 5 \%$, or $1 \%$ or higher level. 
In comparison to the FSEM, the results from the FSAR estimation indicate that only education (AE), total number of business establishments (TESTB), number of food stores (FSTOR) per thousand population and WAGE are significant variables affecting county level rates of obesity. The significant $\rho$ indicates that count prevalence obesity has a significant impact on the obesity prevalence of neighboring counties. However, the restricted F-test presented in Table 4.9 indicates that both random effects spatial models, RSEM and RSAR, are superior to the fixed effect spatial models; FSEM and FSAR.

\section{Table 4.9. Restricted F-tests for Regional Random and Fixed spatial approaches} No of No of

\begin{tabular}{lrrrr} 
Model & R-Squared & Restrictions & Parameters & F-test \\
\hline RSEM & 0.599 & 7 & 18 & $0.873^{*}$ \\
FSEM & 0.626 & & 25 & \\
RSAR & 0.593 & 7 & 18 & $0.898^{*}$ \\
FSAR & 0.621 & & 25 & \\
\hline
\end{tabular}

* not significant at $10 \%$ level.

\subsubsection{Spatial Durbin Approach to Obesity}

This spatial analysis also has been extended to test the hypothesis that county obesity is not only affected by socioeconomic and built environment factors of the county itself but also those of neighboring counties. This is tested by using the spatial Durbin Model (SDM) proposed by Lesage and Pace (2004). The results obtained for this model are given in Table 4.9. The results do not support the above hypothesis since the autoregressive coefficient is insignificant. However, estimation shows that the spatially weighted annual wage of neighboring counties (W-WAGE) and the spatially weighted number of physical activity places (W-PPFAC) available per thousand population in neighboring counties have a significant positive impact on county prevalence of obesity. As annual wage of neighboring counties increase, the prevalence of obesity in a county 
increases by $0.001 \%$. Surprisingly, a unit increase in W-PPFAC causes the county prevalence of obesity to rise by almost $100 \%$.

\section{Table 4.10. Spatial Durbin Estimation}

\begin{tabular}{|c|c|c|c|}
\hline \multirow[b]{2}{*}{ Variable } & \multicolumn{2}{|c|}{ SDM } & \\
\hline & Coeff. & $\operatorname{Pr}>|z|$ & \\
\hline CONS & 4.466097 & 0.374 & \\
\hline PPSM & -0.000481 & 0.921 & \\
\hline PR & 0.109086 & 0.113 & \\
\hline PINC & -0.000048 & 0.870 & \\
\hline $\mathrm{AE}$ & -0.221585 & 0.023 & $* *$ \\
\hline UR & 0.150734 & 0.291 & \\
\hline SSPB & -0.012929 & 0.212 & \\
\hline WAGE & 0.000276 & 0.006 & $* * *$ \\
\hline PAFSTS & -0.015172 & 0.102 & \\
\hline PMCAREB & -0.000027 & 0.187 & \\
\hline PSMOKE & 0.131523 & 0.054 & $* *$ \\
\hline PNHINU & -0.037426 & 0.547 & \\
\hline TESTB & 0.406690 & 0.001 & $* * *$ \\
\hline FSTOR & -2.378639 & 0.047 & $* *$ \\
\hline EDPLA & -1.239086 & 0.084 & $*$ \\
\hline HESER & -0.237725 & 0.769 & \\
\hline PPFAC & -0.449030 & 0.890 & \\
\hline TVTRT & 0.193302 & 0.033 & $* *$ \\
\hline W-PPSM & 0.023322 & 0.268 & \\
\hline W-PR & -0.510701 & 0.113 & \\
\hline W-PINC & -0.001899 & 0.108 & \\
\hline W-AE & 0.088378 & 0.823 & \\
\hline W-UR & -0.486203 & 0.440 & \\
\hline W-SSPB & -0.066175 & 0.062 & * \\
\hline W-WAGE & 0.001013 & 0.079 & * \\
\hline W-AFSTS & -0.050051 & 0.361 & \\
\hline W-MCAREB & -0.000077 & 0.221 & \\
\hline W-PPFAC & 98.196552 & 0.008 & $* * *$ \\
\hline W-PSMOKE & 0.582677 & 0.072 & $*$ \\
\hline W-PTESTB & 0.695288 & 0.206 & \\
\hline W-PFSTOR & 3.159657 & 0.581 & \\
\hline W-PEDPLA & -7.623657 & 0.003 & $* * *$ \\
\hline W-PHESER & 2.091967 & 0.567 & \\
\hline W-PNHINU & 0.319789 & 0.179 & \\
\hline W-TVTRT & 0.215510 & 0.448 & \\
\hline$\rho$ & 0.135981 & 0.484 & \\
\hline
\end{tabular}

Number of cross sections 55, Length of the time series 2, No of Observations 110.

$* / * * / * * *$ : Significant at $10 \%, 5 \%$, or $1 \%$ or higher level 
Percentage of the population with a college education completed (AE), annual average wage (WAGE), percentage of smoking (PSMOKE), total business establishments per thousand population (TESTB), number of food stores per thousand population (FSTOR) and travel time to work (TVTRT) have significant similar directional impact as the random effect model, RSAR. Contrary to expectations, as eating and drinking places (EDPLA) available per thousand population increases, county prevalence of obesity decreases by about $1 \%$.

\subsubsection{Discussion: Aggregate Health Demand Analysis}

The spatial distribution of obesity rates in WV for the two specific time periods (1992 and 1997) is mapped in Figures 4.2 and 4.3. These spatial patterns show that obesity existed in relatively higher proportions in almost all counties in 1997 compared to 1992. However, the empirical findings do not support the proposition that there are unobserved county fixed effects contributing to the spatial patterns.

Figure 4.2. Obesity Prevalence, WV, 1992

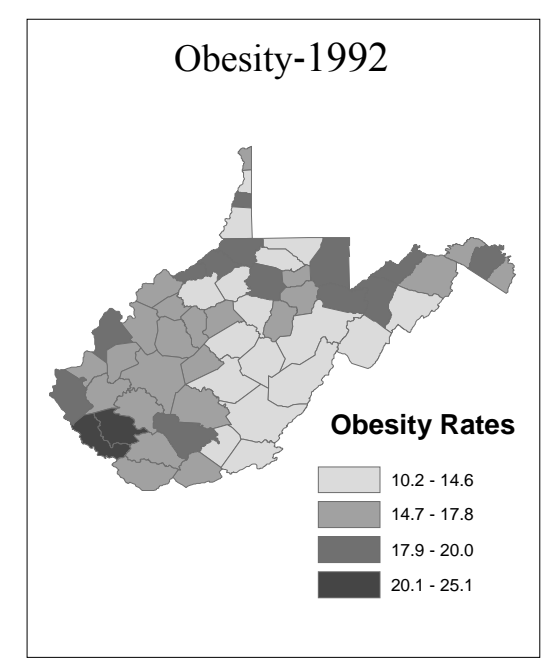


Figure 4.3. Obesity Prevalence, WV, 1997

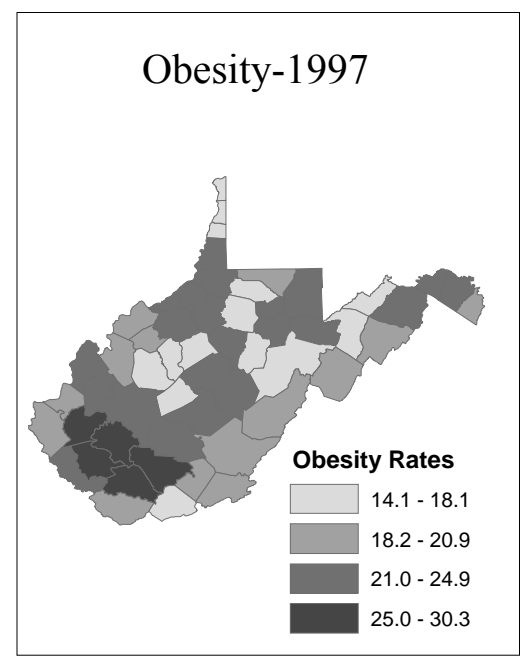

Almost all the empirical specifications in this analysis indicate that the county educational level has a significant impact on county prevalence of obesity. It shows that the number of residents with at least a college education is negatively and significantly correlated with the county prevalence of obesity. This finding is similar to that of Nayga (2000) who showed that knowledge is inversely related to the probability of a person being obese. Similarly, Kenkel (1991) showed that schooling improves choice of health inputs by improving one's knowledge, which also helps one to choose a healthier lifestyle. Other economic studies also conjectured that schooling improves the efficiency of household production of health (Grossman, 1972; Berger and Leigh, 1989). Halverson et al. (2004) state that despite the improvement of educational attainment across WV counties, the relative differences appear to persist over time. The counties in the southern part of the state continue to exhibit a lower percentage of college graduates (Halverson et al., 2004). The pattern is illustrated in Figures 4.4 and 4.5, further explaining the geographic distribution of people with at least a college education and the county prevalence of obesity. 
Figure 4.4. Obesity Rates versus Average College Education Completed During 1992

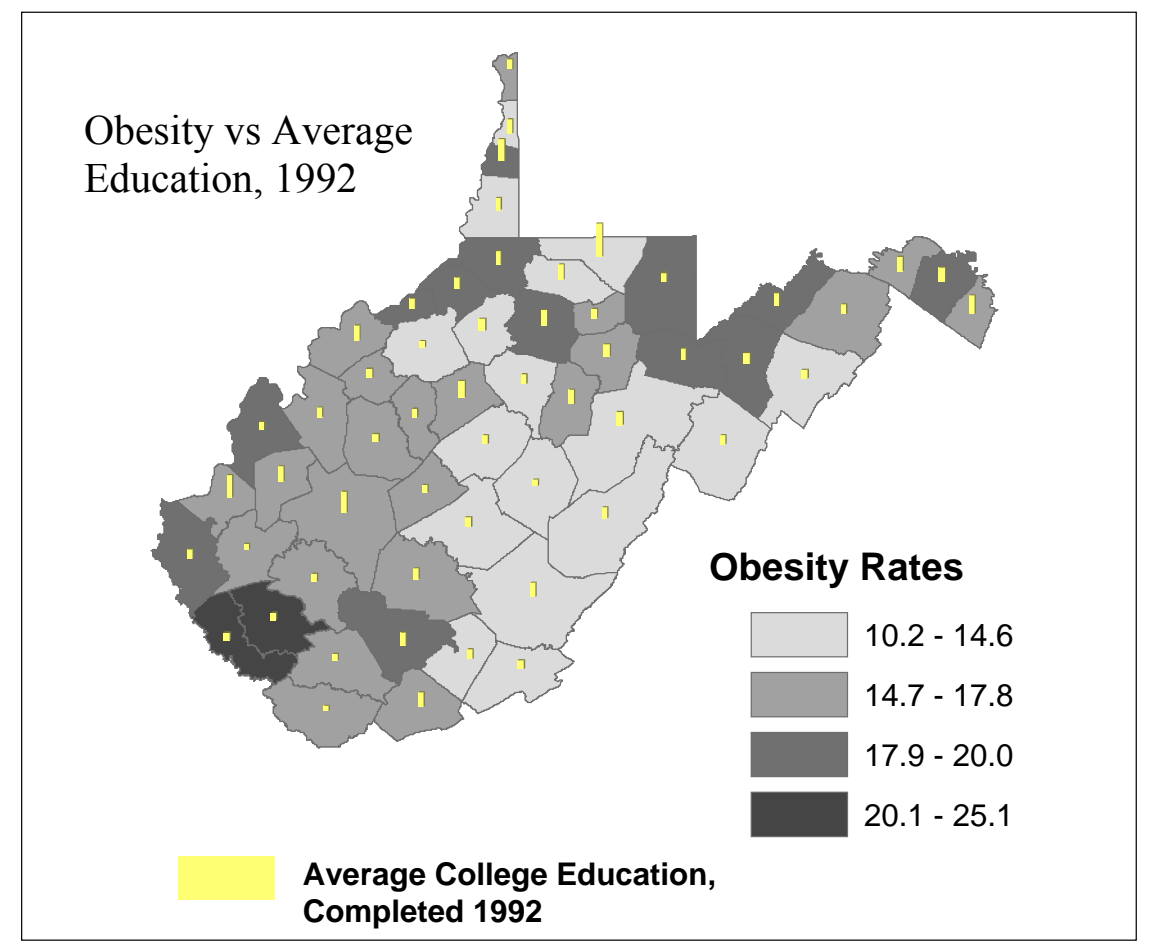

Figure 4.5. Obesity Rates versus Average College Education Completed During 1997

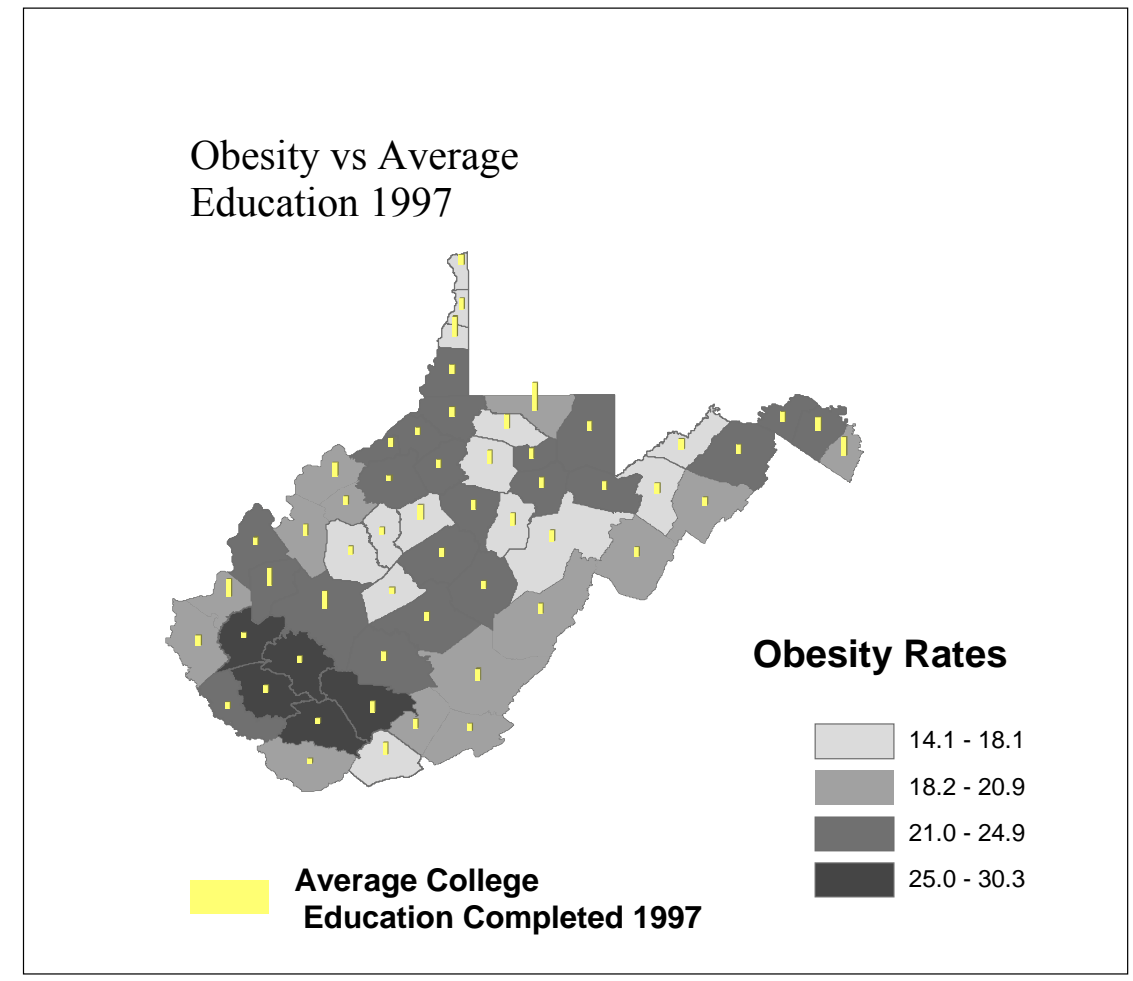


Average wage is a socioeconomic variable shown to influence the county obesity rate by all models considered. Empirical results suggest that as wages increase the county prevalence of obesity increases. Economic theory suggests that wage is a proxy for the opportunity cost of time or price for leisure; the higher the opportunity cost of time, the lower the incentive to substitute leisure for work. As Philipson and Posner (2003) suggest, obesity is accompanied by technological change in developed nations and has resulted in cheaper calories, while exercise has become relatively more expensive. Thus, an unintended consequence of increased labor force participation in advanced economies is a public health consequence like obesity. This economic reasoning seems to be quite applicable for WV's high prevalence of obesity. Mean annual per capita wages for WV counties for the period 1992 to 1997 ranged form $\$ 16,839$ to $\$ 24,991$. This mean annual wage may not be high enough for average WV residents to meet their needs. Thus, economic incentives may induce WV residents to work more, perhaps in sedentary environments, and also to engage in less leisure time physical actives, at the expense of their own health outcomes. On the other hand, one could argue that higher wages could lead to a higher income, thus better food choices reducing obesity. However, a rational consumer who works long hours to earn limited income, may not purchase expensive high quality foods within their budgetary limits. Instead, households may consume convenient foods which also are rich in caloric content, contributing to obesity.

Per capita income and poverty are two other socioeconomic variables that may have an impact on county prevalence of obesity. Even though the OLS and MCSP results indicate that per capita income has a significant impact on obesity, their directional 
impact are opposite to each other. While the OLS model indicates that increasing per capita incomes have a positive impact on obesity, the MCSP indicates that increasing incomes have a negative impact on obesity. Neither RSEM nor RSAR indicate that per capita income has any significant impact on county prevalence of obesity. Even the GLS estimates do not point to a significant effect of income on obesity. Theoretically, OLS estimates are biased and inconsistent in comparison to GLS. Even GLS estimation of random effects does not indicate the significance of income impacting obesity. As mentioned in the methodology section, in the case of Minimum Chi Square Probit (MCSP), we use given percentage of obesity in a county as the probability of a person being obese, rather than considering the actual count of obese people and the actual counts of the total sample in calculating the probability of a person being obese. Therefore, the different results obtained for MSCP and GLS are feasible as they are two different econometric approaches dealing with linear and non-linear specifications. Considering the above mixed income effects, the impact of income on obesity in this study is quite paradoxical and it may be a question that should be further investigated.

Even though there is not enough evidence to definitively make conclusions about the impact of per capita income on obesity, the spatial estimations indicate that county poverty rates have a significant, positive impact on obesity. As other economic health studies have suggested, poverty is an important determinant of many pressing socioeconomic and public health issues (Drewnowski, 2003; Mokdad, Ford, and Bowman, 2003; Basiotis and Lino, 2002; Adler and Ostrove, 1999). Adler and Ostrove (1999) indicate that better health is associated with having more income, more years of education, and a more prestigious job, as well as living in neighborhoods where a higher 
percentage of residents have higher incomes and more education. Drewnowski and Specter (2004), Mokdad, Ford, and Bowman (2003) and Basiotis and Lino (2002) offered evidence to link poverty and food insecurity to obesity. Drewnowski and Specter (2004) indicated that obesity apparently occurs in populations with the highest poverty and the least education. According to Halverson et al. (2004), in the year 1990, approximately $13 \%$ of the U.S. population lived below the poverty level. In the same year, approximately $20 \%$ of the West Virginia population lived below the poverty level. Poverty rates for the whole sample considered in this study range from $14 \%$ to $26 \%$.

The spatial distribution of poverty versus obesity rates in 1992 and 1997 is shown in Figures 4.6 and 4.7. The figures show that the southern counties have a higher percentage of obesity and relatively higher percentage of poverty. For counties with low poverty rates and relatively high obesity rates, factors other than the poverty rate may have contributed to obesity. Based on our spatial empirical results and the above information, it is reasonable to infer that poverty in the state may have some impact on the county prevalence of obesity. 
Figure 4.6. Obesity and Poverty in 1997 (numbers show poverty rate by county)

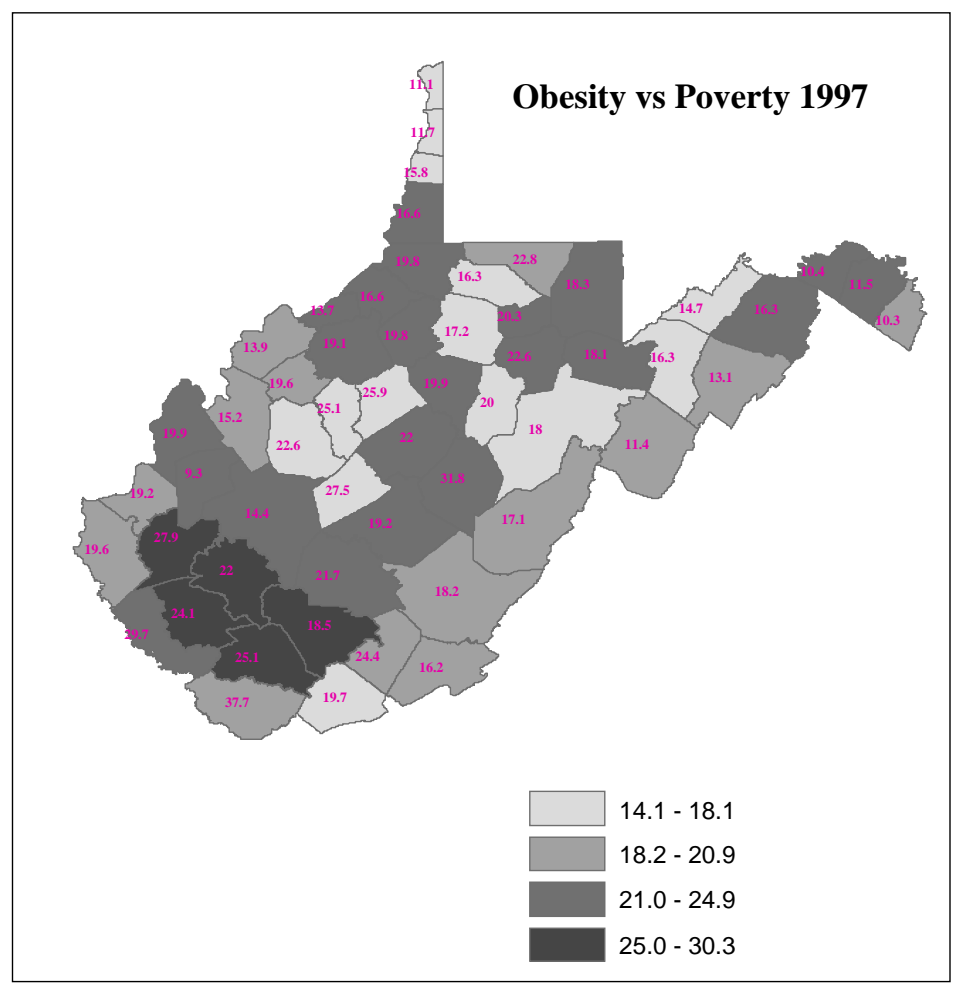

Figure 4.7. Obesity and Poverty in 1992 (numbers show poverty rate by county)

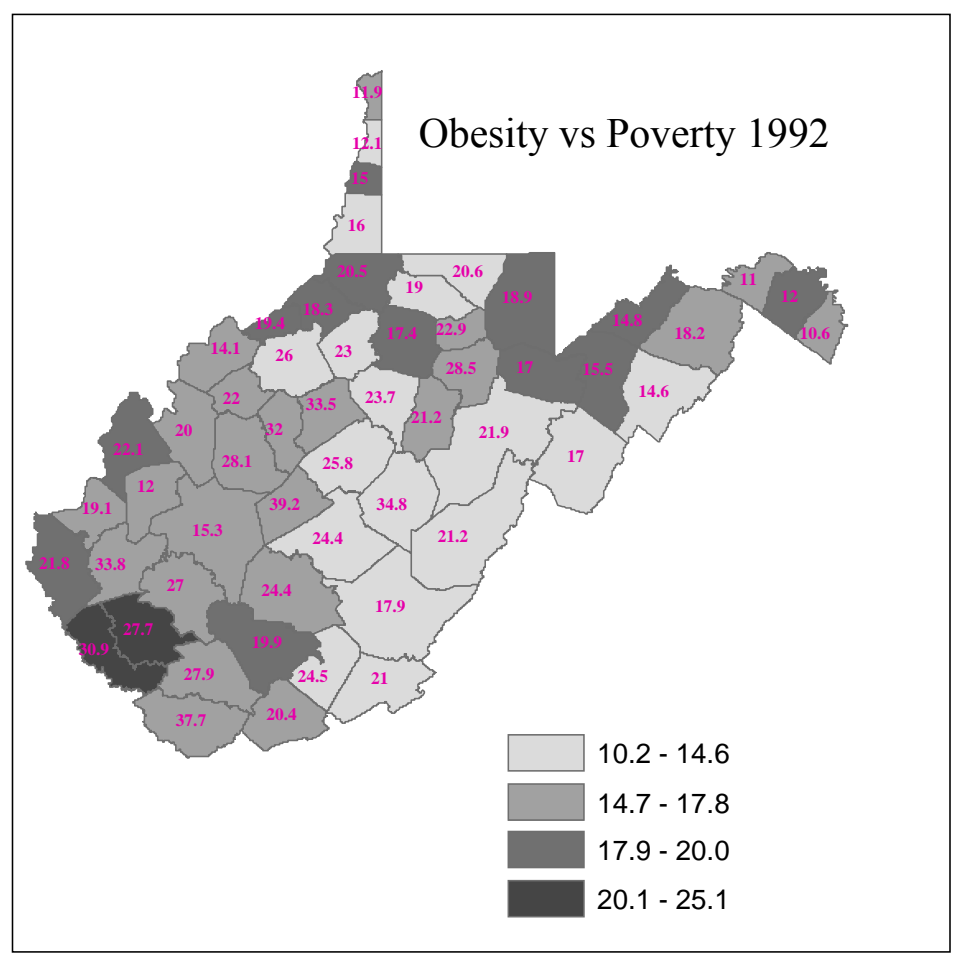


All empirical estimation in the current study shows that TESTB, FSTOR and TVTRT are consistent built environment covariates influencing county obesity rates. Results indicate that total number of business establishments per thousand population (TESTB) in a county is positively and significantly correlated with county prevalence of obesity. As this variable reflects the presence of economic activity in a particular county, we can conclude that as the economy thrives, more and more people engage in long hours of work, perhaps in sedentary environments and may be contributing to the higher prevalence of obesity rates. The positive correlation of TESTB and obesity could also be due to the proposed dilemma of urban sprawl. As the number of establishments per 1,000 population increases, widely dispersed business developments in suburban areas of WV may have induced people to drive more and engage in less biking or walking. This increased reliance on less energy-expending physical activities may have caused WV residents to gain body weight and become obese. This is further evidenced by the positive and significant effect of mean travel time to work (TVTRT) on the obesity rate, which implies that obesity increases as mean travel time to work increases. As previously stated, Frank, Anderson, and Schmid (2004) point out that the likelihood of obesity apparently declines with an increase in mixed land use, but rises with the time spent per day in a car. Considering the results of this study and other previous findings, it is reasonable to conclude that a phenomenon similar to urban sprawl or the surrounding built environment could also be another significant factor causing a high prevalence of obesity in WV counties. Perhaps, in a predominantly rural state like WV, residents living in rural areas may have to travel to distant locations for employment or meeting their 
needs, since there are no thriving business/economic development activities within their own county.

The empirical results also indicate that as the total number of food stores per thousand population increases, obesity tends to decrease. This finding is an indication of a food accessibility problem in some WV counties. As the number of grocery stores increases, people have improved opportunities for finding better quality foods. Not only that, an increasing number of grocery stores creates competition, which, in turn, motivates these businesses to provide better quality food at lower prices. Halverson et al. (2004) indicated that many counties in WV do not have enough grocery stores. Counties with the least favorable grocery store to population ratio occur largely in the southern part of the state. As Derry (2004) noted, the built environment, including work places, stores, transportation systems, etc., could play a major role in controlling weight by shaping food accessibility. Morland, Wing, and Roux (2002) indicate that fruit and vegetable intake is positively associated with the presence of a supermarket, even after controlling for personal economic factors. It seems that these hypotheses are also quite applicable to a rural state like WV, with a high prevalence of obesity. It should also be noted that, empirical results do not indicate that other built environment covariates, such as the total number of eating and drinking places (EDPLA), health care services (HESER), and physical fitness activity places (PPFAC), per thousand population, have significant impacts on the county prevalence of obesity.

In order to better visualize these findings, some of the current county business patterns (eating and drinking places, grocery stores and gas stations) were mapped against obesity prevalence in 1997, and are presented in Figure 4.8. This figure shows 
the general trend of how these business entities are distributed within the state. Generally, areas within concentrated business environments tend to have a high prevalence of obesity. Linking these spatial distributional patterns of business entities to multivariate regressions, it is reasonable to state that one of our key significant covariates, including socioeconomic factors, the built environment or a combination thereof, directly or indirectly affects obesity prevalence in areas adjacent to business environments.

In addition to built environment covariates, some of the empirical specifications show that the county behavioral risk factor, percentage of smokers (PSMOKE), may have a significant positive impact on obesity. Gruber and Frakes (2005) observed that smoking could also lead to weight gain, thus contributing to a higher prevalence of obesity. However, in this study, the significant correlation between smoking and obesity may be due to the fact that counties with several bad health behaviors together were included in the regression analyses. On the other hand, this also raises the dilemma as to whether obesity induces people to smoke as a strategy of reducing weight. 
Figure 4.8. County Business Patterns and Prevalence of Obesity, WV, 1997

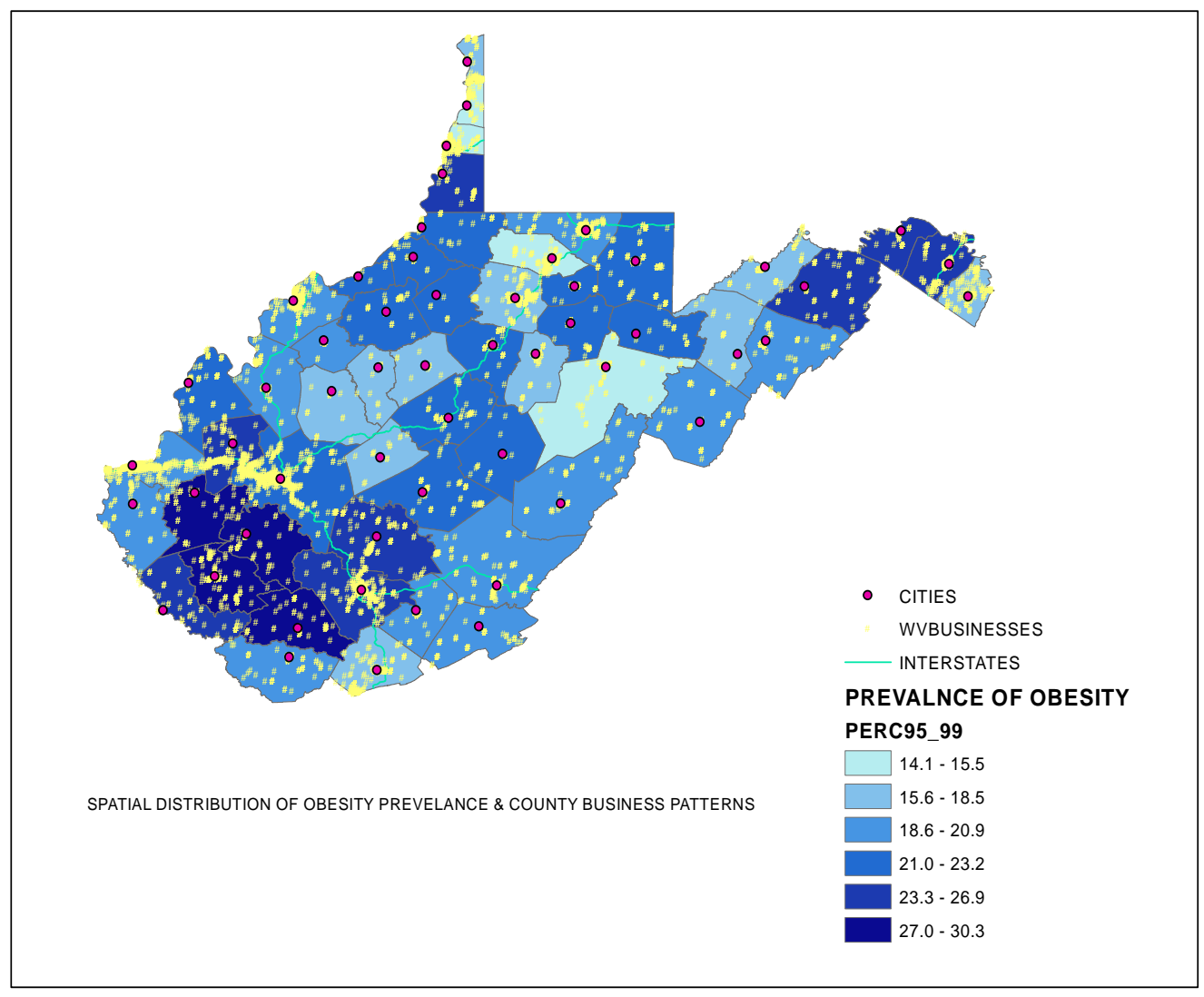

\subsection{Micro Level Analysis}

A recursive multivariate modeling approach is used to estimate individual-level self-assessed health outcomes in terms of socioeconomic, demographic and built environment factors. OGENHLTH is an ordered latent-class dependent variable which indicates the individuals ordered self-assessed health (SAH) responses of "good," "fair" and "poor". Obesity, which determines individual weight status, is considered as an endogenous covariate correlated with the unobserved heterogeneous factors affecting self-assessed health (SAH). Therefore, in the first stage, a latent-class measure of obesity (OBESE) was estimated in terms of socioeconomic, demographic and some built 
environment factors, and then the predicted outcomes of obesity (PREDOBE) were incorporated as a covariate in estimating ordered self-assessed health (OGENHLTH).

The first stage binary logit and probit estimations of risk of being obese (OBESE), are presented in Table 4.11. Empirical results show that the level of educational attainment (LEDUCA) has a significant negative impact an individual being obese. Out of the ethnic groups, Hispanics (HISP) are less like to be obese, in comparison to white non-Hispanic (WNONH), black non-Hispanic (BNONH) and other multicultural nonHispanic (OMNONH). In order to investigate a nonlinear impact of age (AGE) and per capita income (PINC), the squared terms, age squared (AGESQ) and income squared (INCSQ), are also added as explanatory variables to the model. Employed (EMPLOYD), student (STUDENT), retired (RETD) and other (OTHERE) are dummy explanatory variables which represent the employment status of an individual. DSEX is a gender dummy for which female is the base category. Sedentary (SEDENT), smoking (SMOKING), fruit and vegetable consumption index (FRTVINDX), individual possessing a health care plan (HCARE), and risk of heavy alcohol consumption (RFDRHV) are dummy explanatory variables which represent individual risk behaviors. Risk of having heart ailments (HEART) and risk of having asthma problems (RASTHMA) are also dummy indicator variables which represent individual existing health conditions. Average travel time to work in a county (TRVT) is another continuous explanatory variable that is included to capture the potential influence of the built environment on obesity. The dummy variable DDISTD indicates the economic status of the residential county which is equal to one if the county is considered economically depressed. 
The interpretation of the estimated coefficients is not straightforward, other than the sign (or direction). For example, a unit increase in educational level would lower the $\log$ odds of being obese by 0.184 , while other variables in the model are held constant. Out of the ethnic categories, Hispanics (HISP) are less likely to be obese in comparison to the base category of other multicultural non-Hispanics. For a Hispanic, the log odds of being obese is lower by 0.86 units.

The variable per capita income (PINC) represents the midpoint of the income categories for those who earn less than $\$ 50,000$. All respondents who have PINC greater than $\$ 50,000$, are considered to have annual income of $\$ 50,000$. Therefore, PINC varies from $\$ 7,500$ to $\$ 50,000$ for the sample considered for this study. The objective of including one income variable is to reduce the number of dummy variables in the explanatory vector. Results indicate that income has a significant and positive impact at a decreasing rate on the probability of an individual being obese. A $\$ 1,000$ increase in per capita income would raise the probability of being obesity by about 0.004 units in a $\log$ odds scale. Students are less likely to be obese than their base counterparts (i.e., those who are unable to work or are out of work for more than one year). The expected probability of a student being obese is reduced by 0.8 units in a log odds scale. None of the variables that represent marital status indicate a significant impact on the probability of an individual being obese. As a respondent's age increases, the log odds of being obese increases at a decreasing rate. Considering risk behaviors, as expected, smoking (SMOKE) and a sedentary lifestyle (SEDENT) show opposite impacts on an individual being obese. While smoking negatively and significantly contributes to obesity, sedentary behavior positively and significantly contributes to obesity. Respondents who 
smoke reduce the log odds of being obese by 0.8 units. In contrast, respondents with sedentary lifestyles are more likely to be obese with log odds of 0.5 units.

Table 4.11. Maximum Likelihood Probit and Logit Estimates of Obesity Risk

\begin{tabular}{|c|c|c|c|c|c|c|}
\hline \multirow[b]{2}{*}{ Variable } & \multicolumn{2}{|c|}{ Binary Logit } & \multicolumn{4}{|c|}{ Binary Probit } \\
\hline & Estimate & Pr $>$ ChiSq & & Estimate & Pr $>$ ChiSq & \\
\hline CONSTANT & -3.441000 & 0.0001 & $* * *$ & -2.055600 & 0.0001 & $* * *$ \\
\hline LEDUCA & -0.184000 & 0.0008 & $* * *$ & -0.110200 & 0.0007 & $* * *$ \\
\hline WNONH & -0.258500 & 0.2597 & & -0.157600 & 0.2546 & \\
\hline BNONH & 0.166200 & 0.6806 & & 0.079400 & 0.7451 & \\
\hline HISP & -0.866300 & 0.0609 & $*$ & -0.524500 & 0.0497 & $* *$ \\
\hline PINC & 0.000041 & 0.0204 & $* *$ & 0.000024 & 0.0213 & $* *$ \\
\hline INCSQ & -0.000000 & 0.0081 & $* * *$ & -0.000000 & 0.0082 & $* * *$ \\
\hline EMPLOYD & -0.261100 & 0.1138 & & -0.156300 & 0.1149 & \\
\hline STUDENT & -0.791200 & 0.0898 & $*$ & -0.446400 & 0.0813 & $*$ \\
\hline RETD & -0.237400 & 0.2822 & & -0.145300 & 0.2692 & \\
\hline DSEX & 0.172600 & 0.1104 & & 0.108600 & 0.0912 & $*$ \\
\hline MALT & 0.035900 & 0.8565 & & 0.018800 & 0.8724 & \\
\hline DIV_SEP & -0.266200 & 0.2244 & & -0.161300 & 0.2110 & \\
\hline NMARRI & 0.399700 & 0.1137 & & 0.230500 & 0.1242 & \\
\hline AGE & 0.140900 & 0.0001 & $* * *$ & 0.083400 & 0.0001 & $* * *$ \\
\hline AGESQ & -0.001460 & 0.0001 & $* * *$ & -0.000870 & 0.0001 & $* * *$ \\
\hline SEDENT & 0.520100 & 0.0015 & $* * *$ & 0.312600 & 0.0016 & $* * *$ \\
\hline SMOKING & -0.808600 & 0.0001 & $* * *$ & -0.473800 & 0.0001 & $* * *$ \\
\hline HCARE & 0.033000 & 0.8279 & & 0.010500 & 0.9074 & \\
\hline RFDRHV & 0.076100 & 0.8211 & & 0.044600 & 0.8224 & \\
\hline FRTVINDX & -0.118600 & 0.0655 & $*$ & -0.069300 & 0.0697 & $*$ \\
\hline DDISTD & -0.086100 & 0.5035 & & -0.057300 & 0.4553 & \\
\hline TRVT & 0.021800 & 0.0720 & $*$ & 0.013900 & 0.0532 & $* *$ \\
\hline
\end{tabular}

$* / * * / * * *$ : Significant at $10 \%, 5 \%$, or $1 \%$ or higher level. 
The fruit and vegetable consumption index (FRTVINDX), which represents an individual's consumption patterns for these products, is also negatively correlated with obesity. As fruit and vegetable consumption increases, the log odds of being obese decrease by 0.1 units.

DDISTD and TRVT are county specific covariates included in the regressions. DDISTD indicates whether a county is economically distressed, or in a transition stage. TRVT is the average travel time to work in minutes attributable to a respondent's residential county. Although the county economic situation does not seem to show any significant impact on obesity, the average travel time to work positively contributes to the $\log$ odds of being obese. In comparison to the binary logit specification, the binary probit estimation yields similar directional impacts on the odds of being obese with regard to the variables discussed above. In addition, the binary probit specification shows that males (DSEX) are more likely to be obese than females.

Table 4.12 presents the marginal probabilities of an individual being obese for the variables presented in Table 4.11. Both logit and probit estimations indicate that as the level of education increases, the probability of being obese decreases by $3 \%$. Hispanics are $16 \%$ less likely to be obese than the other non-Hispanic ethnic groups.

Even though per capita income (PINC) has a significant effect on the probability of an individual being obese, its marginal impact is shown to be very small. If the respondent is a student, the probability of being obese is reduced by about $16 \%$. As age increases, the marginal probability of being obese increases (by $2 \%$ ) at a decreasing rate. While the marginal impact of physical inactivity or a sedentary lifestyle (SEDENT) increases the risk of a person being obese by $9 \%$, smoking reduces the risk of being obese 
by $14 \%$. An increase in fruit and vegetable consumption significantly lowers the probability of a person being obese by $2 \%$. A one minute increase in travel time would raise the probability of being obese by $0.04 \%$.

Table 4.12. Marginal Probabilities of Risk of Being Obese

\begin{tabular}{|c|c|c|}
\hline \multirow[b]{2}{*}{ Variable } & \multicolumn{2}{|c|}{ Marginal Effects } \\
\hline & Probit & Logit \\
\hline LEDUCA* & -0.0347 & -0.0344 \\
\hline WNONH & -0.0496 & -0.0483 \\
\hline BNONH & 0.0250 & 0.0311 \\
\hline HISP* & -0.1649 & -0.1620 \\
\hline PINC* & 0.0000 & 0.0000 \\
\hline INCSQ* & 0.0000 & 0.0000 \\
\hline EMPLOYD & -0.0492 & -0.0488 \\
\hline STUDENT* & -0.1404 & -0.1480 \\
\hline RETD & -0.0457 & -0.0444 \\
\hline DSEX & 0.0341 & 0.0323 \\
\hline MALT & 0.0059 & 0.0067 \\
\hline DIV_SEP & -0.0507 & -0.0498 \\
\hline NMARRI & 0.0725 & 0.0747 \\
\hline AGE* & 0.0262 & 0.0263 \\
\hline AGESQ* & -0.0003 & -0.0003 \\
\hline SEDENT* & 0.0983 & 0.0973 \\
\hline SMOKING* & -0.1490 & -0.1512 \\
\hline HCARE & 0.0033 & 0.0062 \\
\hline RFDRHV & 0.0140 & 0.0142 \\
\hline FRTINDX* & -0.0218 & -0.0222 \\
\hline DDISTD & -0.0180 & -0.0161 \\
\hline TRVT* & 0.0044 & 0.0041 \\
\hline
\end{tabular}

* indicates variables that have significant impact on probability of being obese 
Table 4.13. presents second stage ordered maximum likelihood probit and logit estimates of self-assessed health (SAH) in terms of socioeconomic, demographic and risk behaviors and the respondent's residential county specific variables. The dependent variable (OGENHLTH) is an ordered latent-class variable which indicates the ordered selfassessed health (SAH) categories of "good," "fair," and "poor." Considering ordered logit estimation of SAH, CONSTANT2 and CONSTANT1, are the estimated ordered logit for the adjacent level health category, "good" versus "fair" and "poor," and "good" and "fair" versus "poor," respectively, when the other covariates are evaluated at zero. For example the log odds of "good" versus "fair" and "poor" SAH for a female (i.e., DSEX evaluated at zero) is 1.77 . The log odds of "good" and "fair" versus "poor" for a female is 3.34. The socioeconomic variables educational attainment (LEDUCA) and income (PINC) significantly and positively raise the expected SAH.

A unit increase in educational attainment would raise the expected SAH in ordered log odds scale by 0.2 units while the other variables in the model are held constant. Similarly, a $\$ 1,000$ increase in income would raise the value of expected health by 0.1 units. Out of the covariates that describe employment status, those who are employed (EMPLOY) and retired (RETD) are the most likely to show good health. There is no significant contribution by gender to expected health. As age increases, expected SAH in log ordered scale tends to decrease. The behavioral risk factors obesity, sedentary lifestyle and smoking negatively and significantly affect expected health. The expected SAH when one is obese decreases by 2.61 units in a log ordered scale. Similarly, having a sedentary lifestyle (SEDENT) would lower expected health by 0.65 units. 
Table 4.13. Maximum Likelihood Ordered Probit and Logit Estimates of an Individual's Self Assessed Health

\begin{tabular}{|c|c|c|c|c|c|c|}
\hline \multirow[b]{2}{*}{ Variable } & \multicolumn{2}{|c|}{ Ordered Logit } & & \multicolumn{3}{|c|}{ Ordered Probit } \\
\hline & Estimate & $\operatorname{Pr}>\mathrm{ChiSq}$ & & Estimate & $\operatorname{Pr}>\mathrm{ChiSq}$ & \\
\hline CONSTANT2 & 1.7731 & 0.0157 & ** & 0.9162 & 0.0260 & $* *$ \\
\hline CONSTANT1 & 3.3478 & 0.0001 & $* * *$ & 1.8006 & 0.0001 & $* * *$ \\
\hline LEDUCA & 0.2013 & 0.0015 & $* * *$ & 0.1220 & 0.0007 & $* * *$ \\
\hline WNONH & -0.0616 & 0.8195 & & -0.0337 & 0.8268 & \\
\hline BNONH & 0.1374 & 0.7641 & & 0.0486 & 0.8516 & \\
\hline HISP & -0.3690 & 0.4504 & & -0.2230 & 0.4194 & \\
\hline PINC & 0.0000 & 0.0001 & $* * *$ & 0.0000 & 0.0001 & $* * *$ \\
\hline EMPLOYD & 1.4168 & 0.0001 & $* * *$ & 0.8505 & 0.0001 & $* * *$ \\
\hline STUDENT & 0.7907 & 0.1535 & & 0.4820 & 0.0932 & * \\
\hline RETD & 1.1810 & 0.0001 & $* * *$ & 0.7280 & 0.0001 & $* * *$ \\
\hline DSEX & -0.0184 & 0.8861 & & -0.0026 & 0.9715 & \\
\hline MALT & -0.2256 & 0.2372 & & -0.1470 & 0.1834 & \\
\hline DIV_SEP & -0.1537 & 0.4496 & & -0.1005 & 0.3927 & \\
\hline NMARRI & 0.0182 & 0.9482 & & -0.0394 & 0.8029 & \\
\hline AGE & -0.0273 & 0.0001 & $* * *$ & -0.0149 & 0.0001 & $* * *$ \\
\hline PREDOBE & -2.6180 & 0.0006 & $* * *$ & -1.2876 & 0.0031 & $* * *$ \\
\hline SEDENT & -0.6526 & 0.0001 & $* * *$ & -0.4162 & 0.0001 & $* * *$ \\
\hline SMOKING & -0.7766 & 0.0001 & $* * *$ & -0.4282 & 0.0001 & $* * *$ \\
\hline HCARE & -0.1713 & 0.3040 & & -0.1054 & 0.2627 & \\
\hline RHEART & -0.8316 & 0.0001 & $* * *$ & -0.4951 & 0.0001 & $* * *$ \\
\hline RASTHMA & -0.8084 & 0.0001 & $* * *$ & -0.4559 & 0.0001 & $* * *$ \\
\hline RFDRHV & 0.0310 & 0.9380 & & 0.0143 & 0.9478 & \\
\hline FRTVINDX & 0.0614 & 0.4159 & & 0.0377 & 0.3752 & \\
\hline DDISTD & -0.4726 & 0.0002 & $* * *$ & -0.2658 & 0.0002 & $* * *$ \\
\hline
\end{tabular}

$* / * * / * * *$ : Significant at $10 \%, 5 \%$, or $1 \%$ or higher level. 
In addition, smoking (SMOKE) lowers expected health by 0.77 units. Respondents who are at risk of having heart ailments and asthma conditions are less likely to have good health. Risk of being a heart and asthma patient lowers the expected SAH in log ordered scale by about 0.80 units. Contrary to expectations, fruit and vegetable consumption does not show a significant impact on health.

Lastly, respondents living in economically distressed counties are less likely to have good health. For a resident of an economically distressed county, the expected SAH in ordered log scale is lower by 0.47 units. None of the categories of marital status shows a significant difference for their expected SAH. In comparison to the ordered logit estimation, ordered probit estimations show similar directional impacts on expected health for the respective variables, except for being a student. The ordered probit estimate shows that students are more likely to have good health relative to the base, their unable-to-work counterparts.

\subsubsection{Discussion: Micro Level Health Analysis}

In this analysis, a recursive system of multivariate ordered probit/logit analysis of self assessed health (SAH) and a binary logit/probit specification for risk of being obese were estimated in terms of socioeconomic, demographic and county specific socioeconomic factors. Both estimations showed that the level of education has a significant impact on the expected (SAH) health outcome and on the risk of being obese. While education positively and significantly contributes to expected SAH, it significantly and negatively contributes to obesity. Previous studies (Nayga, 2000; Chou, Grossman, and Saffer, 2004; Kan and Tasi, 2004) have shown that educational attainment has a 
negative impact on the probability of being obese. Nayga (2000) indicated that not only does diet-disease knowledge decrease the probability of being obese, but also policies to promote diet-disease knowledge could lead to decreasing the incidence of obesity. Mancino, Lin, and Ballinger (2004) found that women with a college education have a greater feeling of control over their own weight and exercise more frequently. Kenkel (1991) and Grossman (1972) also suggest that schooling improves the choice of health inputs by improving an individual's health knowledge. These findings seem quite relevant for a state like $\mathrm{WV}$, where the educational differences across the state have been persistent over time (Halverson et al., 2004)

Ordered probit estimations show that higher educational attainment significantly increases the probability of reporting better expected health outcomes. Although Contoyannis and Jones (2004) point out that it is difficult to identify a gradient of different educational categories in evaluating their self-assessed health. However, Contoyannis and Jones (2004) also stated that individuals in lower educational categories have a significantly lower probability of reporting excellent or good health.

In terms of ethnicity, Hispanics are less likely to be obese than their non-Hispanic counterparts. A reasonable explanation for this may be that the physical labor-intensive activities of this ethnic group, which constitutes a greater proportion of the "working class," also contributes to their relative lack of obesity. The Hispanic share of the working class in the U.S. has increased three-fold in the past twenty years, from $6 \%$ in 1980 to $20 \%$ in 2000, primarily due to immigration (U.S. Census, 2000). In WV, although the population with Hispanic origins has increased at a comparatively slower rate, from $0.5 \%$ in 1990 to $0.7 \%$ in 2000 , the sample considered for this study contained 
2.1\% Hispanics (WV Department of Health and Human Resources, 2004). As Philipson (2001) suggested, work tends to be strenuous in an agricultural or industrial society and, in turn, the worker is "paid to exercise." Perhaps this proposition is quite applicable to this ethnic group. None of the other ethnic groups have a significant impact on self assessed health (SAH).

Chou, Grossman, and Saffer (2004) and Nayga (2000) suggest that income negatively and significantly contributes to an individual being obese. Estimations in the current logit/probit study suggest that the risk of obesity increases at a decreasing rate with household income. This implies that as income increases, the risk of being obese increases up to a certain income level and then, further increases in the level of income lowers the risk of being obese.

Drewnowski and Specter (2004) indicate that the highest rates of obesity occur among groups with the highest poverty rates and the least education. Lee (1982) showed that demand for health rises with "net family assets," since good health is expected to be a normal good.

Marital status does not significantly contribute either to obesity or to expected self-assessed health. This result is contrary to the recent finding of Gruber and Frakes (2005) that married and widowed individuals have higher body mass index (BMI) and obesity odds, than divorced and never-married individuals. Divorced individuals, in turn, have a lower weight outcome than those who have never married. Binary probit estimations show that males are more likely to be obese than females. The impact of gender on obesity cannot be interpreted with great precision as its significance is not consistent across models. The findings of Nayga (2000) reveal that females tend to have 
more diet-disease knowledge than males and that such knowledge has a significant and negative effect on the probability of being obese.

The quadratic effect of age indicates that the probability of being obese increases with age but at a decreasing rate. Similar age effects are also reported by Chou, Grossman, and Saffer (2004) and Kan and Tasi (2004). Gruber and Frakes (2005) showed that age follows a non-linear relationship with both BMI and the probability of obesity. BMI and obesity appear to rise with age and then peak in the 50s, thereafter going down again for those in their 60s. The negative coefficient of the AGE variable in the health equation suggests that as age increases, the probability of reporting good health decreases. Lee (1982) pointed out that health deteriorates with age, with the rate of health depreciation rising with age for middle-aged individuals.

Results from previous studies are equivocal in terms of risk behavior (i.e., smoking and sedentary lifestyles) impacts on obesity. For example, while Chou, Grossman, and Saffer (2004) argue that smoking lowers the risk of being obese, Gruber and Frakes (2005) claim that smoking increases the risk of obesity. Risk behaviors including smoking and a sedentary lifestyle, and risk of having other health-impaired conditions such as heart disease and asthma, as expected, are significantly and negatively correlated with an individual's self-assessed health.

Other interesting findings of this study are that commuting time to work is positively and significantly related to the risk of obesity. This somewhat strengthens the implication of the urban sprawl hypothesis of obesity. Frank, Anderson, and Schmid (2004) suggest that the likelihood of obesity apparently declines with an increase in mixed land use but rises with time spent per day in a car. The authors suggest that the 
potential path of causality between urban sprawl and disease status is: urban sprawl $\rightarrow$ increased automobile use $\rightarrow$ decreased physical activity $\rightarrow$ obesity $\rightarrow$ increased cardiovascular disease, diabetes and other health problems. Urban sprawl may also reduce physical activity because parks or fitness facilities are more distant. It also may affect diets by increasing distance to supermarkets or it may increase the cost of nutrition by conversion of farmland to urban uses (Frumkin, 2002). Similar to the urban sprawl hypothesis, residents of rural states like WV depend heavily on automobile travel when there are no economic development activities within their residential counties. Rural residents may travel to further distant areas not only for employment opportunities but also for their daily needs since supermarkets and grocery stores are sparsely distributed. In addition, respondents from economically distressed counties are more likely to have impaired health outcomes than respondents from economically advantaged counties. 


\section{Chapter 5}

\section{Conclusions and Policy Implications}

Obesity is reaching epidemic proportions across the U.S., especially in the state of West Virginia (WV) and similar predominantly rural regions. Its growing consequences are felt by the entire nation through soaring health care costs, and many geographic and demographic sub-groups, including the state of $\mathrm{WV}$, clearly bear a greater burden than others. This analysis attempts to integrate both theoretical and empirical insights to facilitate understanding of the current obesity epidemic in WV in the presence of land use changes and heterogeneity in socioeconomic and demographic characteristics of the state. In meeting this objective, an investigation of obesity and related health outcomes was conducted at two levels of aggregation: county level and individual level.

To conduct the county level health analysis alternative econometric specifications were used under a panel data structure to identify possible socioeconomic and built environment factors contributing to obesity. Various secondary data sources were used corresponding to two time periods, 1992 and 1997.

Findings reveal that, contrary to expectations, per capita income is positively correlated with obesity; however, the risk of obesity increases at a decreasing rate with household income. As expected, the prevalence of obesity is negatively and significantly correlated with the education level; a $1 \%$ increase in the population with a completed college education is found to decrease the obesity rate by $0.2 \%$. A unit increase in the number of food stores available per thousand population lowers obesity prevalence by $3 \%$. However, each one-minute increase in mean commuting time raises the obesity rate by $0.3 \%$. Other results reveal that students and females are less likely to be obese. In 
addition, as age increases, the log odds of being obese increases at a decreasing rate; in other words, obesity increases with age, peaking at 50 and then declining in the $60 \mathrm{~s}$. In terms of marginal probabilities, we find that as the level of education increases, the probability of being obese decreases by $3 \%$. Hispanics are $16 \%$ less likely to be obese than other non-Hispanic ethnic groups. Being a student reduces the likelihood of being obese by about $16 \%$. Physical inactivity increases the risk of being obese by $9 \%$, while smoking reduces the risk of being obese by $14 \%$. Fruit and vegetable consumption lowers the probability of being obese by $2 \%$, while a one-minute increase in commute travel time raises the probability of being obese by $0.04 \%$.

The results for self-assessed health reveal that employed and retired individuals are most likely to have good health. There is no significant contribution of gender to expected health. The behavioral risk factors, obesity, sedentary lifestyle and smoking negatively and significantly affect expected health. Finally, individuals from economically distressed counties are less likely to have good health.

In general, we find evidence to support the hypothesis that an unintended consequence of increased labor force participation in advanced economies is a public health problem like obesity. We also find evidence to reinforce the previous research finding that obesity clusters in areas with the highest poverty and the least education. Our findings reveal that the southern WV counties have a higher percentage of obesity and a relatively higher percentage of poverty as well as lower education. In addition, counties with the least favorable grocery store to population ratio are also clustered in the southern part of the state, and the results indicate that there is an inverse relationship between the number of food stores and the obesity rate. For counties with low poverty 
and relatively high obesity rates, factors other than poverty may have contributed to obesity.

Findings also suggest that there are no time invariant county or regional fixed effects affecting county obesity rates. Although there is no evidence for unobserved fixed effects or for serial correlation, empirical investigation reveals that obesity is a spatially non-random event. The spatial investigation shows that obesity tends to cluster in certain geographic locations. Obesity tends to cluster around the southern and northeastern parts of the state, near concentrated business or primary manufacturing environments.

Similar to findings of previous studies, county prevalence of poverty rates and percentage of the population with a college education are significant socioeconomic determinants of obesity. While county prevalence of poverty and the annual per capita wage positively contribute to obesity, the number of people with at least a college education negatively contributes to obesity. Total number of business establishments per thousand population (TESTB), total number of food stores per thousand population (FSTOR), and mean travel time to work (TVTRT) are significant built environment determinants of county obesity. While TVTRT and TESTB positively and significantly contribute to obesity, FSTOR negatively and significantly contributes to obesity. Since the impacts of per capita income and the percentage of smokers in a county do not yield consistent results across models, their effects on obesity cannot be explained precisely and should be further investigated.

The individual health demand analysis centered on investigating an individual's socioeconomic, demographic and locational characteristics that contribute to the 
incidence of obesity and subsequent health. In reaching this objective, a recursive system of binary logit/probit models of obesity and an ordered probit/logit specification of selfassessed health were estimated. Results show that educational attainment, age, household income, risky behaviors including smoking and a sedentary lifestyle, fruit and vegetable consumption, and commuting time were significant factors either positively or negatively contributing to obesity. An individual's self -assessed health, which also can be considered a proxy for his/her quality of life, is greatly influenced by age, income, risky lifestyle factors such as obesity, a sedentary lifestyle and smoking, other impaired health conditions like asthma and heart ailments, and county specific economic conditions. In contrast to the county level aggregate analysis, micro level health investigations show that both income and smoking have significant impacts on obesity as well as on health. One's risk of being obese increases at a decreasing rate with income. According to results of the individual health demand analysis, those who smoke are less likely to be obese.

The important policy issue behind obesity is that it creates a negative externality to society thorough increased health care costs which are borne largely by tax payers. In order to correct such externalities, government intervention either through a regulatory or an economic incentive approach is justified. Using command and control approaches to correct inadvertent behavioral problems may not be acceptable morally and socially. Perhaps the use of economic incentives is more efficient and equitable than command and control approaches. The dilemma is whether to tax the obese individual or the associated complementary goods which contribute to obesity. Taxing the individual directly may not be practical and may also be unjustifiable, as obesity is not only 
associated with hereditary issues, but is partly the unintended consequence of current economic activities. Similar to taxes on smoking, imposing taxes on fast foods, food away from home, snacks, and promotional food advertisements might be better intervention processes than taxes on individuals. However, it should also be noted that implementing such a tax policy would create other market distortions in the economy. Imposing a tax would also create an excess burden or deadweight loss on the economy in the long run. If the external cost of fast food consumption is greater than the excess burden of imposed taxes, a tax on these goods may be justifiable. The use of economic instruments in controlling obesity therefore requires further investigation.

As the results of this study suggest, in addition to socioeconomic factors, built environment factors are also significant determinants of the county prevalence of obesity. Therefore, the current obesity epidemic is not only due to individual behavior, but can also be interpreted as an unintended consequence of current land use planning. As this study suggests, a higher number of food stores per thousand population results in a lower prevalence of obesity, at least in $\mathrm{WV}$, meaning land use planners and economic developers need to focus special attention on local food accessibility. Frank, Anderson and Schmid (2004) note that the likelihood of obesity apparently declines with increases in mixed land use, but rises with the time spent per day in a car; the adverse impact on obesity of mean commute time is confirmed by results from this study.

Because poverty is another contributing factor to the current obesity epidemic, especially in a rural state like $\mathrm{WV}$, it might be necessary to implement poverty alleviation programs in the state. Lastly, this study indicates that educational attainment (at both the county level and the individual level) has a significant negative impact on the prevalence 
of obesity. Previous health and economic studies (Grossman, 1972; Kenkel, 1991;

Farrell and Fuchs, 1982; Variyam, Blaylock, and Smallwood, 1996; Adler and Ostrove, 1999; Nayga, 2000) also showed that educational attainment has a powerful impact on socioeconomic lifestyles (e.g., dietary patterns, recreational activities) as well as on health. At the same time, level of education is a remedial factor for other pressing socioeconomic problems such as poverty and unemployment. Education is one of the key determinants of human capital, not only providing an economic return, but also increasing employment rates and earnings, and improving health, well-being and parenting (OECD, 2001). Therefore, interventions which enhance educational attainment could play a vital role in addressing the obesity epidemic in WV. This may be especially true of childhood obesity, a growing problem in WV. In addition, establishment of a reward system for young school children for maintaining healthier weight limits, tax credits to households for maintaining healthier weight limits, and reward systems in the work place for maintaining healthier lifestyles could be other community intervention strategies to control obesity.

\subsection{Limitations and Future Research}

In this study, the theoretical model suggests that relative price differences of goods (i.e., prices of fruit, vegetables, and fast foods), and costs of medical services should be included. However, no existing county level data on food prices were available, thus, it was assumed that prices were constant across cross sectional units as suggested by Adelaja and Nayga (1997). Since prices of fast foods and fruits and vegetables were not included in the estimations, this study cannot explain the impact of relative food prices on 
obesity. Therefore, this study does not have enough evidence to identify the precise role of fast food as a culprit in the obesity epidemic. There also were no available medical expense data directly attributable to obesity. Even though medical expenditures on hospital treatments for obesity-related diseases (e.g., heart disease) are available, these confidential data are not tabulated and are difficult to obtain for several time periods. A comprehensive sprawl or land use index was unavailable due to the lack of reliable amenity or land use data for the two time periods. Even though a weak measure of a sprawl index based on urban and rural population of counties was calculated, it was excluded as it did not seem to provide any additional explanatory power to the model.

Suggestions for future research include extending the individual health demand analysis to incorporate spatial characteristics. The county level analysis could also be extended to a simultaneous or spatial simultaneous equation approach to investigate possible endogeneity between obesity, sedentary lifestyles, and self-assessed health. Analyzing the excess burden from the use of economic incentives in controlling obesity is another possible area of research which would help policy decision makers.

In addition, future research could be expanded to include more states, which would not only be helpful in the investigation of cross-border spatial effects but also to improve the estimations which would then be more reliable as a result of more observations with greater heterogeneity. Lastly, health is a dynamic concept as one's health and weight status changes due to changing socioeconomic, market and environmental conditions, which in turn affects one's value of life or expected life time utility. Therefore it would also be worthwhile to undertake a dynamic modeling approach to understand health and obesity. In spite of the limitations, the results may be 
of use to researchers and policy makers for better understanding the obesity problem and to better prioritize resources to address the obesity issue at the county level in WV and other states with similar geographic and demographic characteristics. Causes for obesity are multifaceted. Allocation of physical and financial resources to community intervention strategies through educational programs as well as better land use planning strategies would be helpful in promoting healthier communities and stimulating economic development in WV. 


\section{References}

Adelaja, O. A., and R. M. Nayga, Jr. 1997. "Income and Racial Differentials in Selected Nutrient Intakes.” American Journal of Agricultural Economics, 79(5):1452-1460.

Adler, N. E., and J. M. Ostrove. 1999. "Socioeconomic Status and Health: What We know and What We Don't." Annals of the New York Academy of Sciences 896:3-15.

Alaimo, K., R. R. Briefel, E. A. Frongillo, and C. M. Olson. 1998. "Food Insufficiency Exists in the United States: Results from the Third National Health and Nutrition Examination Survey (NHANES III)." Am Journal of Public Health 88:419-26.

Anderson, P. M., K. F. Butcher, and P. B. Levine. 2003. "Economic Perspectives of Childhood Obesity." Economic Perspective Federal Reserve Bank of Chicago, 3Q.

Appalachian Regional Commission (ARC). 2006. Regional data, available at http://www.arc.gov (accessed on August 2004)

Bahl, R. 1998. "Why Levy Discriminatory Excises on Soft Drinks?"., Working Paper 98-3, School of International Studies Program, Policy Studies, Georgia State University, Atlanta, Georgia.

Baltagi, B. H. 2001. Econometric Analysis of Panel Data. 2nd. ed. New York. John Wiley.

Barnett, E., G. A. Elmes, V. E. Braham, J. A. Halverson, J. Y. Lee, and S. Loftus. 1998. Heart Disease in Appalachia: An Atlas of County Economic Conditions, Mortality and Medical Care Resources Office for Social Environment and Health Research Prevention Research Centre, Robert C. Byrd Health Science Center, West Virginia University.

Basiotis, P. P., and M. Lino. 2002. "Food Insufficiency and Prevalence of Overweight Among Adult Women." Nutrition Insights 26:1-2.

Baum, C.L., and W. F. Ford. 2004. "The Wage Effects of Obesity: A Longitudinal Study." Health Economics 13:885-899.

Becker, G. 1965. “A theory of the Allocation of Time.” The Economic Journal. 75(299):493517.

Behavioral Risk Factor Surveillance System (BRFSS) 2003. "Technical Information and Data." available on line at http://www.cdc.gov/brfss/technical infodata/surveydata/ (accessed on August 2004).

Belloc, N., and L. Breslow. 1972. "Relationship of Physical Health Status and Health Practices." Preventive Medicine 1:409-421. 
Berger, M., and J. Leigh. 1989. "Schooling, Self selection, and Health.” Journal of Human Resources 24:443-435.

Bhattacharya, J., and N. Sood. 2005. "Health Insurance and Obesity Externality." National Bureau of Economic Research, Working Paper No 11529.

Bianchini, F., R. Kaaks, and H. Vainio. 2002. "Weight Control and Physical Activity in Cancer Prevention." Obes Rev 3(1):5-8.

Binkley, J. K., J. Eales, and M. Jekanowski. 2000. "The Relation Between Dietary Change and Rising U.S. Obesity.” International Journal of Obesity 24:1032-1039.

Blanchard, T., and T. Lyson. 2003. "Access to Low Cost Groceries in Nonmetropoliton Counties: Large Retailers and the Creation of Food Deserts." Social Science Research Centre, Mississippi State University.

Block, J. P., R. A. Scribner, and K. B. DeSalvo. 2004. "Fast food, Race/Ethnicity, and Income, Geographic Analysis." American Journal of Preventive Medicine 27(3):211-217.

Brown, H. S., J. A. Pagan, and E. Bastida. 2004. "The Impact of Diabetes on Employment; Genetic IVs in a Bivariate Probit." Health Economics 14(5):537544.

Bureau of Economic Analysis, U.S. Department of Commerce 2005. CA35 Personal Income Transfer Receipts in Different Years, Available on line at http://www.bea.gov/regional/reis/ (Accessed on August 2005).

Byrne, P., O. Capps Jr, and A. Saha. 1998. "Analysis of Quick-serve, Mid-scale, and Upscale Food Away from Home Expenditures." The International Food and Agribusiness Management Review 1:51- 72.

Capps, O. Jr., A. Clauson, J. Guthrie, G. Pittman, and M. Stockton. 2005. Contributions of Nonalcoholic Beverages to the U.S. Diet, U.S. Department of Agriculture, Economic Research Service, Agricultural Economic Research Report No 829.

Carlson, S. J., M. S. Andrews, and G.W. Bickel. 1999. "Measuring food insecurity and Hunger in the United States: Development of a National Benchmark Measure and Prevalence Estimates." J. Nutri.129:510s-6s.

Cash, S. B., D. L. Sunding, and D. Zilberman. 2004. "Fat taxes and Thing Subsidies: Prices, Diet and Health Outcomes." Paper presented at the Annual Meeting of the American Agricultural Economics Association, Denver, Colorado.

Cavadini, C., A. M. Siega-Riz, and B. M. Popkin. 2000. "U.S. Adolescent Food Intake Trends from 1965 to 1966." Archives of Diseases in Childhood 83:18-24. 
Cawley, J. 2004. "An Economic Framework for Understanding Physical Activity and Eating Behaviors." American Journal of Preventive Medicine 27(3s)

Centers for Disease Control and Prevention (CDC). 2003. "Physical Activity and Good Nutrition: Essential Elements to Prevent Chronic Diseases and Obesity." Available on line at www.hooah4health.com/body/nutrition/aag dnpa2003.pdf (accessed August 2006).

Centers for Disease Control and Prevention (CDC). 2003. Health topics. Available online at http://www.cdc.gov/health/default.htm (accessed January 2004).

Centers for Disease Control and Prevention (CDC). 2005. Overweight and obesity: Frequently asked questions. Available online at http://www.cdc.gov/nccdphp/dnpa/obesity (accessed January 2005).

Chou, S.Y., M. Grossman, and H. Saffer 2002. "An Economic Analysis of Adult Obesity." Working Paper 9247, Available online at http://www.nber.org/papers./w9247 (accessed January 2004).

Chou, S.Y., M. Grossman, and H. Saffer. 2004. "An economic analysis of adult obesity: Results from the behavioral risk factor surveillance system." Journal of Health Economics 23:565-587.

Coate, D., and Grossman M. 1988. "Effects of Alcoholic Beverage Prices and Legal Drinking Ages on Youth Alcohol Use." Journal of Law and Economics 31(1):145-171.

Contoyannis, P., and A. M. Jones. 2004. "Socio-Economic Status, Health and lifestyle." Journal of Health Economics 23(5):965-995.

Curtin, S., and S. L. Hofferth. 2004. "Leisure activities and child overweight." Working Paper, Department of Family Studies, College of Health and Human Performance, University of Maryland.

Cutler, D. M., and E. Richardson. 1998. "The Value of Health: 1970-1990.”The American Economic Review 88(2):97-100.

Cutler, D., E. Glaeser, and J. Shapiro. 2003. "Why Have Americans Become More Obese?." Journal of Economic Perspectives 17(3):93-118.

Derry, A. 2004. "Impacts of Our Built environment on Public Health.” Environmental Health Perspective 112(11):A600-601.

Drewnowski, A. 2003. "Fat and Sugar: An Economic Analysis." Journal of Nutrition $133: 838 \mathrm{~S}-840 \mathrm{~S}$. 
Drewnowski, A. and S. Specter. 2004. "Poverty and Obesity: The Role of Energy density and Energy costs." Am Journal of Clinical Nutrition 79(6):6-16.

Ebbeling, C. B., B. P. Dorota, and S. L. David. 2002. "Chilhood Obesity: Public-health crisis, Common Sense Cure." The Lnacet 360(9331):473-482.

Edwards, L. N., and M. Grossman. 1979. "Adolescent Health, Family Background, and Preventive Medical Care.” Working paper No 398, Cambridge Mass: National Bureau of Economic Research.

Egede, L., and D. Zheng. 2002. "Modifiable cardiovascular risk factors in adults diabetes: prevalence and missed opportunities for physician counseling" Arch Inten Med 162(4):427-433.

Elhorst, J. P. 2003. "Specification and Estimation of Panel Data Models.” International Regional Science Review 26(3):244-268.

Ewing, R., T. Schmid, R. Killingsworth, A. Zlot, and S. Raudenbush. 2003. "Relationship between urban sprawl and physical activity, obesity, and morbidity." American Journal of Health Promotion 18:47-57.

Ewing R., R. A. Schieber, and C. V. Zegeer. 2003. "Urban Sprawl as a Risk Factor in Motor Vehicle Occupant and Pedestrain Fatalities." American Journal of Public Health 93(9):1541-1545.

Farrell, P., and V. R. Fuchs. 1982. "Schooling and health: the cigarette connection." Journal of Health Economics 1:217-30.

Feldstein, M. 1997. "How Big Should Government Be.” National Tax Journal 50(2)197-214.

Foster-Bey, J. 2002. "Sprawl, Smart Growth and Economic Opportunity." The Urban Institute, Metropolitan Housing Communities Policy Center, Program on Regional Economic Opportunities, Washington, DC.

Frank, L., and G. Pivo. 1995. "Impacts of mixed use and density on utilization of three modes of travel: single-occupant vehicle, transit, and walking." Transportation Res Rec 1466:44-52.

Frank, L., M. Anderson, and T. Schmid. 2004. "Obesity Relationships with Community Design, Physical Activity, and Time Spent In cars." American Journal of Preventive Medicine Available 27(2):87-96.

Frazao, E. 1996. “The American Diet: A Costly Health Problem.” Food Review 19(1):1-6. 
Freeman, L. 2001. "The Effects of Sprawl on Neighborhood Social Ties. An explanatory Analysis." Journal of American Planning Association 67(1):69-77.

French, S. A., L. Harnack, and R.W. Jeffery. 2000. "Fast Food Restaurant Use Among Women in the Pound of Prevention Study: Dietary behavioral and demographic Correlates." International Journal of Obesity 24:1353-1359.

Freudenberg, N., S. Galea, and D. Vlahov. 2005. "Beyond Urban Penalty and Urban Sprawl: Back to Living Conditions as the Focus of Urban Health." Journal of Community Health 30(1):1-11.

Friddle, C., S. Mangraj, and J. Kinsey. 2001. "The Food Service Industry: Trends and Changing Structure in the New Millennium." Working Paper, 01-02, The Retail Food Industry Centre, University of Minnesota.

Frumkin, H. 2002. "Urban sprawl and public health.” Public Health Rep. 117:201-217.

Fukuda, Y., K. Nakamura, and T. Takano. 2004. "Municipal socioeconomic status and mortality in Japan: Sex and age difference and trends of 1973-1998." Social Science Medicine 59:2435-2445

Fukuda, Y., M. Umezaki, K. Nakamura, and T. Takano. 2005. "Variations in Societal Characteristics of spatial disease clusters: examples of colon, lung and breast cancer in Japan." International Journal of Health Geographic 4(16):1-13.

Fuller, W, A., and G. E. Battese. 1974. "Estimation of Linear Models with Crossed-Error Structure." Journal of Econometrics 2:67-78.

Greene, W. H. 2003. Econometric Analysis, 5th. ed. Prentice Hall, New Jersey, 2003.

Gronau, R. 1977. "Leisure, Home Production, and Work - The Theory of the Allocation of Time Revisited." The Journal of Political Economy. 85(6):1099-1124.

Grossman, M. 1972. "On the Concept of Health Capital and the Demand for Health.” The Journal of Political Economy 80:223-253.

Grossman, M. 1989. "Health benefits of Increase in Alcohol and Cigarette Taxes." National Bureau of Economic Research, No 3082.

Gruber, J., and M. Frakes. 2005. "Does Falling Smoking Lead to Rising Obesity." Journal of Health Economics 30:1-15.

Gujarati, D. N. 2003. Basic Econometrics, Fourth Edition. McGraw Hill, New York, NY.

Guthrie, J. F., and J. F. Morton. 2000. "Food Sources of Added Sweeteners in the Diets of Americans." J Am Diet Assoc. 100:43-48. 
Guthrie, J. F., B. H. Lin, and E. Frazao. 2002. "Role of Food Prepared Away From Home in the American diet, 1977-78 Versus 1994-96: Changes and consequences." Journal of Nutrition Education and Behavior 34:140-150.

Halverson, J. A., L. Ma, E. J. Harner, R. Q. Hanham, and V. E. Braham. 2004. Adult Obesity in Appalachia, An Atlas of Geographic Disparities. West Virginia University, Morgantown.

Hamilton, W., J. Cook, W. Thompson, L. Buron, E. Frongillo, C. Olson, and C. Wehler. 1997. Household Food Security in the United States in 1995: Summary Report of the Food Security Measurement Project. FCS/USDA,Washington, D.C.

Hana, R., and F. J. Chaloupka. 2003. "The Effect of Cigarette Prices of Youth Smoking." Health Economics 12:217-230.

Handy, S.L., M.G. Boarnet, R. Ewing, and R. E. Killingsworth. 2002. "How the built Environment Affects Physical Activity. Views form Urban Planning." American Journal of Preventive Medicine 23(2):64-73.

Harris, J. E. 1982a. "Increasing the Federal Excise Tax on Cigarettes." Journal of Health Economics 1:117-120.

. 1982b. " Parental Medical Care and Infant Mortality.” In V.R. Fuchs, ed. In Economic Aspects of Health. Chicago:University Chicago Press.

1999. "The Continuum-of-Addiction: Cigarette Smoking in Relation to Price Among Americans Aged 15-29." Health Economics 8:81-86.

Heckman, J. J. 1978. "Dummy endogenous Variables in a Simultaneous Equation System” Econometrica 46(4):931-959.

Hiemstra, S., and W. G. Kim. 1995. "Factors Affecting Expenditures for Food Away From Home in Commercial Establishment by Type of Eating Place and Meal Occasion," Hospitality Research Journal 19:15-31.

Huang, K. S., and B. H. Lin. 2000. Estimation of Food Demand and Nutrient Elasticities from Household Survey Data. Food and Rural Economics Division, Economic Research Service, U.S. Department of Agriculture. Technical Bulletin No. 1887.

Jacobson, M. F., and K. D. Brownell. 2000. "Small Taxes on Soft Drinks and Snack Foods to Promote Health.” American Journal of Public Health 90(6):854-857.

Jekanowski, M. 1999. "Causes and Consequences of Fast Food Sales Growth." Food Review 22(1):11-16. 
Jekanowski, M., J. Binkley, and J. Eales. 2001. "Convenience, Accessibility and the Demand for Fast food." Journal of Agricultural and Resource Economics 26:58-74.

Johanson, R. C., L. Mancino, and J. Cooper. 2004. "The Big Picture: Production and Environmental Impacts of Reduced US Obesity." Accepted paper for the 2004 Annual Meetings of the American Agricultural Economics Association, Denver, Colorado.

Kan, K., and W. Tasi. 2004. “Obesity and Risk knowledge.” Journal of Health Economics 23:907-934.

Kementa, J. 1986. Elements of Econometrics $2^{\text {nd }}$ ed, Macmillan, New York.

Kemma, H. 1987. "Working Conditions and the Relationship between Schooling and Health." Journal of Health Economics 6:189-210.

Kenkel, D. 1990. "Consumer Health information and the demand for medical care." Review of Economics and Statistics 72:587-95.

Kenkel, D. 1991. "Health behavior, health knowledge, and schooling." Journal of Political Economy 99:287-305.

Kenkel, D. 1995. "Should you eat breakfast? Estimates form health productions functions." Health Economics 6:189-210.

Kenkel, D. S. 2000. "Prevention.” In A. J. Culyer and J.P. Newhouse, ed. Handbook of Health Economics 1B:1539-1627.

Kim, K., D. W. Marcouiller, and S. C. Deller. 2005. "Natural Amenities and Rural Development: Understanding Spatial and Distributional Attributes." Growth and Change 36(2):273-297.

Kip, V. W. 1993. "Value of Risks to Life and Health." Journal of Economic Literature 31:1912-46.

Knadula, N. R. 2005. "Leisure Time, Non-Leisure Time, and Occupational Physical Activity in Asian Americans.” Annals of Epidemiology 15 (4):257-265.

Knutson, R. D., J. B. Penn, and W.T. Boehm. 1995. Agricultural and Food Policy. Prentice Hall, New Jersey.

Krummel, D. A., P. Gordon, R. R. Newcomer, X. Lui, D. M. Christy, and A. Holmes 2002. "Dietary intakes and Leisure-Time Physical Activity in West Virginians." West Virginia Medical Journal 97:295-301. 
Kuchler, F., and N. Ballenger. 2002. "Social Cost of Obesity: How Can We Assess When Federal Interventions Pay?" Food Review 25(3):33-37.

Kuchler, F., A. Tegene, and M. J. Harris. 2004. Taxing Snack Foods: What to Expect for Diet and Tax Revenues. Agriculture Information Bulletin No 747-08, Economic Research Service, USDA.

Lakdawalla, D., and T. Philipson. 2002. "The growth of Obesity and Technological Change: A theoretical and Empirical examination.” NBER working paper No. 8946.

Lancaster, K. 1966. "A New Approach to Consumer Theory." The Journal of Political Economy. 74(2):132-157.

Lee, L. 1982. "Health and Wage: A simultaneous Equation Model with Multiple Discrete Indicators." International Economic Review 23:199-221.

Leicester, A., and Windmeijer. 2004. "The Fat Tax: Economic Incentives to Reduce Obesity." The Institute of Fiscal Studies, Briefing Note No 49.

Lesage, J. P., and R. K. Pace. 2004. "Introduction to Advances in Econometrics." In J. P. Lesage and R. K. Pace, ed. Spatial and Spatiotemporal Econometrics, Oxford: Elsevier Ltd 18:1-32.

Levedahl, J. W., and V. Oliveira. 1999. Dietary impacts of food assistance programs, In: Frazao E, ed. America's eating habits US Department of Agriculture, Economic Research Service.

Lewit, E. M., and D. Coate. 1981. "The Potential for Using Excise Taxes to Reduce Smoking." Journal of Health Economics 1(2):121-54.

Lin, B., and E. Frazao. 1999. Away-From-Home Foods Increasingly Important to Quality of American Diet. USDA, Economic Research Service, AIB-749.

Lin, B. H., C. L. Huang, and S. A. French. 2004. "Factors Associated with Women's and Children's Body Mass Indices by Income Status.” International Journal of Obesity 28:536-542.

Lin, G. 2003. “A spatial Logit Model Association Model for Cluster Detection.” Geograpical Analysis 35:4.

Lopez, R. 2004. "Urban Sprawl and Risk for Being Overweight or Obese.” American Journal of Public Health September 94(9).

Maddala, G. S. 1983. Limited-dependent and qualitative variables in econometrics Cambridge University Press. 
Maddala, G. S. 1989. Microeconomics theory and Applications, MaGrawhill Book Co. Singapore.

Mancino, L., and J. Kinsey. 2004. "Diet Quality and Calories Consumed: The impact of being Hungrier, Busier, and Eating out." Working Paper, 04-02, The Food Industry Center, University of Minnesota.

Mancino, L., B. H. Lin, and N. Ballinger. 2004. "The role of economics in eating choices and weight outcomes." USDA Economic Research Service Agriculture Information Bulletin Number 791.

McCracken, V., and J. Brandt. 1987. "Household Consumption of Food Away from Home: Total Expenditure and by Type of Food Facility." American Journal of Agricultural Economics 69:274-84.

McCrory M. A., P. J. Fuss, N. P. Hays, A. G. Vinken, A. S. Greenberg, and S.B. Roerts. 1999. "Overeating in America: Association between Restaurant Food Consumption and Body Fatness in Healthy Adult Men and Women ages 19 to 80.” Obesity Research 7:564-571.

Miller, J. C., and K. H. Coble. 2005. “Cheap Food Policy: Fact or Rhetoric?.” Paper Presented at AAEA Annual Meeting, Rhode Island, 24-27 July.

Mokdad, A. H., E. S. Ford, and B. A. Bowman, 2003. "Prevalence of obesity, Diabetes, and Obesity-Related Health Risk Factors." Journal of American Medical Association 289:76-9.

Morland, K., S. Wing, and A. Roux. 2002. "The Contextual Effect of the Local Food Environment on Residents Diets: The Atheroslerosis Risk in Communities Study.", American Journal of Public Health 92:1761-1768.

Morland, K., S.Wing, A. Diez Roux, and C. Poole. 2002. "Neighborhood Characteristics Associated with the Location of Food Stores and Food Service Places." American Journal of Preventive Medicine 22:23-29.

Mundlak, Y. 1978. "On the Pooling of Time Series and Cross Section Data." Econometrica 46(1):69-85.

Muth, R. F. 1966. "Household Production and Consumer Demand Functions." Econometrica 34(3): 699-708.

Nayga, R. M. 2000. "Schooling, Health Knowledge and Obesity." Applied Economics, 32:815-822. 
Office of the Surgeon General. 2003. Overweight and Obesity: at glance. Available Online at http://www.surgeongeneral.gov/topics/obesity/ (accessed December 2005).

Ohsfeldt R. L., R. G. Boyele, and E. I. Capilouto. 1998. "Tobacco Taxes, Smoking Restrictions, And Tobacco Use.” NBER working Paper, 6486.

Organization for Economic Co-operation and Development. (OECD). 2001. The well-being of nations: The role of human and social capita. Paris .France

Pagan, J.A., and A. Davila. 1997. "Occupational Attainment and Earnings.” Social Science Quarterly 78(3):756-770.

Parry, I. W. H. 2001. "Comparing the Marginal Excess Burden of Labor, Petrol, Cigarette, and Alcohol Taxes: An Application to the United Kingdom." Discussion Paper 00$33 R E V$, Resource for the Future Washington D.C.

Philipson, T. J. 2001. "The World-wide Growth in Obesity: An Economic Research Agenda." Health Economics, 10:1-7.

Philipson, T. J., and R. A. Posner. 1999. "The Long-Run Growth in Obesity as a Function of Technological Change." Working Paper, No.78, The University of Chicago.

Philipson, T. J., and R. A. Posner. 2003. "The Long-run Growth in Obesity as a Function of Technological Change." Perspectives in Biology and Medicine, 46(3):PP S87-S07.

Plantinga, A. J., and S. Bernell. 2005. "A Spatial Economic Analysis of Urban Land Use and Obesity.” Journal of Regional Science, 45(3):473-492.

Pogue, F. T., and L. G. Sgontz. (1989), "Taxing to Control Social Costs: The Case of Alcohol.” The American Economic Review, 79(1): 235-243.

Pollan, M., 2000. "The (Agri) Cultural Contradictions of Obesity." The New York Times, Sec 6, pg. 41.

Pratt, M., C. A. Macera, J. F. Sallis, M. O’Donnell, and L. D. Frank. 2004. Economic Interventions to Promote Physical Activity: Application of the SLOTH model. American Journal of Preventive Medicine. 27(3S):136-145.

Purath, J., T. Lansinger, and C. Ragheb. 1995 "Cardiac Risk Evaluation for Elementary School Children.” Public Health Nurs, 12:189-195.

Putnam, J., 1999. “US Food Supply Providing More Food and Calories.” Food Review 22:11. 
Register, C. A., and Williams D. R. 1990. "Wage effects of Obesity Among Young Workers.” Social Science Quarterly 71(1):130-141.

Reidpath, D., C. Burns, J. M. Garrand, and M. Townsend. 2002. “An Ecological Study of the Relationship between Social and Environmental Determinants of Obesity." Health Place, 8:141-5.

Rose D. 1999. "Economic Determinants and Dietary Consequences of food insecurity in the United States." Journal of Nutrition, 129:517-20.

Rose, D., C. Gundersen, and V. Oliveira. 1998. "Socio-Economic Determinants of Food Insecurity in the United States: Evidence from the SIPP and CSFII Datasets." U.S. Department of Agriculture, Economic Research Service, Technical Bulletin 1869.

Rosenberger, R. S., Y. Sneh, and T.M. Phipps. 2002. "Recreational Opportunities and Health Status in West Virginia" Paper presented at the Northeastern Agricultural Economics Association Annual Meeting, Camp Hill, PA, Available on line at http://www.rri.wvu.edu/pdffiles/rosenbergeretal2002-6.pdf .

Rosenzweig, M. R., and T. P. Schultz. 1983. "Estimating a Household Production Function: Heterogenity, the Demand for Health Inputs, and their Effects on Birth Weight." Journal of Political Economy, 91, 723-46.

Ruhm, C. 2000. “Are Recessions Good for Your Health?” Quarterly Journal of Economics. 115(2):616-650.

Saez, M., C. Saurina, G. Coenders, and S. Gonzalez-Raya. 2006. "Use of Health Care Services According to the Different Degrees of Obesity in the Girona Health Region, Spain." Health Economics 15:173-193.

Saffer, H., and D. Dave. 2003.“Alcohol Advertising and Alcohol consumption by Adolescents.” Working Paper 9676, NBER, Cambridge, MA 02138.

Salens, B., J. Sellis, J. Black, and D. Chen. 2003."Neighborhood-based Differences in Physical Activity: An Environment Scale Evaluation." American Journal of public Health, 93:1552-1558.

Sickles, R. C., and A. Yazbeck. 1998. "On the Dynamics of Demand for Leisure and Production of Health." Journal of Business and Economic Statistics, 16:2.

Smith, T.G. 2002. "Obesity and Nature's Thumbprint: How Modern Waistlines can Inform Economic Theory." Working paper 18-02, Dept of Economics, University of California, Santa Barbara. 68 pp. 
Stewart, H., N. Blisard, S. Bhuyan, and R. M. Jr. Nayga. 2004. The Demand for Food Away From Home Full-Service or Fast Food?, Department of Agriculture, Economic Research Service, Economic Research Report No 1.

Stinson, S. 2000. "Weightier Issues than Diet Challenge $21^{\text {st }}$ Century." Healthy Weight Journal, pp. 46-47.

Sturm, R. 2004. The Economics of Physical Activity: Societal Trends and Rationales for Intervention. American Journal of Preventive Medicine. 27(3S):126-135.

The Dominian Post 2004. "Legislators Takes on Obesity.” October 13.

Thorpe, K. E., C. S. Florance, D. H. Howard and P. Joski. 2004. "The impact of Obesity on Rising Medical Spending.”, Health Tracking, W4, 480-485.

U.S. Census Bureau, Decennial Census 1990. Summary Files and Detailed tables available online at http://factfinder.census.gov/servlet/ (accessed on August 2004)

U.S. Census Bureau, Decennial Census 2000. Summary Files and Detailed tables available online at http://factfinder.census.gov/servlet/ (accessed on August 2004)

U.S. Census Bureau, Economic Census 1993. County Business Patterns available online at http://censtats.census.gov/cgi-bin/cbpnaic/cbpcomp.pl (accessed on August 2004)

U.S. Census Bureau, Economic Census 1997. County Business Patterns available online at http://censtats.census.gov/cgi-bin/cbpnaic/cbpcomp.pl (accessed on August 2004)

Varian, H. R. 2002. Intermediate Microeconomics: A modern Approach, $6^{\text {th }}$ ed. :W. W. Norton Company, USA.

Variyam, J. N. 2005. "Economics and Rising Obesity." Amber Waves. Economic Researh Service, USDA, 3(1).

Variyam, J. N., Blaylock, J. and D. Smallwood. 1996. “A Probit Latent Variable Model of Nutrition Information and Dietary Fiber Intake." American Journal of Agricultural Economics, 78:628-39.

Wang, G., Z. Zheng, G. Heath, C. Macera, M. Pratt, and D. Buchner. 2002. "Economic Burden of Cardiovascular Disease Associated With Excess Body Weight in U.S. Adults." Am J Pre Med. 23(1):1-6. 
Wolf, A. M. and G. A. Colditz.1998. "Current Estimates of the Economic Cost of Obesity in the United States”. Obes Res 6:97-106.

Wooldridge, J. M. 2002. Econometric Analysis of cross section and panel data, Cambridge, MIT press.

WV, Department of Health and Human Resources. 2000. West Virginia County Health Profiles, http://www.wvdhhr.org/bph/oehp/hsc/prof2000/default.htm access on August 2002.

WV, Department of Health and Human Resources. 2002. Obesity: Facts Figures and guidelines, West Virginia, http://www.wvdhhr.org/bph/oehp/obesity/mortality.htm access on January 2004.

WV, Department of Health and Human Resources. 2004. West Virginia 2004 Vital Statistics: Table of Contents, http://www.wvdhhr.org/bph/oehp/obesity/mortality.htm access on September 2006.

Yen, S. T., and L. Biing-Hwan. 2002. "Beverage Consumption Among U.S. Children and Adolescents: Full-Information and Quasi Maximum-Likelihood Estimation of a Censored System.” European Review of Agricultural Economics 29(1):85-103. 


\section{Appendices}

Appendix A. Variance and Covariance Structure of Composite Error Term in Random Effect Model

Random specification of the panel data structure which can be represented as

$$
y_{i t}=\mu+\beta^{\prime} x_{i t}+v_{i t}, t=1 \ldots \ldots T,
$$

Where, $v_{i t}=a_{i}+e_{i t}$, is the composite error terms of unobserved effects $a_{i}$ and the error term, $e_{i t}$. It is also assumed that $\mathrm{E}\left(e_{i t} \mid x_{i}, a_{i}\right)=0, t=1 \ldots \ldots T$, and the $\mathrm{E}\left(a_{i} \mid x_{i}\right)=\mathrm{E}\left(a_{i}\right)=0$, where $x_{i}=\left(x_{i 1}, x_{i 2} \ldots x_{i T}\right)$. Also assumed that $\mathrm{E}\left(e_{i t} e_{i s}\right)=0$, for all $\mathrm{t} \neq \mathrm{s}$.

Mean of the error term: $\mathrm{E}\left(v_{i t}\right)=\mathrm{E}\left(a_{i}+e_{i t}\right)=\mathrm{E}\left(a_{i}\right)+\mathrm{E}\left(e_{i t}\right)=0$

\section{Variance-covariance Matrix of the Error term:}

Diagonal elements: $\mathrm{E}\left(v_{i t}^{2}\right)=\mathrm{E}\left(a_{i}^{2}+2 a_{i} e_{i t}+e_{i t}{ }^{2}\right)$

$$
=\mathrm{E}\left(a_{i}^{2}\right)+2 \mathrm{E}\left(a_{i} e_{i t}\right)+\mathrm{E}\left(e_{i t}^{2}\right)
$$

By assumption: $2 \mathrm{E}\left(a_{i} e_{i t}\right)=0$

Such that $\mathrm{E}\left(v_{i t}^{2}\right)=\mathrm{E}\left(a_{i}{ }^{2}\right)+\mathrm{E}\left(e_{i t}{ }^{2}\right)=\sigma_{a}^{2}+\sigma_{e}^{2}$

Off Diagonal Elements: $\quad \mathrm{E}\left(v_{i t} v_{i s}\right)=\mathrm{E}\left[\left(a_{i}+e_{i t}\right)\left(a_{i}+e_{i s}\right)\right]$

$$
\begin{aligned}
& =\mathrm{E}\left[\left(a_{i}^{2}+a_{i} e_{i s}+a_{i} e_{i t}+e_{i t} e_{i s}\right)\right] \\
& =\mathrm{E}\left(a_{i}^{2}\right)+a_{i} \mathrm{E}\left(e_{i s}\right)+a_{i} \mathrm{E}\left(e_{i t}\right)+\mathrm{E}\left(e_{i t} e_{i s}\right)
\end{aligned}
$$

By assumption $\mathrm{E}\left(e_{i s}\right), \mathrm{E}\left(e_{i t}\right)$ and $\mathrm{E}\left(e_{i t} e_{i s}\right)$ equals to zero

Therefore $\quad \mathrm{E}\left(v_{i t} v_{i s}\right)=\mathrm{E}\left(a_{i}^{2}\right)=\sigma_{a}^{2}$ 
$\Omega=E\left(v_{i} v_{i}^{\prime}\right)=\left[\begin{array}{cccc}\sigma_{a}^{2}+\sigma_{e}^{2} & \sigma_{a}^{2} & \cdots & \sigma_{a}^{2} \\ \sigma_{a}^{2} & \sigma_{a}^{2}+\sigma_{e}^{2} & \cdots & \vdots \\ \vdots & \vdots & \sigma_{a}^{2}+\sigma_{e}^{2} & \sigma_{a}^{2} \\ \sigma_{a}^{2} & \sigma_{a}^{2} & \cdots & \sigma_{a}^{2}+\sigma_{e}^{2}\end{array}\right]$

$\Omega=\sigma_{a}^{2} j_{T} j_{T}^{\prime}+\sigma_{e}^{2} I_{T}$

where, $j_{T} j_{T}^{\prime}$ is a $T x T$ matrix with unity in every element and $I_{T}$ is $T x T$ identity matrix with unity in the diagonal.

Such that BLUE estimator $\hat{\beta}_{G L S}, \quad \hat{\beta}_{G L S}=\left(X^{\prime} \Omega^{-1} X\right)^{-1} X^{\prime} \Omega^{-1} y$

Since $\Omega$ is unknown to the researcher, the feasible GLS, i.e., $\hat{\beta}_{F G L S}=\left(X^{\prime} \hat{\Omega}^{-1} X\right)^{-1} X^{\prime} \hat{\Omega}^{-1} y$, in which $\Omega$ is estimated thorough the information of variance $y$ would be the BLUE random effect estimator.

Rewriting the random effect model in matrix form

$y=1_{T} \mu+\beta X+D a+e$

$E(y)=1_{T} \mu+\beta X$

$\operatorname{Var}(y)=E[(y-E(y))(y-E(y))]$

$\operatorname{Var}(y)=E\left[(D a+e)(D a+e)^{\prime}\right]$

$\operatorname{Var}(y)=E\left(D_{a a^{\prime}} D^{\prime}+D a e^{\prime}+e a^{\prime} D^{\prime}+e e^{\prime}\right)$

$\operatorname{Var}(y)=D D^{\prime} E\left(a a^{\prime}\right)+D E\left(a e^{\prime}\right)+E\left(e a^{\prime}\right) D^{\prime}+E\left(e e^{\prime}\right)$

By assumptions $D E\left(a e^{\prime}\right), E\left(e a^{\prime}\right) D^{\prime}=0$

$\operatorname{Var}(y)=D D^{\prime} \sigma_{a}^{2}+I_{T} \sigma_{e}^{2}$ 
$\operatorname{Var}(y)=D D^{\prime} \sigma_{a}^{2}+I_{T} \sigma_{e}^{2}=\left(I_{T}+D D^{\prime} \frac{\sigma_{a}^{2}}{\sigma_{e}^{2}}\right) \sigma_{e}^{2}=\sigma_{a}^{2} j_{T} j_{T}^{\prime}+\sigma_{e}^{2} I_{T}$, where D is a $T x l$ vector.

Therefore $\hat{\Omega}=[\operatorname{Var}(\hat{y})]$ and $\hat{\Omega}^{-1}=[\operatorname{Var}(\hat{y})]^{-1}$

$\hat{\Omega}^{-1}=[\operatorname{Var}(\hat{y})]^{-1}=\left(I_{T}+D D^{\prime} \frac{\sigma_{a}^{2}}{\sigma_{e}^{2}}\right)^{-1} \sigma_{e}^{-2}$

if could estimate $\sigma_{e}^{2}, \sigma_{a}^{2}$, we could define $\hat{\Omega}, \hat{\Omega}^{-1}$

then $\hat{\beta}_{F G L S}=\left(X^{\prime} \hat{\Omega}^{-1} X\right)^{-1} X^{\prime} \hat{\Omega}^{-1} y$ is BLUE random effects estimator. 


\section{Appendix B. Different Regions Considered for the Aggregate Analysis}

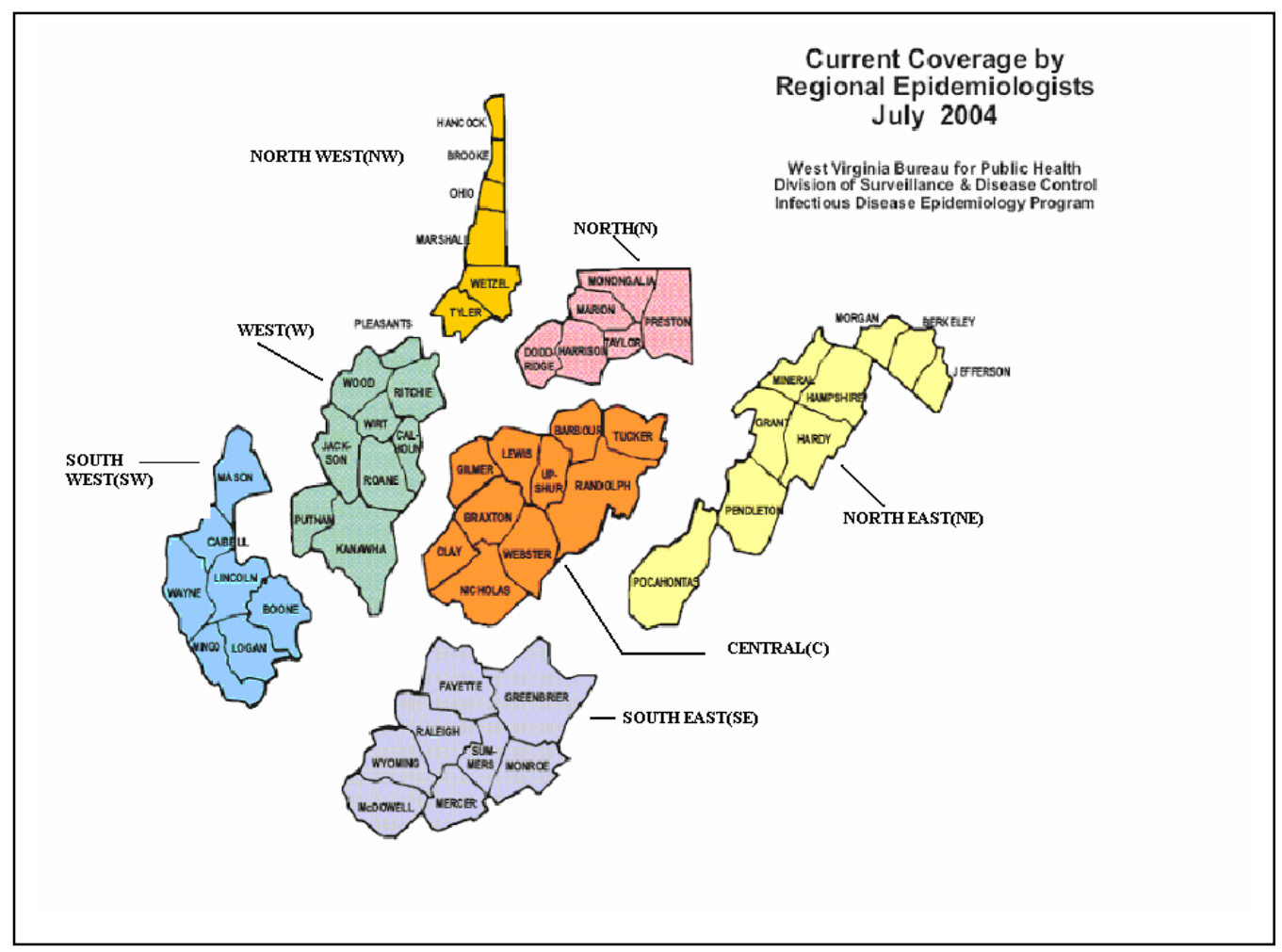

